Aus der Abteilung Neurochirurgie

(Prof. Dr. med V. Rohde)

im Zentrum Neurologische Medizin

der Medizinischen Fakultät der Universität Göttingen

\title{
Das Spätödem, induziert durch gewebeständigen Plasminogenaktivator bei Lyse einer tierexperimentellen intrazerebralen Blutung, wird durch die Gabe von Plasminogenaktivatorinhibitor 1 vermindert
}

\author{
INAUGURAL-DISSERTATION \\ zur Erlangung des Doktorgrades \\ der Medizinischen Fakultät \\ der Georg-August-Universität zu Göttingen
}

vorgelegt von

Gerrit Steffen Maier

aus

Lörrach

Göttingen 2012 
Dekan:

1. Berichterstatter:

2. Berichterstatter:

3. Berichterstatterin:
Prof. Dr. med. C. Frömmel

Prof. Dr. med. V. Rohde

Prof. Dr. med. Knauth

Prof. Dr. rer. nat. Virsik-Köpp

Tag der mündlichen Prüfung: 20.8.2012 


\section{Inhaltsverzeichnis}

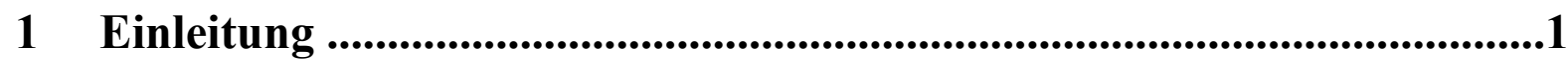

1.1 Die spontane intrazerebrale Blutung (ICB) ............................................................

1.1.1 Epidemiologie der intrazerebralen Blutung............................................................

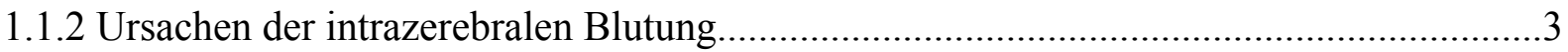

1.1.3 Risikofaktoren der intrazerebralen Blutung.............................................................

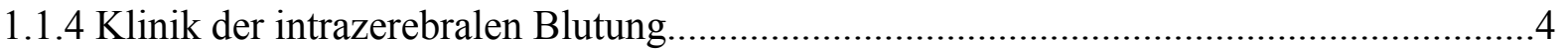

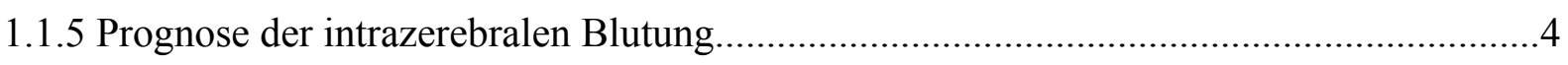

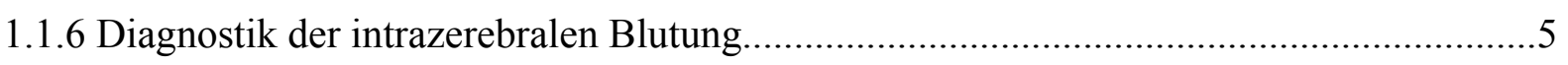

1.1.7 Therapieoptionen der intrazerebralen Blutung.......................................................

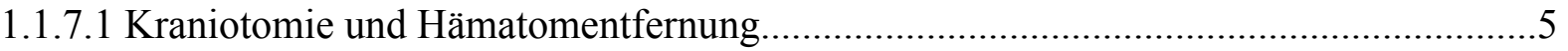

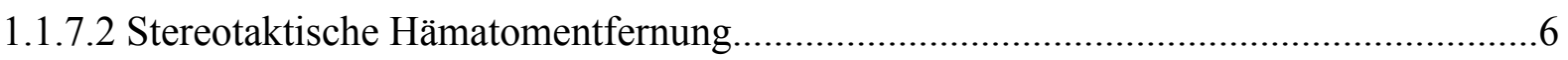

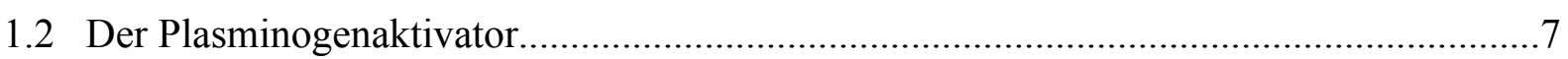

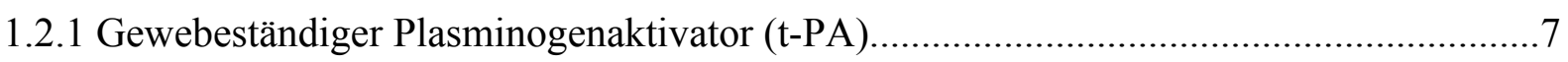

1.2.2 Rekombinanter gewebeständiger Plasminogenaktivator (rt-PA) ....................................

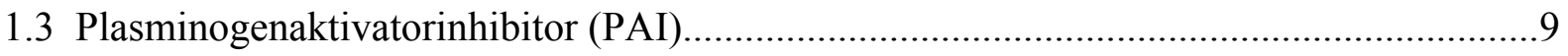

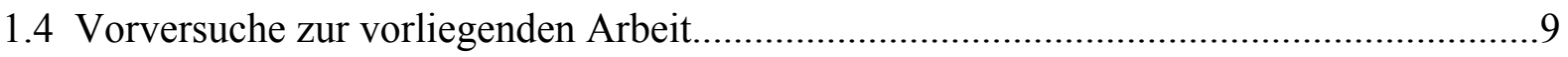

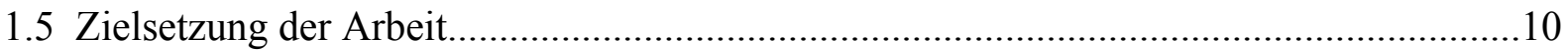

2 Material und Methoden......................................................................................12

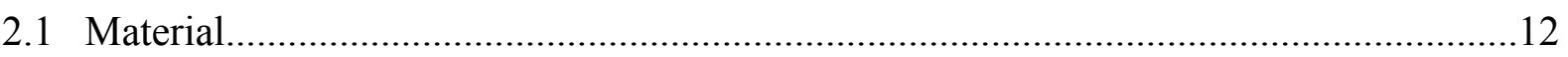

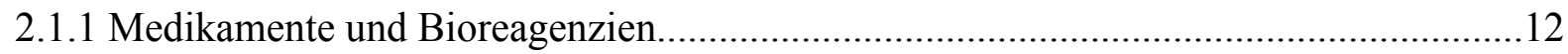

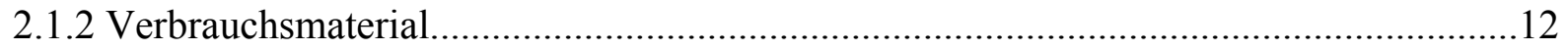

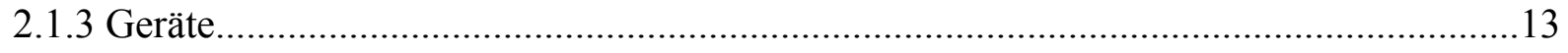

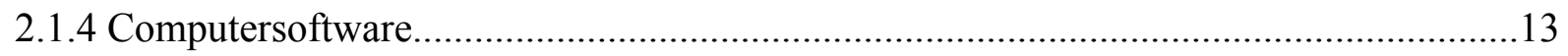




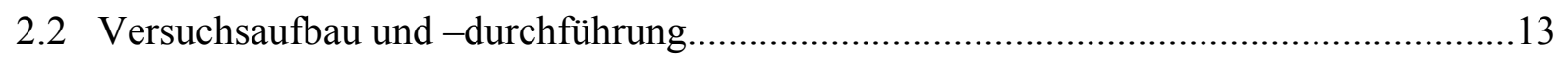

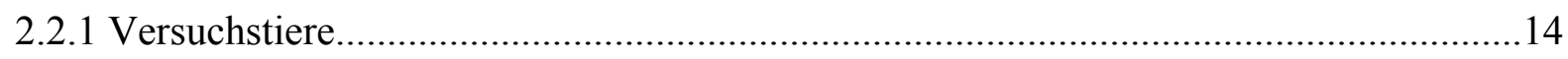

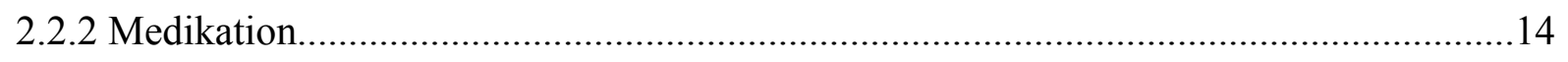

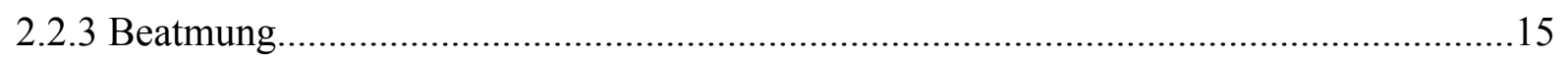

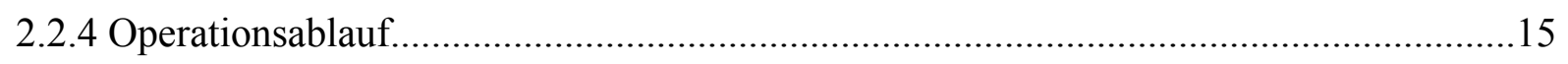

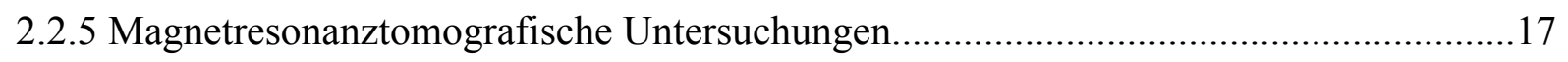

2.2.6 Fibrinolyse und Plasminogenaktivatorinhibitor (PAI) ...............................................19

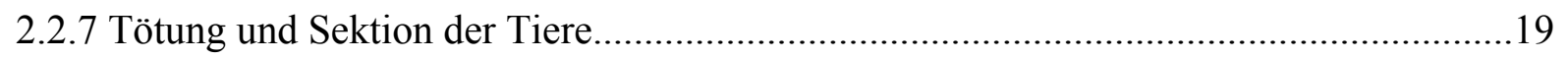

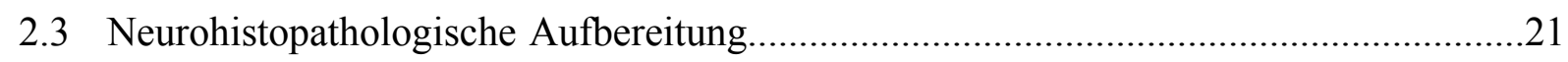

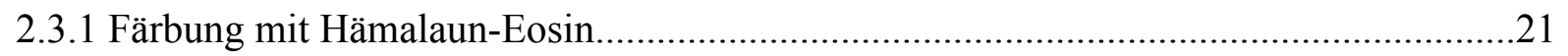

2.4 Rekombinanter gewebeständiger Plasminogenaktivator (rt-PA) ...............................21

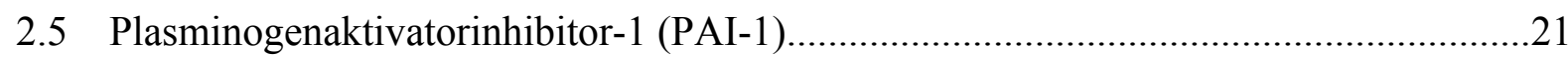

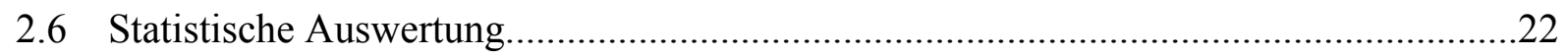

$3 \quad$ Ergebnisse...............................................................................................23

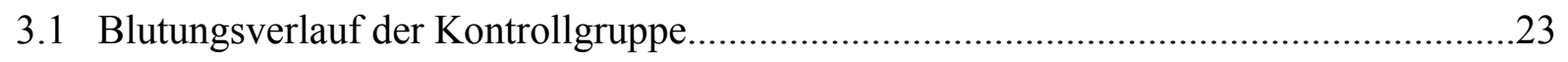

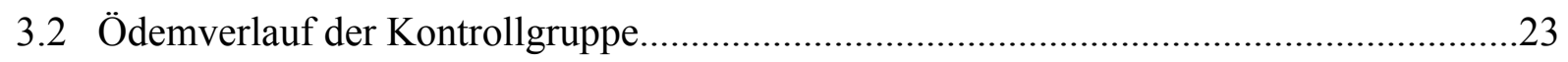

3.3 T2-Relaxationszeit (T2rt) und ADC der Kontrollgruppe...........................................24

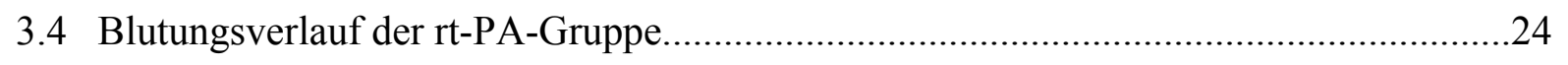

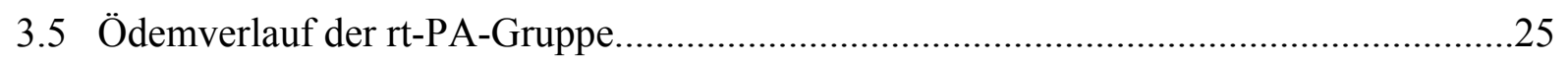

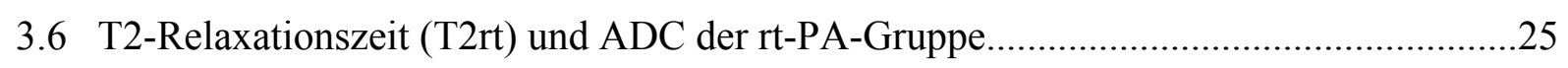

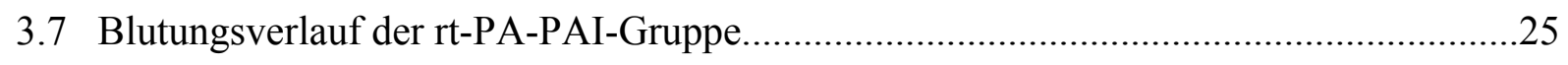

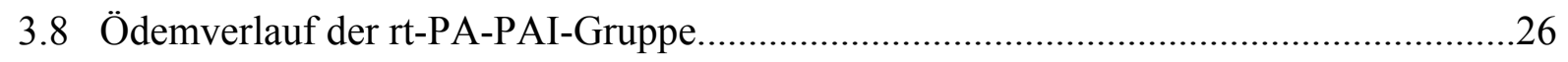

3.9 T2-Relaxationszeit (T2rt) und ADC der rt-PA-PAI-Gruppe.........................................26

3.10 Vergleich Kontrollgruppe vs. rt-PA-Gruppe vs. rt-PA-PAI-Gruppe..............................27

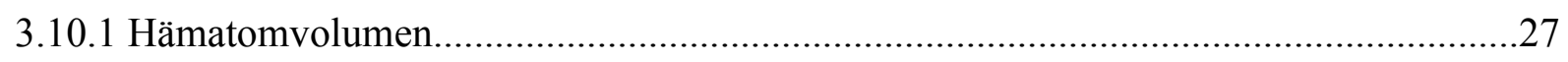

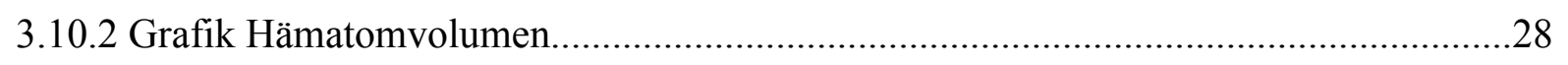

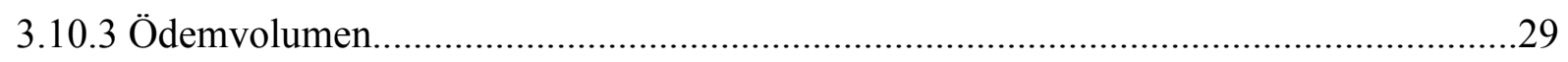

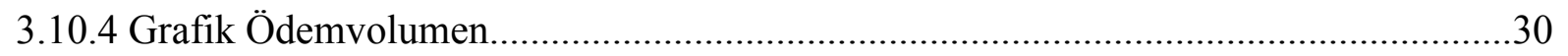

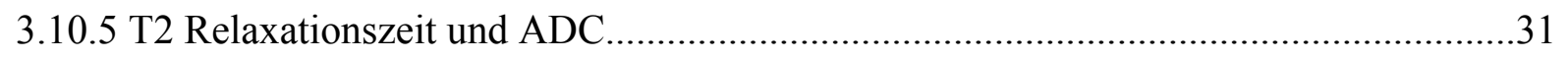

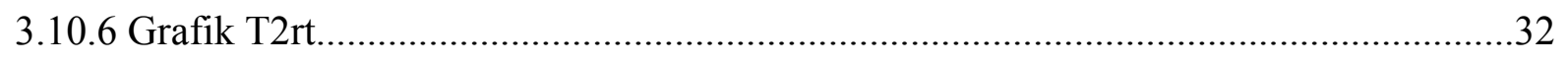

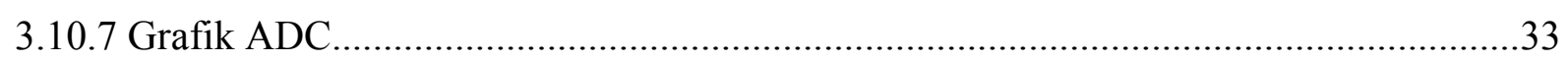




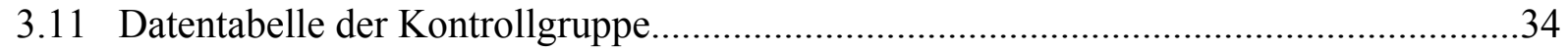

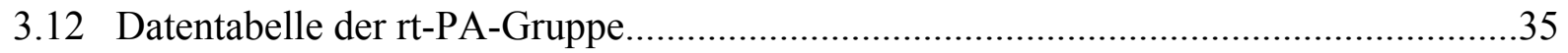

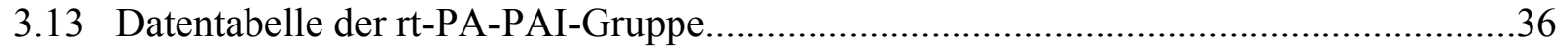

3.14 Datentabelle zur T2rt- und ADC-Messung der Kontrollgruppe.....................................37

3.15 Datentabelle zur T2rt- und ADC-Messung der rt-PA-Gruppe........................................38

3.16 Datentabelle zur T2rt- und ADC-Messung der rt-PA-PAI-Gruppe................................39

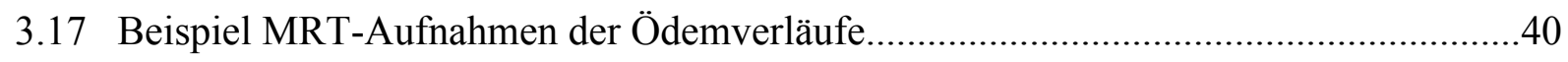

3.18 Beispiel MRT-Aufnahmen der Hämatomverläufe........................................................42

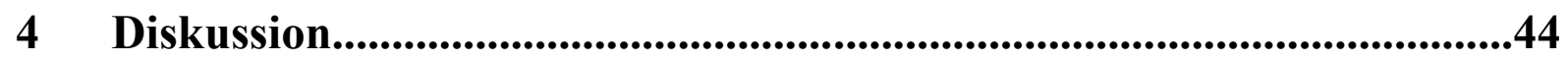

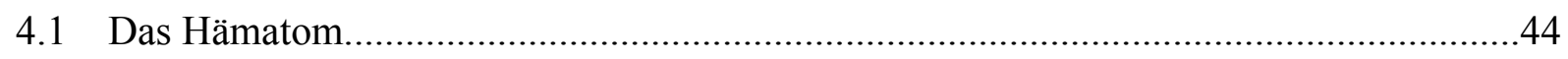

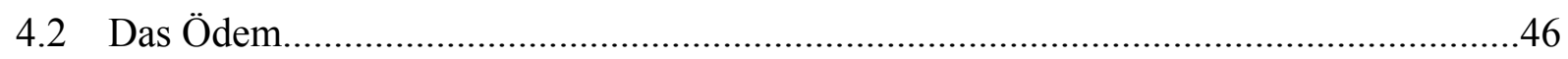

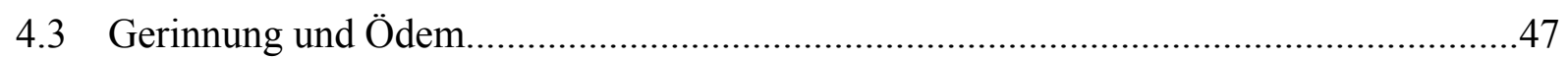

4.4 Zytotoxizität der Blut- und Plasmabestandteile..........................................................47

4.5 Gewebeständiger Plasminogenaktivator und rekombinanter t-PA.................................50

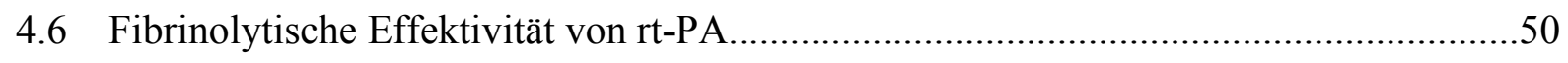

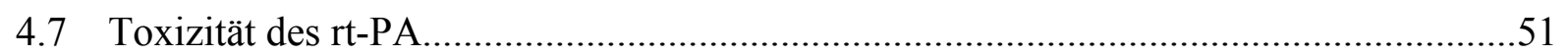

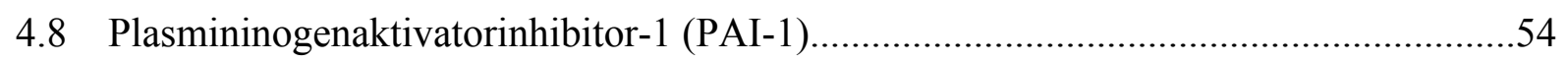

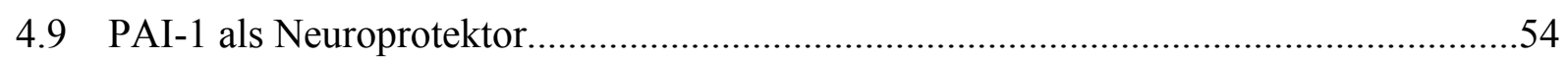

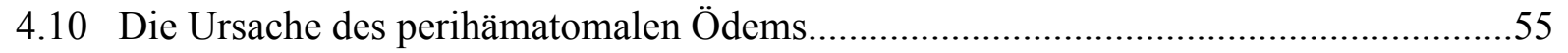

4.11 Übertragbarkeit des Modells auf den Menschen..............................................................56

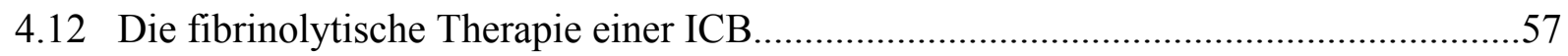

5 Zusammenfassung........................................................................60

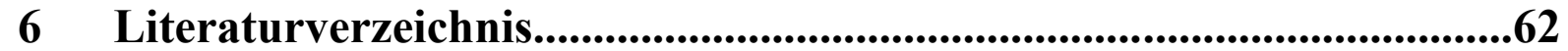




\section{Abkürzungsverzeichnis}

$\begin{array}{ll}\text { ADC } & \text { Aktivierter Diffusionskoeffizient } \\ \text { AT III } & \text { Antithrombin } 3 \\ \text { AVM } & \text { Arterio-venöse Malformation } \\ \text { Bcl } & \text { B-Zelllymphoma } \\ \text { ca. } & \text { circa }\end{array}$

CAA Zerebrale amyloide Angiopathie

$\mathrm{Ca}^{2+} \quad$ Ionisiertes Kalzium

$\mathrm{cm} \quad$ Zentimeter

$\mathrm{cm}^{3} \quad$ Kubikzentimeter

$\mathrm{CO}_{2} \quad$ Kohlendioxid

CT Computertomographie

DIC Disseminierte intravasale Gerinnung

DNA Desoxyribonucleinsäure

EPI Echo planar imaging

Fa. Firma

FLAIR Fluid attenuated inversion recovery

g Gramm

GCS Glasgow Coma Scale

h Stunde(n)

ICB Intrazerebrale Blutung

IVH Intraventrikuläres Hämatom

i.v. intravenös

$\mathrm{kg} \quad$ Kilogramm

mg Milligramm

MISTIE Minimally invasive surgery plus t-PA for intracerebral

hemorrhage evacuation

$\mathrm{m}^{2} \quad$ Quadratmeter

$\mathrm{mm}^{2} \quad$ Quadratmillimeter

$\mathrm{mm}^{3} \quad$ Kubikmillimeter

mRNA Botenstoff-Ribonucleinsäure

MRT Magnetresonanztomographie

ms Millisekunde 


$\begin{array}{ll}\mathrm{NaCl} & \text { Natrium-Chlorid } \\ \text { NMDA } & \text { n-Methyl-d-Aspartat } \\ \text { PAI-1 } & \text { Plasminogenaktivator 1 } \\ \text { PN-1 } & \text { Protease Nexin 1 } \\ \text { Rt-PA } & \text { Rekombinanter gewebeständiger Plasminogenaktivator } \\ \text { s } & \text { Sekunde } \\ \text { SAB } & \text { Subarachnoidalblutung } \\ \text { STICH } & \text { International Surgical Trial in Intracerebral Haemorrhage } \\ \text { t-PA } & \text { Gewebeständiger Plasminogenaktivator } \\ \text { T2rt } & \text { T2-Relaxationszeit } \\ \text { U } & \text { Einheiten }\end{array}$




\section{$1 \quad$ Einleitung}

Der Schlaganfall ist die häufigste neurologische Erkrankung, und mit circa $12 \%$ aller Todesfälle in Deutschland, nach den ischämischen Herzerkrankungen und bösartigen Neubildungen, die dritthäufigste Todesursache. Bei einer Prävalenz von 600/100.000 Einwohnern ist er darüber hinaus die häufigste Ursache für Plegebedürftigkeit im Alter, sowie für erworbene, lebenslange Behinderungen im Erwachsenenalter. Epidemiologisch stellen die ischämischen Hirninfarkte mit etwa $80 \%$ die bedeutendste Gruppe unter den Schlaganfällen dar (Kolominsky-Rabas und Heuschmann 2002). Ursache der Hirninfarkte sind Arteriosklerose, Kardioembolie, Mikroangiopathie, sowie seltener zum Beispiel Vaskulitiden, Nebenwirkungen von Kontrazeptiva oder bakterielle Entzündungen. (Kolominsky-Rabas et al. 2001)

Mit einem Anteil von etwa 10 bis $15 \%$, gemessen an allen Schlaganfällen, stellen intrazerebrale Blutungen ( ICB ) die zweitgrößte Gruppe dar. Jedes Jahr erleiden etwa 50000 Menschen in den Vereinigten Staaten eine intrazerebrale Blutung. Die Mortalität ist mit einer 1-Jahresüberlebensrate von nur $38 \%$ hoch. Eine Einteilung der ICB erfolgt in primäre und sekundäre Blutungen. Der Großteil der Blutungen ( etwa 80 \% ) wird den primären Blutungen zugeordnet. Diese beruhen auf einer spontanen Ruptur kleinerer Gefäße (z.B. basierend auf einer Vorschädigung der Gefäße durch chronischen Bluthochdruck) oder auf amyloider Angiopathie. Sekundäre ICBs sind mit vaskulären Anomalien, Tumoren oder einer beeinträchtigten Gerinnung assoziiert (Quinones-Hinojosa et al. 2003). Hauptlokalisationsorte der primären ICB sind die Basalganglien, der Thalamus und das Kleinhirn (Fewel et al. 2003). Über die optimale Therapie der ICB besteht bis heute Uneinigkeit, so reichen die Empfehlungen von konservativem Management bis hin zur Kraniotomie und Lysetherapie der ICB (Pouratian et al. 2003).

In der vorliegenden Arbeit wird an einem Schweinemodell einer intrazerebralen Blutung untersucht, ob die Lysetherapie durch den Einsatz des Plasminogenaktivatorinhibitor 1 (PAI1) optimiert werden kann. 


\subsection{Die spontane intrazerebrale Blutung (ICB)}

Blutungen ins Hirnparenchym, intrazerebrale Blutungen, sind die Folge unterschiedlicher Grunderkrankungen und beruhen entweder auf Diapedeseblutungen, die sich überwiegend im Bereich der Kapillaren abspielen, oder auf Rhexisblutungen, die sich als eine arterielle Blutung ins Hirngewebe darstellen. Von klinischer Relevanz ist jedoch nicht nur die primäre irreversible Hinschädigung, sondern auch die sekundäre Hirnschädigung durch Ödementwicklung. Zur Diskussion der bisher noch nicht vollständig geklärten Pathogenese der Ödementstehung stehen momentan neben der perihämatomalen Ischämie eine Erhöhung des lokalen Gewebedruckes und vor allem toxische Effekte der Blutabbauprodukte (Gröschel 2002).

\subsubsection{Epidemiologie der intrazerebralen Blutung}

Eine intrazerebrale Blutung ist mit 37000 bis 52400 berichteten Fällen (in den U.S.A.) an ca. $15 \%$ der Schlaganfälle ursächlich beteiligt. Es wird erwartet, dass sich diese Zahl bis zum Jahr 2050 aufgrund des demographischen Wandels verdoppelt (Fewel et al. 2003). Im Vergleich $\mathrm{zu}$ ischämischen Infarkten ist die Prognose der ICB deutlich schlechter. Eine Mortalität von 35 bis $50 \%$ innerhalb der ersten 30 post-hämorrhagischen Tage verdeutlicht die schlechte Prognose, $6 \%$ aller Patienten versterben auf dem Weg ins Krankenhaus (Broderick JP et al. 1993b). In einer Erhebung aller Fälle von ICB und Subarachnoidalblutung (SAB) im Raum Cincinnati wurde 1988 festgestellt, dass die ICB mehr als doppelt so häufig vorkommt wie die SAB. Die Inzidenzen werden mit 15/100 000 für die ICB und 6/100 000 für die SAB angegeben (Broderick JP et al. 1992; Broderick JP et al. 1993a). Die Inzidenz zeigt eine Variabilität in Bezug auf Alter, Geschlecht und Rasse. Männer sind geringfügig häufiger betroffen als Frauen, und auch mit zunehmendem Alter steigt die Wahrscheinlichkeit eine ICB zu erleiden. Bei Afro-Amerikanern (55/100 000) und Japanern (50/100 000) ist die Inzidenz im Vergleich zur kaukasischen Bevölkerung deutlich erhöht (Broderick JP et al. 1992). Hauptlokalisationsorte einer ICB sind die Basalganglien mit einem Anteil von $40 \%$, gefolgt von dem subkortikalen Marklager des Okzipital- und Temporallappens (ca. $25 \%$ ), dem Thalamus (ca. $20 \%$ ), dem Zerebellum (ca. $10 \%$ ) und des Pons (ca. $5 \%$ ). 


\subsubsection{Ursachen der intrazerebralen Blutung}

Neben dem Auftreten nach Trauma kann die ICB auch spontan entstehen.

Bei den spontanen ICBs wird zwischen primären und sekundären Blutungen unterschieden. Zerebrovaskuläre Schäden der kleinen Arterien und Arteriolen aufgrund von chronischem Bluthochdruck werden mittlerweile als die Hauptursache einer primären spontanen ICB angesehen, über $60 \%$ aller ICBs entstehen auf dem Boden einer arteriellen Hypertonie. Eine weitere wichtige Ursache der primären ICB stellt die zerebrale amyloide Angiopathie (CAA) dar, sie gilt als einer der Hauptursachen für eine lobäre ICB im Alter. Die Hauptursache einer sekundären Blutung, und gleichzeitig insgesamt die zweithäufigste Ursache einer ICB, ist eine Gefäßanomalie. Arteriovenöse Malformationen haben ein mittleres Blutungsrisiko von circa $4 \%$ (Fewel et al. 2003). Eine spontane ICB kann auch bei Hirntumoren, sei dieser primärer oder metastasischer Natur, auftreten. Bis zu $10 \%$ aller Hirntumore zeigen sich für eine ICB verantwortlich (Fewel et al. 2003). Weitere Ursachen einer ICB zeigt Tabelle 1:

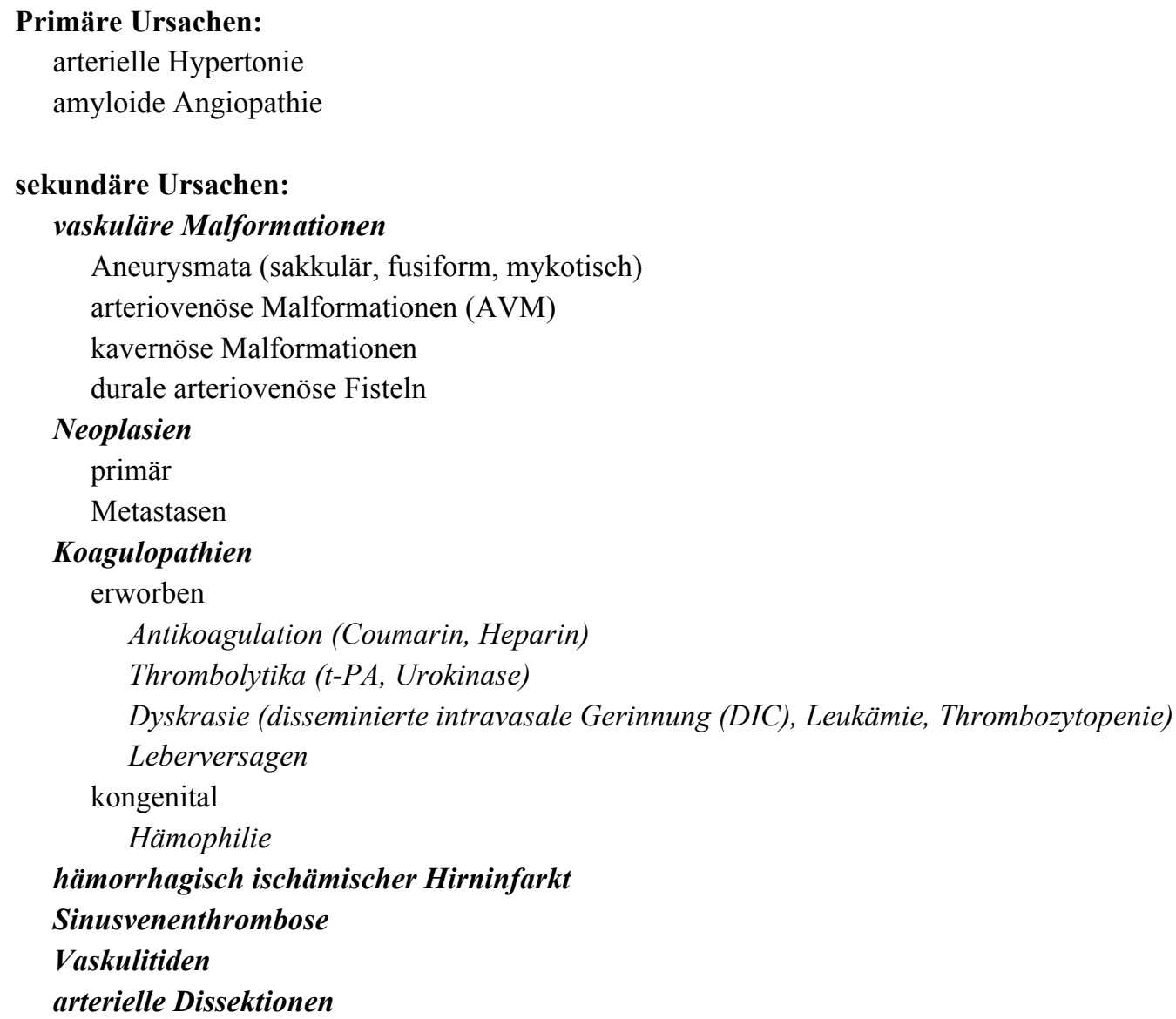

Tabelle 1: Zusammenfassung der Ursachen einer primären und sekundären spontanen ICB (Fewel et al. 2003) 


\subsubsection{Risikofaktoren der intrazerebralen Blutung}

Wie bereits oben beschrieben stellt die Hypertonie eine der Hauptrisiken für eine ICB dar. Das relative Risiko, eine ICB zu erleiden, liegt für Hypertoniker 3,9 bis 13,3 mal höher als für normotensive Menschen (Brott et al. 1986). Auch regelmäßiger Alkoholabusus, Drogenabusus und Diabetes mellitus werden als Risikofaktoren gezählt (Juvela et al. 1995). Rauchen scheint das Risiko einer SAB zu erhöhen, das einer ICB jedoch weniger (Thrift et al. 1996). Eine antikoagulative Therapie gilt insbesondere bei älteren Menschen als Risikofaktor für eine ICB. So steigert eine konventionelle antikoagulative Therapie das ICB-Risiko um das 7- bis 10-fache (Hart et al. 1995). Auch die Nutzung von Thrombolytika kann eine ICB verursachen. In Metaanalysen von Studien zur Behandlung ischämischer Hirninfarkte mit tPA ergab sich ein Risiko für eine ICB von 6,5 \% (Hacke et al. 1999).

\subsubsection{Klinik der intrazerebralen Blutung}

Klassischerweise präsentiert sich eine ICB mit fokalen neurologischen Ausfällen, die sich über Stunden entwickeln. Begleitet werden sie häufig von heftigen, akut einsetzenden Kopfschmerzen. Bei größeren Blutungen kommt es zudem zu Symptomen eines gesteigerten intrakraniellen Drucks mit Erbrechen und Bewusstseinstrübung bis zum Koma. Auch Krampfanfälle können auftreten. Subakute Verläufe ohne Schmerzsymptomatik und ohne neurologische Ausfälle sind ebenfalls möglich. Ein erhöhter Blutdruck ist bei $90 \%$ der Patienten mit einer ICB zu bemerken (Bladin et al. 2000). Selten bricht die Blutung in die Ventrikel ein und verursacht einen Hydrozephalus.

\subsubsection{Prognose der intrazerebralen Blutung}

Generell ist die Prognose einer ICB relativ schlecht, so starben von 37000 Amerikanern, die im Jahre 1997 eine ICB erlitten, 52 \% innerhalb des ersten Monats nach Auftreten der ICB (Broderick et al. 1993a). Nur $38 \%$ aller Patienten überleben das erste Jahr (Dennis et al. 1993).

Prognostische Auswirkungen haben unter anderem der Zeitpunkt des Einsetzens des Komas, die Lokalisation, als auch die Größe der Blutung. So sind ein frühes Einsetzen, eine große Blutung (bei Volumina über $100 \mathrm{ml}$ beträgt die Mortalität $90 \%$ ) sowie Blutungen im Thalamus und Hirnstamm prognostisch schlecht für das Überleben des Patienten .

Die häufig stark verminderte Lebensqualität stellt für Überlebende einer ICB eine große Herausforderung dar. Nur $10 \%$ der Patienten können nach einem Monat unabhängig leben, 
nach 6 Monaten sind über $80 \%$ der Patienten noch auf fremde Hilfe angewiesen. Sozioökonomisch gesehen weist der daraus resultierende lange und oftmals frustrane Weg durch die Instanzen des Krankenhaussystems eine hohe Relevanz auf (Fewel et al. 2003).

\subsubsection{Diagnostik der intrazerebralen Blutung}

Als Goldstandard der Diagnostik haben sich gegenwärtig die Computertomographie (CT) und die Magnetresonanztomographie (MRT) etabliert. Darüber hinaus wird oft bei atypisch lokalisierten Blutungen auch die zerebrale Angiographie als Diagnostikum zur Identifikation bzw. zum Ausschluss einer Gefäßmalformation genutzt.

\subsubsection{Therapieoptionen der intrazerebralen Blutung}

Ein klares und einheitliches Behandlungskonzept der intrazerebralen Blutung existiert bis heute nicht. Die möglichen Therapieansätze reichen von rein konservativen Maßnahmen bis hin zur operativen Hämatomausräumung. Kleinere Blutungen mit blandem Verlauf werden eher konservativ behandelt. Bei Patienten mit sehr schlechter Prognose (komatös, große Blutungsvolumina) ist ebenfalls eine konservative Therapie indiziert. Hinsichtlich der Operationsindikation herrscht höchste Uneinigkeit. Wird eine Operationsindikation gesehen, bieten sich 2 Methoden zur Wahl an:

\subsubsection{Kraniotomie und Hämatomentfernung}

Bis in die 1980er Jahre wurde die Kraniotomie mit Hämatomentfernung als Standardtherapie der ICB angesehen. Für die Kraniotomie sprach die vollständige Darstellung und Entfernung der Blutung, jedoch wurde häufig gesundes Hirnparenchym auf dem Weg zu tiefsitzenden Hämatomen verletzt. Auch heute noch gilt die Kraniotomie bei Lebensgefahr oder zerebellären Blutungen über $3 \mathrm{~cm}$ als Methode der 1. Wahl, bei den übrigen Hämatomen besteht Uneinigkeit bezüglich der Wertigkeit der Kraniotomie (Broderick J et al. 2007). Diese Uneinigkeiten basieren auch auf einer unzureichenden Studienlage. So sind bis heute nur wenige randomisierte Studien zur Hämatomevakuierung nach Kraniotomie veröffentlicht worden. McKissock et al. veröffentlichten 1961 ihre Studie mit dem Ergebnis eines gleichwertigen Outcomes der konservativ und chirurgisch behandelten Patienten (McKissock 1961). Weitere Studien von Juvela et al. 1989 und Batjer et al. 1990 bekräftigten dieses Ergebnis (Batjer et al. 1990; Juvela et al. 1989). Einen signifikanten Vorteil bei endoskopischer Hämatomausräumung ermittelte Auer et al. 1989. Die bislang größte Studie, 
International Surgical Trial in Intracerebral Haemorrhage (STICH), kam 2005 zu dem Ergebnis, dass das Outcome nicht signifikant unterschiedlich ist bei konservativer Therapie und Operation. Lediglich bei Blutungen, die nicht tiefer als $1 \mathrm{~cm}$ unter der Hirnoberfläche liegen, zeigten sich leichte Vorteile auf Seiten der operativen Gruppe. Gleichzeitig fand sich, dass bei komatösen Patienten die Operation mehr schadet als nutzt. Für Patienten mit tiefer gelegenen Blutungen deuten sich Vorteile der stereotaktischen Hämatomentleerung an (Mendelow et al. 2005).

\subsubsection{Stereotaktische Hämatomentfernung}

Die einfache Hämatomaspiration, als auch die Kombination von Aspiration und lokaler Lyse des Hämatoms sind weniger invasive Alternativen zur mikrochirurgischen Hämatomevakuierung nach Kraniotomie. Die deutlich weniger ausgeprägte Traumatisierung intakten Hirngewebes stellt den größten Vorteil dieser Therapieform dar. Durch die Durchführbarkeit in Lokalanästhesie bietet sich auch die Möglichkeit der Behandlung internistisch vorerkrankter Patienten. Als Fibrinolytikum der Wahl hat mittlerweile rekombinanter gewebeständiger Plasminogenaktivator (rt-PA) Urokinase ersetzt, da rt-PA im Vergleich eine wesentlich höhere fibrinolytische Potenz besitzt. So zeigten Rohde et al. (1995) dass intraventrikuläre Blutungen unter der Behandlung mit rt-PA innerhalb von 1-3 Tagen abgebaut wurden (Rohde et al. 1995). Ähnliche Studien zur stereotaktischen Lyse mit rekombinantem Plasminogenaktivator (rt-PA) zeigten erfolgversprechende Resultate (Lippitz et al. 1994; Schaller et al. 1995). Bislang fehlen jedoch randomisierte klinische Studien, die die Überlegenheit dieser Therapieform aufzeigen.

Die Diskussion um die Vor- und Nachteile der verschiedenen Behandlungsmethoden hält weiterhin an. Konsens besteht einzig darin, dass die Idealtherapie letztlich eine möglichst schnelle, minimal invasive Komplettausräumung des Hämatoms wäre. 


\subsection{Der Plasminogenaktivator}

\subsubsection{Gewebeständiger Plasminogenaktivator (t-PA)}

Die gewebeständigen Plasminogenaktivatoren haben im Rahmen der Hämostase bei der Plasminbildung größte physiologische Bedeutung. Die proteolytische Spaltung von Plasminogen zu Plasmin verläuft normalerweise relativ unspezifisch im Blutplasma durch Serinproteasen. Setzen nun jedoch die Endothelzellen des Gefäßsystems das in ihnen synthetisierte t-PA frei, so bindet dieses an einen PlasminogenFibrin-Komplex, der sich am Blutklot befindet (Hoylaerts et al. 1982; Zamarron et al. 1984). Durch die darauf einsetzende Konformationsänderung des Komplexes erhöht sich die an der Blutklotoberfläche ablaufende Plasminsynthese. Durch die hohe Fibrinaffinität des Plasmins und seiner Fähigkeit, aus dem Fibrin lösliche Peptidstücke abzuspalten, wird das Hämatom stückweise abgebaut. Der Wirkort des t-PA ist auf die Fibrinoberfläche begrenzt. Die Bindung an den Plasminogen-Fibrin-Komplex, beziehungsweise die Aktivierung des Plasmins an der Gerinnseloberfläche schützt vor einer physiologischen Inaktivierung durch im Blut zirkulierende Inaktivatoren (Plasminogenaktivatorinhibitor, PAI). Sowohl diese im Blut zirkulierenden Inaktivatoren als auch die höhere Affinität des t-PA zum FibrinPlasminogen-Komplex als zu freiem Plasminogen, schützen vor einer systemischen Fibrinolyse. Der Wirkort des t-PA bleibt auf den Blutklot begrenzt (Bergmann et al. 1983; Hoylaerts et al. 1982; Zamarron et al. 1984).

\subsubsection{Rekombinanter gewebeständiger Plasminogenaktivator (rt-PA)}

Gentechnisch hergestelltes t-PA, sogenanntes rekombinantes t-PA (rt-PA), machte eine größere pharmakologische Anwendung möglich, wobei kein Unterschied bezüglich der Pharmakodynamik nachweisbar ist (Zamarron et al. 1984). Experimentelle pharmakologische Studien zu Plasmahalbwertszeiten von rt-PA nach intravenöser Applikation ergaben Werte zwischen 3 und 9 Minuten (Crabbe und Cloninger 1987). Der Abbau zu niedermolekularen Formen und Aminosäuren erfolgt nach rezeptorvermittelter Endozytose in Leberparenchym-, Endothel- und Kupferzellen der Leber. Die Metabolite sind nach circa 45 Minuten im Urin nachweisbar (Nilsson et al. 1984; Tanswell et al. 1991). Die gute Dosierbarkeit, basierend auf der kurzen Halbwertszeit und der hohen fibrinolytischen Potenz, führte schnell zu einem routinemäßigen intravenösen Einsatz des rt-PA vor allem bei thrombotischen Gefäßverschlüssen, aber auch bei ischämischen Schlaganfällen (Chiu et al. 1998). Zur intrathekalen und besonders intrazerebralen Pharmakokinetik von rt-PA gibt es bislang nur 
wenige Untersuchungen. Die Plasminogenkonzentration im Liquor ist im Vergleich zu der im Blut deutlich erniedrigt. In Verbindung mit einer verlängerten Halbwertszeit von rt-PA im Liquor (2-3 h) wird so eine exakte Dosierung erschwert. Darüber hinaus erschwert die Zerstörung der Bluthirnschranke bei einer ICB die intrazerebrale Applikation von rt-PA: Die Durchmischung von intrazerebralem Milieu und intravasalen Blutbestandteilen erschwert die exakte Vorhersage von Pharmakokinetik und-dynamik (Hindersin et al. 1984). Die von Mayfrank et al. durchgeführten Studien zur intraventrikulären Anwendung von rt-PA zeigten eine deutliche Verbesserung des Glasgow-Coma-Scale-Wertes (GCS) bei prognostisch ungünstigen intraventrikulären Blutungen (Mayfrank et al. 1993). Ähnlich gute Ergebnisse zeigten auch Rohde et al. 1995, hier wurde keine Vergrößerung der bestehenden Blutung beschrieben, die Wirkung des rt-PA schien sich auf den intraventrikulären Raum zu beschränken (Rohde et al. 1995). Weitere nicht randomisierte Studien zeigten deutliche Effekte, wie die Reduktion des Blutungsvolumens nach Lyse und Aspiration um bis zu 70 \% (Rohde et al. 2000; Schaller et al. 1995).

Allerdings zeigte sich tierexperimentell auch eine Neurotoxizität des t-PA (Tsirka et al. 1996). Es kommt durch die Aktivierung von Plasmin, einer Serinprotease, zu einer Zerstörung extrazellulärer Matrix (Chen und Strickland 1997). Auch die Aktivierung von Mikrogliazellen, unter anderem durch t-PA, kann neurotoxisch wirken (Rogove und Tsirka 1998). In Schweinemodellen der ICB zeigte sich, dass rt-PA, trotz signifikanter Reduktion des Hämatomvolumens, die Entwicklung eines verspäteten Ödems (Auftreten erst nach 72 h) und eine entzündliche Reaktion des umliegenden Hirngewebes förderte (Rohde et al. 2002; Thiex et al. 2003). Weitere in-vivo-Studien bestätigten, dass rt-PA neurotoxische Eigenschaften entwickeln kann. Bei wiederholter Anwendung kann diese Neurotoxizität zu einer Ruptur der mikrovaskulären Blut-Hirn-Schranke führen, und damit eine weitere Ödembildung verursachen (Goto et al. 2007).

Armstead et al. stellten 2006 die Hypothese auf, dass es möglich ist, die neurotoxischen Effekte von rt-PA zu reduzieren, ohne dabei die fibrinolytische Aktivität zu dezimieren. Dies gelang ihnen mit Hilfe des vom Plasminogenaktivatorinhibitor Typ 1 (PAI-1) abgeleiteten Hexapeptids EEIIMD (Armstead et al. 2006). 


\subsection{Plasminogenaktivatorinhibitor (PAI)}

Momentan gibt es 4 Moleküle, die Plasminogenaktivatoren in vitro inhibieren können. Dies sind Plasminogenaktivatorinhibitor Typ 1 (PAI-1), PAI-2, PAI-3 und Protease Nexin 1 (PN$1)$.

Der primär physiologisch wirksame Inhibitor ist PAI-1. PAI-1 ist ein multifunktionales Glykoprotein aus der Gruppe der Serinproteaseinhibitoren (Serpine) (Stoop et al. 2000). Er reguliert das fibrinolytische System durch die schnelle Bildung von inaktiven Komplexen mit seinen Ziel-Serin-Proteasen, t-PA und Urokinase. Die Spezifität von PAI-1 wird durch Cofaktoren erweitert. In Anwesenheit des Glykoproteins Vitronectin oder des Glykosaminoglykans Heparin inhibiert PAI-1 äußerst effizient die Serinprotease Thrombin (Ehrlich et al. 1990; Ehrlich et al. 1991). Der Syntheseort von PAI-1 ist bis dato unbekannt. PAI-1 wird von Thrombozyten freigesetzt, bindet dann an den Fibrin-Klot und inhibiert anschließend die fibrinspezifischen Plasminogenaktivatoren wie z.B. t-PA (Braaten et al. 1993). Verschiedene Studien deuten darauf hin dass PAI-1 der Hauptgrund für die Lyseresistenz thrombozytenreicher Blutklots ist (Levi et al. 1992; Potter van Loon et al. 1992). Studien, die die Interaktion zwischen PAI-1 und t-PA untersuchten, zeigten die Möglichkeit einer separierten Unterdrückung der durch t-PA vermittelten Signaltransduktion (Akkawi et al. 2006) ohne eine Einschränkung der katalytischen Aktivität (Armstead et al. 2005; Nassar et al. 2004). Wie bereits beschrieben gelang es der Arbeitsgruppe Armstead et al. 2006 durch die Applikation von EEIIMD, die t-PA-induzierte Neurodegeneration und Ödembildung nach traumatischer Hirnverletzung zu reduzieren. Als Erklärung diente die Fähigkeit des EEIIMD, die durch t-PA bedingte Vasodilation, und damit eine Verstärkung des Ödems, zu unterbinden (Armstead et al. 2006).

\subsection{Vorversuche zur vorliegenden Arbeit}

Basierend auf bereits durchgeführten klinischen Studien zur lokalen Lysetherapie untersuchten Rohde et al. 2002 tierexperimentell die Lyse frontaler intrazerebraler Blutungen unter Einsatz von rt-PA an Schweinen. Rt-PA-behandelte Tiere wurden mit konservativ behandelten Tieren der Kontrollgruppe bezüglich der Histopathologie und Darstellung des Hämatoms im MRT verglichen. Unter Berücksichtigung bereits ermittelter Ergebnisse ist die hier beschriebene Studie als eine Fortführung dieser Studien zu sehen. In den Vorversuchen von Rohde et al. kam die sogenannte „Doppelinjektions-Technik“ zum Einsatz, hierbei wurde in eine durch Ballondilatation geschaffene Hämatomhöhle zuerst eine kleine Menge autologes 
Blut vorinjiziert. Erst nach der Gerinnung dieses Blutes wurde die eigentliche Blutungsmenge injiziert. So wurde unerwünschter Reflux entlang des Stichkanals vermieden (Rohde et al. 2002).

Für das Schwein als Versuchstier spricht eine Reihe verschiedenster Gründe. Das große gyrierte Hirn, die gut entwickelte weiße Substanz, ein überwiegend einheitlicher Gesundheitszustand und die relativ geringen Kosten sprechen eindeutig für eine Eignung des Schweines als Versuchstier in diesem Modell. Darüber hinaus ist die Möglichkeit eines um das 20-30 fache größeren Blutungsvolumens, im Vergleich zum Nagetiermodell, ein weiterer Vorteil des Schweines. Reproduzierbare Hämatomvolumina lassen sich vor allem durch Injektionen in die subkortikale weiße Substanz erreichen, da sich Blut leichter zwischen den myelinisierten Fasern, als im dichten Neuropil der grauen Substanz, ausbreitet. Das relativ große Volumen der weißen Substanz beim Schwein ermöglicht eine Ödementwicklung angrenzend an das Hämatom. Darüber hinaus ermöglicht die Ähnlichkeit des fibrinolytischen Systems, ebenso wie die der Neurophysiologie des Schweines, eine Übertragbarkeit der Ergebnisse auf den Menschen (Röttger 2002).

Die ursprüngliche Zielsetzung der Vorversuche bestand in der Überprüfung der Wirksamkeit des in die Hämatomhöhle applizierten rt-PA. Im Vordergrund stand die Klärung der Frage, ob durch die rasche und minimal invasive Blutungsentlastung sowohl eine deutliche Verkleinerung des Hämatoms als auch eine Reduktion des parenchymalen Sekundärschadens erreicht werden könne. Zwar konnte eine drastische Reduktion des Hämatomvolumens gezeigt werden, das Begleitödem jedoch zeigte eine deutliche Volumenzunahme. Basierend auf diesen Ergebnissen kam die Vermutung auf, dass rt-PA in Verbindung mit dem Restblut das Ödem induzieren könnte. Darüber hinaus sprachen starke meningeale und subkortikale Entzündungsreaktionen bei den mit rt-PA behandelten Tieren für eine Toxizität des rt-PAs.

\subsection{Zielsetzung der Arbeit}

Aufgrund dieser Ergebnisse sowie neuerer Erkenntnisse über die Suppression der unerwünschten Nebenwirkungen des rt-PA durch Plasminogenaktivatorinhibitor 1 (PAI-1) (Armstead et al. 2006) erschien es möglich, durch zusätzliche Applikation von PAI-1 die rtPA-induzierten Sekundärschäden im Schweinemodell der ICB zu verringern.

Als Ziele des Versuchsvorhabens wurde dementsprechend folgendes definiert: 
- Es soll untersucht werden, ob durch die zusätzliche Applikation von PAI-1 nach der Lyse mit rt-PA eine Reduktion des parahämatomalen Ödems, als Indikator für die Neurotoxizität des rt-PA, im Vergleich zu den nur mit rt-PA behandelten Tieren erreicht werden kann.

- Es soll untersucht werden, wie sich die Reduktion des Hämatoms durch Gabe von PAI-1 im Vergleich zur Kontrollgruppe verhält.

- Es soll untersucht werden, ob sich die Begleitödeme der verschiedenen Gruppen in Bezug auf ihre Beschaffenheit unterscheiden. 


\section{Material und Methoden}

\subsection{Material}

\subsubsection{Medikamente und Bioreagenzien}

$\begin{array}{ll}\text { Actilyse (rt-PA) } & \text { Thomae GmbH, Biberach } \\ \text { Betaisodonalösung } & \text { Mundipharma GmbH, Limburg } \\ \text { Cefazolin Fresenius 2g } & \text { Fresenius Kabi Deutschland GmbH, } \\ & \text { Bad Homburg } \\ \text { Cutasept G (Desinfektionsmittel) } & \text { Bode Chemie, Hamburg } \\ \text { Disoprivan 1\% (Propofol) } & \text { Astra Zeneca, Wedel } \\ \text { Ketamin 10\% } & \text { SANOFI-CEVA GmbH, Düsseldorf } \\ \text { NaCl 0,9\% } & \text { B Braun Melsungen AG } \\ \text { Nobecutan Spray } & \text { Astra Chemicals GmbH, Wedel } \\ \text { Stresnil (Azaperon) } & \text { Janssen GmbH, Neuss } \\ \text { T 61 (Tetracainhydrochlorid) } & \text { Intervet, Unterschleißheim } \\ \text { Temgesic 5mg (Buprenorphin) } & \text { Essex Pharma, München } \\ \text { Thiopental } & \text { Rotexmedica, Trittau } \\ \text { Paraformaldeyd reinst. } & \text { Merck, Darmstadt } \\ \text { Plasminogen Activator Inhibitor 1 } & \text { Oxford Biomediacal Research } \\ \text { Xylocain Gel 2\% } & \text { Astra Zeneca GmbH, Wedel }\end{array}$

\subsubsection{Verbrauchsmaterial}

Butterfly Injektionsnadeln 19G Becton Dickinson, Frankreich

Einmalhandschuhe Hartmann AG, Heidenheim

Einmalhandschuhe, steril Hartmann AG, Heidenheim

Fogarty Katheter EMB80 Edward Lifesciences, U.S.A.

Injektionskanülen 17G,20G,23G B Braun, Melsungen

Kompressen, steril Hartmann AG,Heidenheim

Lochtuch, steril Hartmann AG, Heidenheim 
Präparationsbesteck

Rickham Kapsel

Spritzen Injekt Solo

Trachealtubus $6,5 \mathrm{~mm}$

Venenverweilkanüle Vasofix
Fine Science Tools, Heidelberg

Codman, U.S.A.

B Braun, Melsungen

Portex Limited, England

B Braun, Melsungen

\subsubsection{Geräte}

Gefrierschrank $-20^{\circ} \mathrm{C}$

Herz Perfusionspumpe

Magnetom Trio

Narkosegerät Tiberius

Narkosemonitor PM 8050

Workstation

\subsubsection{Computersoftware}

Excel 2008

Syngo

Word 2008

Statistica

\author{
Liebherr, Ochsenhausen \\ Polystan \\ Siemens Medical Solutions, Erlangen \\ Dräger, Lübeck \\ Dräger . Lübeck \\ Siemens, Erlangen
}

Siemens, Erlangen

Microsoft Europe, Berlin

Statsoft Europe GmbH

\subsection{Versuchsaufbau und -durchführung}

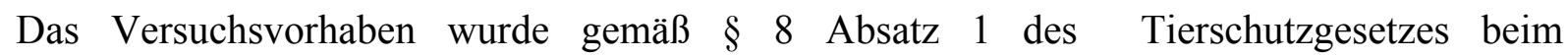
Niedersächsischen Landesamt für Verbraucherschutz und Lebensmittelsicherheit beantragt und genehmigt.

Bei 21 Schweinen wird mittels autologer Blutinjektion eine intrazerebrale Blutung im Frontallappen induziert. Der Blutungsabbau sowie die Veränderung des Hämatoms im zeitlichen Verlauf wird mittels magnetresonanztomografischer (MRT) Messungen verfolgt. Eine MRT-Kontrolle erfolgt direkt postoperativ, am 3. postoperativen Tag, sowie abschließend am 10. Tag postoperativ. Die 21 Schweine wurden in 3 Gruppen zu je 7 Schweinen eingeteilt. Gruppe 1, die Kontrollgruppe, durchläuft keine weitere Behandlung, die Blutung wird ihrem Spontanverlauf überlassen. Den Tieren der Gruppen 2 und 3 wird rt-PA 
in die Blutung injiziert, nach einer 15 minütigen Einwirkzeit wird die lysierte Blutung manuell aspiriert. Den der Gruppe 3 zugehörigen Tieren wird nach der Aspiration zusätzlich PAI-1 in die Blutung injiziert. Die Entwicklung von Blutungs- und Ödemgröße wird verglichen.

\subsubsection{Versuchstiere}

21 männliche Schweine der Gattung „Deutsche Landrasse“ wurden als Versuchstiere genommen.

Die Schweine waren zum Versuchszeitpunkt zwischen 14 und 18 Wochen alt, ihr Gewicht betrug zwischen 30 und $36 \mathrm{Kg}$. Sie wurden alle vom gleichen Zuchtbetrieb (Fa. Zuchtgut Relliehausen) geliefert.

Die Unterbringung, sowie Pflege der Schweine erfolgte in der zentralen tierexperimentellen Einrichtung der Universität Göttingen. Bis zu 2 Schweine wurden in etwa $16 \mathrm{~m}^{2}$ großen Ställen in Bodenhaltung mit Heueinstreu, bei einer Raumtemperatur von $18-22^{\circ} \mathrm{C}$ und einer Luftfeuchtigkeit von 40-50\%, untergebracht. Auf einen konsequenten Schlaf- Wachrhythmus wurde mittels eines Kunstlichtzyklus von 12h Dauer geachtet. Die Fütterung erfolgte 2 mal täglich mit einer Getreidemischung, Wasser stand zur freien Verfügung. Zwölf Stunden vor Operations- und MRT-Kontrolltermin bestand Nahrungsmittelkarenz. Es wurde darauf geachtet, dass die Schweine mindestens 5 Tage Zeit hatten, sich an die Bodenhaltung zu gewöhnen, um dann bei klinischer Gesundheit operiert werden zu können.

\subsubsection{Medikation}

Zur Prämedikation wurde den Schweinen Azaperon (Stresnil, Fa. Janssen GmbH, Neuss) mit der Dosierung 7-10 mg pro Kg Körpergewicht intramuskulär injiziert. Nach circa 20 Minuten waren die Tiere soweit sediert, dass ihnen ein intravenöser Zugang (Braunüle 18G, Fa. Braun) in eine der Ohrvenen gelegt werden konnte. Über diesen Zugang erfolgte die Gabe von 10-15 $\mathrm{mg} / \mathrm{kg}$ Körpergewicht Ketamin (Ketamin 10\%, SANOFI-CEVA GmbH) und Propofol (Disoprivan 1\%, Fa. AstraZeneca, Wedel) zur Narkotisierung und Erleichterung der Intubation. Die Anästhesierung wurde durch die Gabe von Temgesic $5 \mathrm{mg}$ (Wirkstoff Buprenorphin, Fa. Essex Pharma) i.m. sichergestellt. Jeder Medikamentengabe folgte eine Spülung mit $10 \mathrm{ml} \quad 0,9 \% \mathrm{NaCl}$ Lösung. Präoperativ erfolgte außerdem eine Antibiotikaprophylaxe mit Cefazolin Fresenius 2g (Fa. Fresenius Kabi Deutschland GmbH). 
An Tagen der Einschläferung der Versuchstiere wurde die Narkose zusätzlich durch Thiopental (Fa. Rotexmedica,15-20 mg/Kg Köpergewicht i.v.) ergänzt.

\subsubsection{Beatmung}

Die Intubation der Tiere erfolgte mit einem Trachealtubus (Innendurchmesser 6,5 mm, Fa Portex Limited, England), wobei die Tubusspitze zum Zwecke einer verbesserten Gleitwirkung und zur Vorbeugung von Laryngospasmen mit Xylocain Gel 2 \% (Fa. Astra Zeneca $\mathrm{GmbH}$ ) eingerieben wurde.

Zum Zwecke der kontrollierten Beatmung wurde der Tubus fixiert und an ein Narkosegerät der Firma Dräger angeschlossen. Die Beatmung erfolgte durch die Gabe von Sauerstoff mit der Atemfrequenz von 10 Atemzügen pro Minute und einem Atemzugvolumen von $500 \mathrm{ml}$. Das Verhältnis von Inspirationsdauer zu Exspirationsdauer lag bei 1:2. Zum Monitoring der physiologischen Beatmung wurde der $\mathrm{CO}_{2}$-Anteil der Exspirationsluft mit einem Narkosemonitor der Fa. Dräger gemessen.

Die Aufrechterhaltung der Narkose erfolgte durch die bedarfsgerechte weitere Gabe von Propofol.

\subsubsection{Operationsablauf}

In Bauchlage wurde der Kopf des Schweines rasiert und mit Hilfe von Betaisodonalösung desinfiziert. Nach Herstellung eines sterilen Operationsfeldes wurde die frontale Kopfhaut über einen circa $6 \mathrm{~cm}$ langen medianen Hautschnitt eröffnet und die Kalotte dargestellt. Koronar- und Sagittalnaht waren das Ziel einer stumpfen Präparation. Nach Orientierung an diesen Strukturen wurde $0,7 \mathrm{~cm}$ rechts paramedian und $1,7 \mathrm{~cm}$ präkoronar die Schädeltrepanation mit einem 3,97 mm Bohrer vorgenommen (siehe Abbildung 1). Die Spitze eines 6 French EMB 80 Fogartykatheters (Edwards Lifesciences) wurde über das Bohrloch etwa $1 \mathrm{~cm}$ tief in den rechten Frontallappen eingeführt. Zur Schaffung der zukünftigen Hämatomhöhle wurde der Katheter mehrere Male für jeweils 2 Sekunden dilatiert. Der Ballonkatheter wurde entfernt und eine Rickham-Kapsel (Fa. Codman) mit 1,2 cm langem Katheter eingeführt. Die Spitze des Katheters kam in der zuvor präparierten Parenchymhöhle zum Liegen, so dass die Rickham-Kapsel zur Injektion des autologen Blutes, des rt-PAs und des PAIs genutzt werden konnte (siehe Abbildung 2). Das Blut wurde zuvor aus einer peripheren Vene des Ohres entnommen. Die Injektion des Blutes erfolgte in Anlehnung an das Doppel-Injektionsmodell (Deinsberger et al. 1996). Nach der Injektion von 
$2 \mathrm{ml}$ Blut und einer darauf folgenden Wartezeit von 1 Minute wurden weitere $5 \mathrm{ml}$ Blut zur Hämatombildung injiziert.

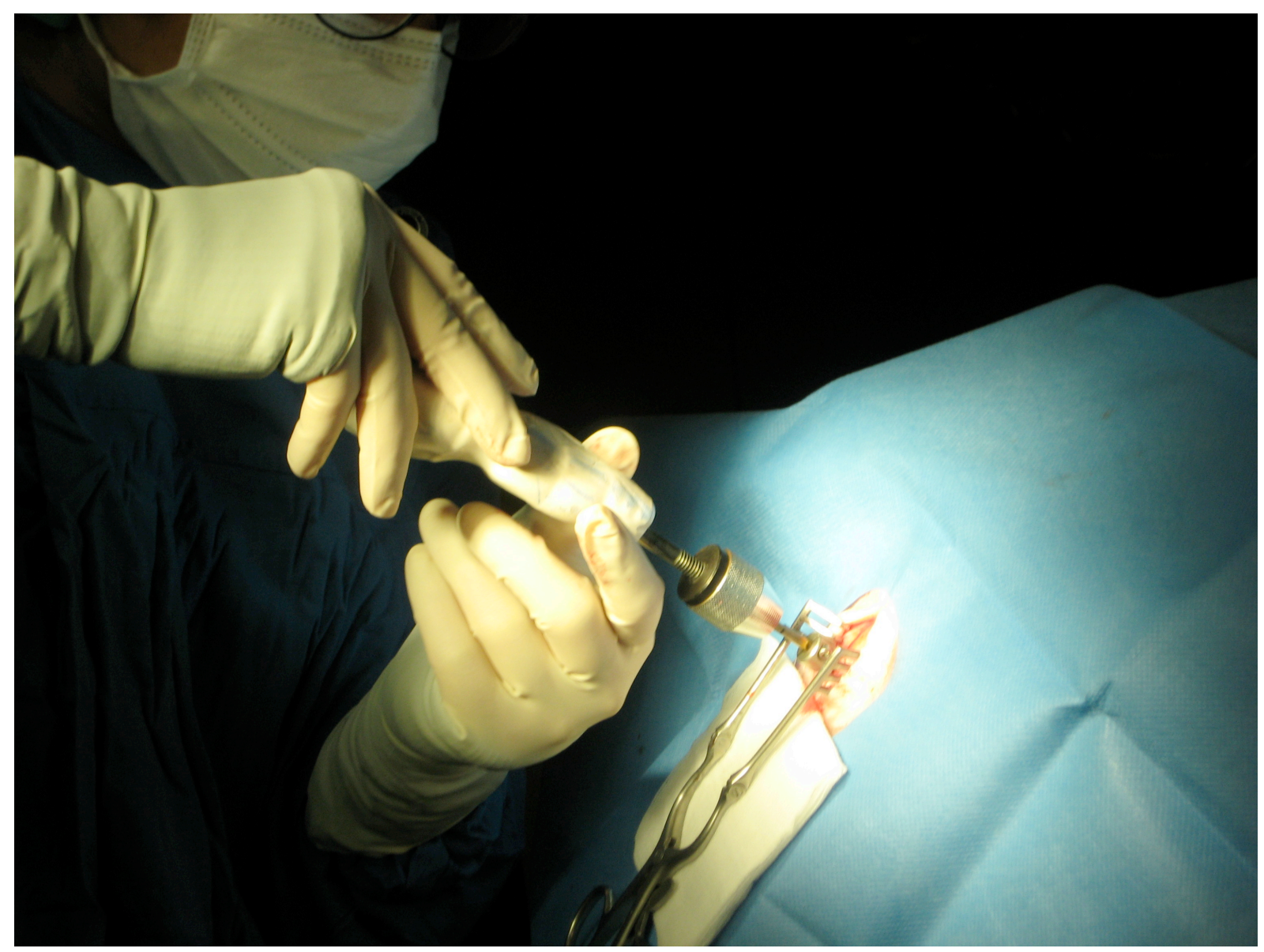

Abb. 1: Intraoperatives Setzen der Trepanation mittels 3,97 mm Bohrer 


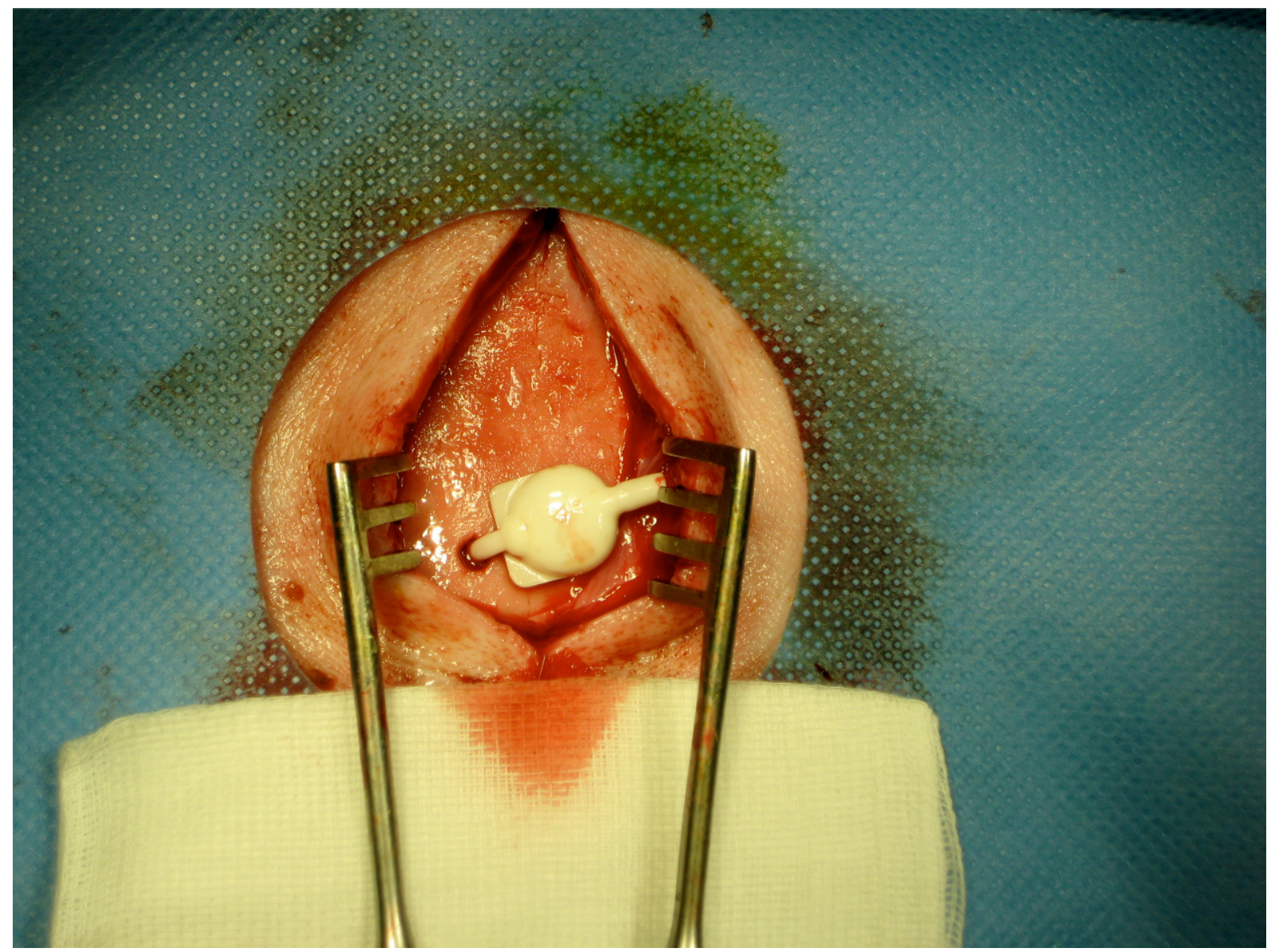

Abb.2: Rickham-Kapsel in situ

Die Kopfwunde wurde nun unter subgalealer Belassung der Rickham-Kapsel durch eine Hautnaht verschlossen. Ein Sprühverband (Nobecutan -Spray, Fa. Astra Chemicals GmbH, Wedel) sorgte für weiteren Schutz.

\subsubsection{Magnetresonanztomografische Untersuchungen}

Direkt im Anschluss an die Operation erfolgte unter manueller Beatmung eine MRTUntersuchung des Schädels der Tiere. Des Weiteren wurden Kontroll-MRTs an den Tagen 3 beziehungsweise 4 und 10 beziehungsweise 11 postoperativ durchgeführt. Die Prämedikation für die Narkose zur Durchführung der MRT-Untersuchungen entsprach dem Prämedikationsprotokoll der Operationstage. Die MRT-Untersuchungen wurden in einem 3,0Tesla-MRT (Magnetom Trio, Siemens Medicals Solutions, Erlangen/Germany) angefertigt. Als Wichtungen wurden folgende Einstellungen genutzt: T2* $(1.2 / 1.0 \mathrm{~mm})$, FLAIR (fluidattenuated inversion recovery) $(1.4 / 1.1 \mathrm{~mm})$, Echo planar imaging (EPI) diffusion weighted imaging (DWI) $(1.8 / 1.8 \mathrm{~mm})$ und TSE-Dual weighted echo $(0.6 / 0.6 \mathrm{~mm})$.

Zur Bestimmung des Hämatomvolumens wurden die Bilder in der T2*-Wichtung ausgewertet. Das Ödemvolumen wurde in der FLAIR-Wichtung bestimmt. Die Auswertung 
erfolgte an einem Arbeitscomputer der Firma Siemens, sowie mit Hilfe einer Software der Firma Syngo. Das Blutungs- und Ödemvolumen wurde direkt auf dem Bildschirm für jedes Bild markiert, und dann mit einer von Kothari et al. beschriebenen Formel berechnet (Kothari et al. 1996).

Diese Formel lautet:

$$
\mathrm{V}_{\mathrm{icb}}=\mathrm{A} * \mathrm{~B} * \mathrm{C} / 2
$$

Das Produkt aus dem jeweils größten Längendurchmesser (A) und dem entsprechenden Querdurchmesser (B) der Blutung und der Anzahl (C) der MRT-Schnitte, auf denen die jeweilige ICB zu erkennen ist, wird durch zwei dividiert.

Außerdem wurden die T2-Relaxationszeit (T2rt) und der aktivierte Diffusionskoeffizient (ADC) bestimmt, um Wassergehalt, bzw. Wasserkonzentration des Ödems zu berechnen.

T2rt-Bilder wurden mit Hilfe der folgenden Formel generiert:

$$
\mathrm{T} 2 \text { value }=(\mathrm{TE} 2-\mathrm{TE} 1) / \mathrm{Ln}(\mathrm{SI} 1 / \mathrm{SI} 2)
$$

SI1 und SI2 sind Variablen für die Signalintensität des ersten und zweiten Echobildes.

T2rt ist ein indirekter Indikator für die parenchymale Wassermenge (Kamman et al. 1988).

Der ADC-Wert, der aktivierte Diffusionskoeffizient, stellt eine gewebs- bzw.

funktionsspezifische Größe dar und ist ein Maß für die Stärke der Diffusionsbewegung in der Richtung des applizierten Gradientenpulses. Er wird in der Einheit $\mathrm{mm}^{2} / \mathrm{sec}$ gemessen. Zur Bestimmung des ADC-Wertes sind mehrere Messungen (mind. 2) bei verschiedenen bWerten nötig. Dabei gilt, je höher der Signalabfall, desto höher die Diffusionsgeschwindigkeit und somit höher der ADC, d.h. ein Areal verminderter Intensität bei der diffusionsgewichteten Bildgebung zeigt sich im ADC-Bild als Areal mit erhöhter Intensität. Als Referenzwert bei der diffusionsgewichteten MR-Bildgebung verschiedenster wissenschaftlicher Untersuchungen wird der ADC-Wert des Liquors (cerebrospinale Flüssigkeit (CSF)) bestimmt. Die Angaben reichen von 2,1 bis 3,63 x 10-3 $\mathrm{mm}^{2} / \mathrm{sec}$ (Goßrau 2005; van Bruggen et al. 2002).

Die Schweine der Kontrollgruppe wurden nach dem ersten MRT-Termin bei regelmäßiger Spontanatmung extubiert und zum Zwecke der Erholung in ihre Stallungen zurückgebracht.

\subsubsection{Fibrinolyse und Plasminogenaktivatorinhibitor (PAI)}

Bei den Tieren der rt-PA- sowie der rt-PA-PAI-Gruppe wurde nach der Bildgebung die Wunde wieder eröffnet und die Rickham-Kapsel freigelegt. Nun folgte die Injektion des Fibrinolytikums über die Rickham-Kapsel. Hierbei orientierte sich die Menge des rt-PAs 
(Actilyse, Fa. Thomae $\mathrm{GmbH}$ ) an dem zuvor mit Hilfe der T2*-Bilder berechneten Blutungsvolumen. Die Dosierung erfolgte nach der von Schaller et al beschriebenen Methode (Schaller et al. 1995). Hierbei entsprach $1 \mathrm{~mm}^{3}$ der maximalen Blutungsgröße 0.1mg rt-PA. Nach 15 Minuten Einwirkzeit erfolgte die vorsichtige Aspiration der verflüssigten Hämatomanteile.

Bei den Tieren der rt-PA-PAI-Gruppe schloss sich der Aspiration die Gabe des Plasminogenaktivatorinhibitors 1 (PAI-1) (Fa. Oxford Biomedical Research) über die Rickham-Kapsel an. Die Dosierung betrug $1.1 \mathrm{mg}$.

Bei allen Versuchstieren wurden die eingebrachte Rickham-Kapsel und der Katheter in subgalealer Lage belassen. Die Wunden wurden per Einzelknopfnaht verschlossen und zur weiteren Sicherung mit einem Sprühverband versehen.

\subsubsection{Tötung und Sektion der Tiere}

Nach dem letzten Kontroll-MRT-Termin an Tag 10 beziehungsweise 11 wurden die Tiere durch die Gabe von T61 (pharmazeutisch wirksamer Bestandteil Embutramid, Mebezonlumjodid und Tetracainhydrochlorid, Fa. Intervet) getötet. Bei einer Gabe von $20 \mathrm{ml}$ setzte nach wenigen Minuten ein Herz-Kreislaufstillstand ein. Der Brustkorb wurde durch eine Mittelliniensternotomie eröffnet und das Herz frei präpariert. Es folgte die Freilegung der Vena cava superior sowie der Aorta ascendens. Ein Katheter wurde jeweils in den beiden Gefäßen platziert. Der Katheter in der Aorta ascendens wurde mit einer Herz-PerfusionsPumpe der Firma Polystan verbunden, am Katheter in der Vena cava superior wurde ein ableitender Schlauch befestigt. Über die Pumpe wurden nun 15 Liter 0,9\% Kochsalzlösung in das Kreislaufsystem des Tieres geleitet. Durch den sich aufbauenden Druckgradienten konnte das Schwein über die Vena cava superior exsanguiniert werden. Die Pumpfrequenz lag bei $200 \mathrm{ml}$ pro Minute. An die Durchspülung mit Kochsalz schloss sich die Perfusion mit 5 Litern $4 \%$ Paraformaldehyd (Paraformaldehyd reinst, Fa. Merck) an. Die Katheter wurden in situ belassen, und das Paraformaldehyd über die Pumpe zugeführt. Die Pumpfrequenz betrug 100 $\mathrm{ml}$ pro Minute. 


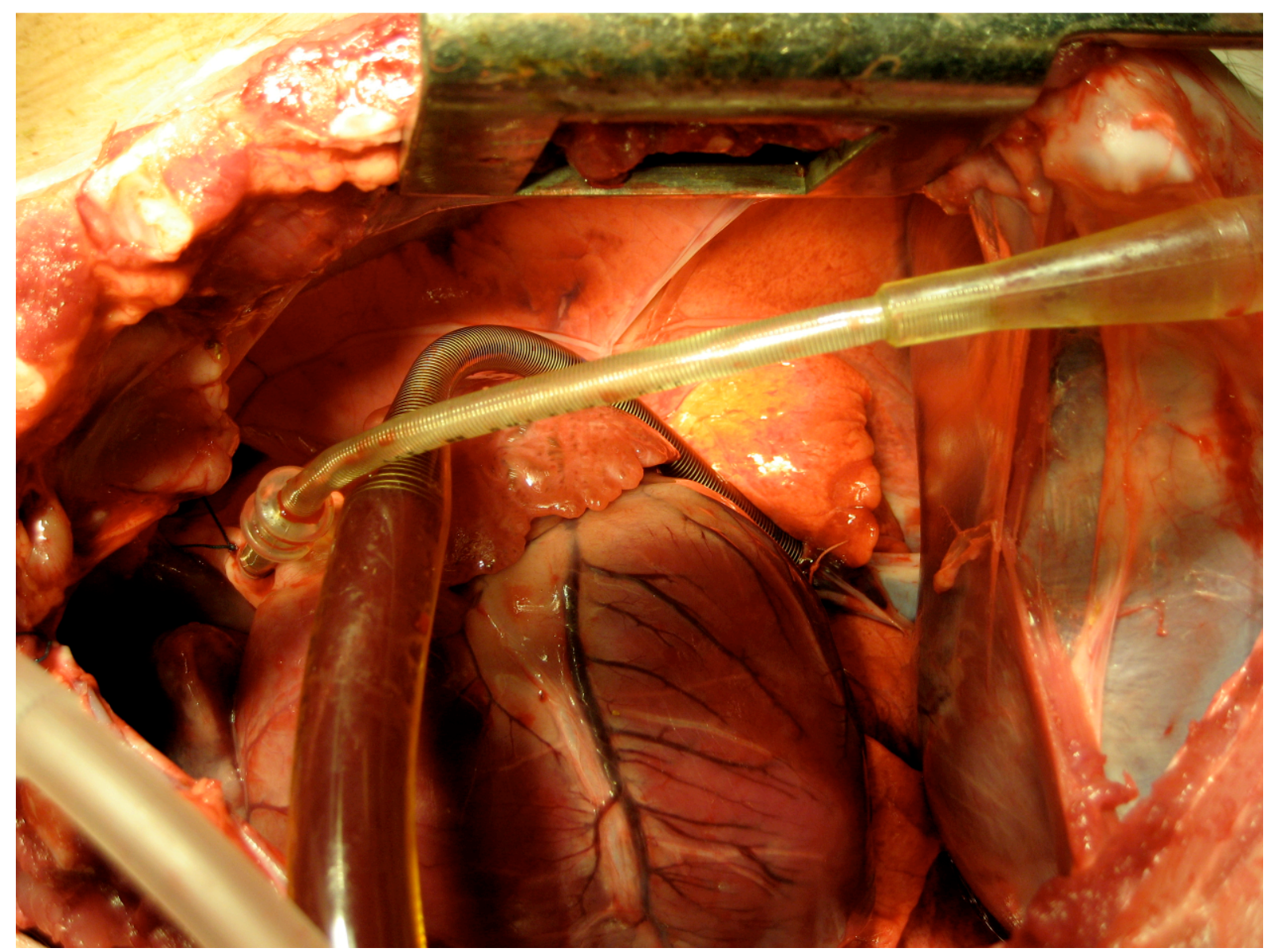

Abb.3: Katheter in Vene cava superior und Aorta ascendens

Nach vollständiger Perfusion des Tieres wurde die Kopfhaut abpräpariert und die Schädelkalotte mit Hilfe einer Knochensäge sowie eines Meißels eröffnet. Nach Durchtrennung der Medulla oblongata und der Hirnnerven konnte das Hirn entnommen werden. Bis zur neurohistologischen Aufbereitung wurde das Hirn zur weiteren Fixierung in einer 10 \%igen Formalinlösung schwimmend gelagert.

Der Kadaver wurde fachgerecht durch die Mitarbeiter der tierexperimentellen Einrichtung entsorgt. 


\subsection{Neurohistopathologische Aufbereitung}

Zum Zwecke der neurohistopathologischen Aufbereitung wurden die Gehirne in $3 \mathrm{~mm}$ breite koronare Scheiben geschnitten. Es folgte eine Anfärbung der Schnitte zur mikroskopischen Untersuchung. Als Färbemethode der Wahl diente eine Hämalaun-Eosin-Übersichtsfärbung.

\subsubsection{Färbung mit Hämalaun-Eosin}

Diese Färbemethode dient der Übersichtsfindung. Eine semiquantitative Beurteilung des Ödems und der entzündlichen Infiltrate wurde ermöglicht. Zellkerne erscheinen blau, die übrigen Gewebsbestandteile hingegen rot bis rosa.

Methodik der Färbung:

1. Aqua dest., anschließend 10 Minuten Kernfärbung in Hämalaun (Fa Merck)

2. Spülung des Schnittes mit Wasser

3. 10 Minuten Bläuen der Präparate in einem zweiten Wasser

4. Überfärbung der Schnitte (circa 5 Minuten) in 1 \%iger wässriger Eosinlösung (Fa Merck), einige Tropfen Essig wurden zugesetzt.

5. 2maliges Abspülen der Schnitte mit Wasser

6. Differenzierung in $70 \%$ igem und in $96 \%$ igem Alkohol

7. 2-3 malige weitere Differenzierung in absolutem Alkohol für jeweils 2 Minuten

8. Xylol

9. Eindeckung mit Vitroclud.

\subsection{Rekombinanter gewebeständiger Plasminogenaktivator (rt-PA)}

Zum Zwecke der Studie wurde der Wirkstoff Alteplase (Actilyse, Fa. Dr. Karl Thomae $\mathrm{GmbH}$ ) in der Darreichungsform einer wässrigen Lösung (Konzentration 1mg/ml) verwendet.

\subsection{Plasminogenaktivatorinhibitor 1 (PAI-1)}

Der in dieser Studie genutzte Plasminogenaktivatorinhibitor 1 wurde von der Firma Oxford Biomedical Research bezogen. Er wurde zu einer Konzentration von 1,1mg/ml mit einer sterilen 0,9\%igen Kochsalzmischung verdünnt. 


\subsection{Statistische Auswertung}

Zur statistischen Auswertung wurde der unverbundene Student's-t-Test genutzt. Unterschiede wurden als signifikant für $\mathrm{P}<0,05$ festgelegt. 


\section{Ergebnisse}

\subsection{Blutungsverlauf der Kontrollgruppe}

Die Kontrollgruppe bestand aus sechs Tieren. Diesen wurde, protokolarisch festgelegt, $7 \mathrm{ml}$ Eigenblut zur Produktion der intrazerebralen Blutung injiziert. Das postoperative Blutvolumen variierte am ersten Tag zwischen 1,83 und 7,14 $\mathrm{cm}^{3}$. Der Mittelwert für das Blutungsvolumen unmittelbar nach Operation betrug $3,844 \mathrm{~cm}^{3}\left(+/-2,4 \mathrm{~cm}^{3}\right)$.

Die am vierten postoperativen Tag bestimmten Werte für das Blutungsvolumen variierten zwischen 1,42 $\mathrm{cm}^{3}$ und 5,32 $\mathrm{cm}^{3}$. Dies ergab einen Mittelwert von $3.01 \mathrm{~cm}^{3}\left(+/-2,02 \mathrm{~cm}^{3}\right)$. Dies entspricht, im Vergleich zum initialen Blutungsvolumen, einer Volumenreduktion um $0,843 \mathrm{~cm}^{3}$ auf $78,3 \%$, so dass sich innerhalb der ersten 3 Tage eine Abnahme um 21,7\% verzeichnen lässt.

In der abschließenden Messung an Tag 10 konnte eine weitere Volumenreduktion beobachtet werden. Das Blutungsvolumen hatte sich im Durchschnitt auf $2.62 \mathrm{~cm}^{3}\left(+/-0,87 \mathrm{~cm}^{3}\right)$ reduziert. Dies entspricht einer Reduktion des Blutungsvolumens bezogen auf das Initialvolumen von $3,844 \mathrm{~cm}^{3}$ auf $68,2 \%$ des Ausgangswertes. Spontan betrug also die Reduktion des Blutungsvolumens bei den Tieren der Kontrollgruppe innerhalb der 10 beobachteten Tage 31,8 \%. Bei Tier 6 konnte aufgrund technischer Probleme keine Messung an Tag 10 erfolgen.

\section{2 Ödemverlauf der Kontrollgruppe}

Das perifokale Ödem wurde mittels der FLAIR-Sequenz direkt postoperativ, am 3. bzw. 4. Tag und am 10. bzw. 11. Tag bestimmt.

Direkt postoperative Ödemgrößen reichten von nicht wahrnehmbar $\left(0 \mathrm{~cm}^{3}\right)$ bis $1,56 \mathrm{~cm}^{3}$, daraus ergab sich eine durchschnittliche Ödemgröße von $0,914 \mathrm{~cm}^{3}\left(+/-2,82 \mathrm{~cm}^{3}\right)$.

Das Ödemvolumen an Tag 3 reichte von 7,76 $\mathrm{cm}^{3}$ bis 29,58 $\mathrm{cm}^{3}$. Der Mittelwert betrug 14,82 $\mathrm{cm}^{3}\left(+/-9,45 \mathrm{~cm}^{3}\right)$. Dies entspricht einer Volumensteigerung um 13,06 $\mathrm{cm}^{3}$, bzw. um $1621 \%$ des Ausgangswertes.

Bis zum Sektionstag wurde ein Rückgang des Ödemvolumens registriert. Die Werte schwankten hier zwischen 2,51 $\mathrm{cm}^{3}$ und 30,57 $\mathrm{cm}^{3}$. Der Mittelwert betrug hier 12,90 $\mathrm{cm}^{3}(+/-$ $11,15 \mathrm{~cm}^{3}$ ), was einer Reduktion von $1,92 \mathrm{~cm}^{3}$ oder um 12,9\% in Bezug auf Tag $3 / 4$ 
entspricht. Verglichen mit der initialen Volumenmessung konnte man eine Steigerung um $11,9 \mathrm{~cm}^{3}$ oder um $1411 \%$ des Ausgangswertes verzeichnen.

Aufgrund technischer Probleme war es bei Tier 6 nicht möglich am Sektionstag eine MRTAufnahme zu machen, so dass nur 5 von 6 Tieren zur Auswertung gelangten.

\subsection{T2-Relaxationszeit (T2rt) und ADC der Kontrollgruppe}

Die T2-Relaxationszeit- und ADC(activated diffusion coefficient)- Messung ergab direkt postoperativ Werte zwischen 112 - $137 \mathrm{~ms}$ (T2rt) und $72-76 \times 10^{-6} \mathrm{~mm}^{2} / \mathrm{s}$ (ADC). Dies ergab eine mittlere T2rt von 121,7 ms und einen mittleren ADC von 73,3 x $10^{-6} \mathrm{~mm}^{2} / \mathrm{s}$. Die zweite postoperative Messung offenbarte T2rt-Werte zwischen 133,2 und 155 ms, entsprechend einem Mittel von 147 ms. Die Messung des ADC ergab einen Mittelwert von $86,7 \times 10^{-6} \mathrm{~mm}^{2} / \mathrm{sec}$ bei Werten zwischen 84,3 und $92 \times 10^{-6} \mathrm{~mm}^{2} / \mathrm{s}$. Die am Sektionstag gemessenen Werte variierten zwischen 111 und $142 \mathrm{~ms}$ für die T2rt und 78 bis $89,6 \times 10^{-6}$ $\mathrm{mm}^{2} / \mathrm{s}$ für den ADC. Dies entsprach Mittelwerten von 123,4 ms (T2rt) und $81,8 \times 10^{-6} \mathrm{~mm}^{2} / \mathrm{s}$ $(\mathrm{ADC})$.

\subsection{Blutungsverlauf der rt-PA-Gruppe}

Auch den Tieren der rt-PA-Gruppe wurden $7 \mathrm{ml}$ Blut injiziert. Es resultierten Blutvolumina zwischen $0,812 \mathrm{~cm}^{3}$ und 6,72 $\mathrm{cm}^{3}$. Dies ergab einen Mittelwert von 3,70 $\mathrm{cm}^{3}\left(+/-5,02 \mathrm{~cm}^{3}\right)$.

Bei der MRT-Kontrolle am dritten bzw. vierten postoperativen Tag lässt sich eine deutliche Reduktion des Blutungsvolumens feststellen. Die festgestellten Volumina variierten zwischen den Maximalwerten 0,416 $\mathrm{cm}^{3}$ und 5,323 $\mathrm{cm}^{3}$. Es zeigte sich ein durchschnittliches Volumen von $2,42 \mathrm{~cm}^{3}\left(+/-2.02 \mathrm{~cm}^{3}\right)$, entsprechend einer Reduktion um $1,28 \mathrm{~cm}^{3}$ bzw. $34,6 \%$ in Bezug auf das durchschnittliche Initialvolumen.

Bei der MRT- Kontrolle am Sektionstag wurden Blutungsvolumina zwischen 0,416 $\mathrm{cm}^{3}$ und $3,048 \mathrm{~cm}^{3}$ gemessen. Dies entsprach einem mittleren Blutungsvolumen von $1,36 \mathrm{~cm}^{3},(+/-$ $1,12 \mathrm{~cm}^{3}$ ) beziehungsweise einem Rückgang auf $36,7 \%$ des durchschnittlichen Initialvolumens von $3,7 \mathrm{~cm}^{3}$. Unter der Behandlung der Blutung mit rt-PA konnte also bei den 7 von uns untersuchten Tieren eine durchschnittliche Blutungsreduktion um 63,3\% erzielt werden. 


\section{5 Ödemverlauf der rt-PA-Gruppe}

Bei 3 von 7 Tieren konnte direkt postoperativ noch kein Ödem nachgewiesen werden. Bei den restlichen Tieren wurden Ödemvolumina zwischen $0,52 \mathrm{~cm}^{3}$ und $1,73 \mathrm{~cm}^{3}$ gemessen. Dies ergab ein mittleres Initialvolumen von $0,53 \mathrm{~cm}^{3}\left(+/-0,62 \mathrm{~cm}^{3}\right)$.

Alle 7 Tiere boten am dritten bzw. vierten Tag eine Steigerung des Ödemvolumens mit Werten zwischen 2,86 $\mathrm{cm}^{3}$ und $24.36 \mathrm{~cm}^{3}$. Es ergab sich ein Durchschnittswert von 17,37 $\mathrm{cm}^{3}\left(+/-8,2 \mathrm{~cm}^{3}\right)$. Dies entspricht einer Zunahme des Ödemvolumens von $16,84 \mathrm{~cm}^{3}$ oder um $3277 \%$ bezogen auf das direkt postoperativ gemessene Ödemvolumen.

Bei der MRT-Kontrolle an Tag 10 konnte noch einmal eine deutliche Zunahme des Ödemvolumens bei allen 7 Tieren beobachtet werden. Es fand sich ein mittleres Ödemvolumen von $31,47 \mathrm{~cm}^{3}\left(+/-16,02 \mathrm{~cm}^{3}\right)$, wobei eine relativ große Streubreite der Werte zu verzeichnen ist. Tier 13 hat das kleinste Ödem mit 10,38 $\mathrm{cm}^{3}$, Tier 4 das Größte mit 48,69 $\mathrm{cm}^{3}$. Der Zuwachs im Vergleich zu den Messwerten an Tag 3 beträgt $181 \%$, bezogen auf den gesamten Beobachtungszeitraum lässt sich eine Zunahme des Volumens von 30,94 $\mathrm{cm}^{3} \mathrm{bzw}$. $5937 \%$ des Ausgangswertes bestimmen.

\subsection{T2-Relaxationszeit (T2rt) und ADC der rt-PA-Gruppe}

In der rt-PA-Gruppe zeigten sich direkt postoperativ gemessene T2rt-Werte von 115 bis 136,2 ms, Mittelwert 123,5 ms, und ADC-Werte von $72-79 \times 10^{-6} \mathrm{~mm}^{2} / \mathrm{s}$, Mittelwert 73,02 x $10^{-6}$ $\mathrm{mm}^{2} / \mathrm{s}$. In der Messung am vierten postoperativen Tag konnte eine deutliche Zunahme der Werte beobachtet werden. Es wurde eine mittlere T2rt von 258,1 ms und ein mittlerer ADC von $142 \times 10^{-6} \mathrm{~mm}^{2} / \mathrm{s}$ festgestellt. Zum Sektionstag hin nahmen die Werte wieder leicht ab. Es ergaben sich mittlere Werte von $209 \mathrm{~ms}$ für die T2rt und $126 \times 10^{-6} \mathrm{~mm}^{2} / \mathrm{s}$. für den ADC.

\subsection{Blutungsverlauf der rt-PA-PAI-Gruppe}

Den 6 Tieren der rt-PA-PAI-Gruppe wurden wiederum $7 \mathrm{ml}$ Eigenblut injiziert. Es wurden intrazerebrale Blutungen mit Volumina zwischen $0,74 \mathrm{~cm}^{3}$ und 7,472 $\mathrm{cm}^{3}$ gemessen. Dies ergab eine mittlere Blutungsgröße von $3,5 \mathrm{~cm}^{3}\left(+/-2,65 \mathrm{~cm}^{3}\right)$.

Die MRT- Kontrolle am dritten bzw. vierten Tag ergab eine Reduktion des Blutungsvolumens bei allen 6 Tieren. Die festgestellten Werte bewegten sich zwischen $0,58 \mathrm{~cm}^{3}$ und 5,24 $\mathrm{cm}^{3}$. 
Das durchschnittliche Blutungsvolumen bei der zweiten MRT- Messung betrug 2,46 $\mathrm{cm}^{3}(+/-$ $1,28 \mathrm{~cm}^{3}$ ). Entsprechend einer Reduktion von 1,04 $\mathrm{cm}^{3}$, oder um 29,7 \% bezogen auf die postoperativ ermittelten Volumina.

Die dritte MRT-Kontrolle an Tag 10 zeigte Volumina zwischen 0,48 $\mathrm{cm}^{3}$ und 4,94 $\mathrm{cm}^{3}$. Die durchschnittliche Blutungsgröße betrug $2,12 \mathrm{~cm}^{3}\left(+/-0,98 \mathrm{~cm}^{3}\right)$.

Für den gesamten Beobachtungszeitraum ergab sich so eine durchschnittliche Reduktion des Blutungsvolumens von $1,38 \mathrm{~cm}^{3}$. Dies entspricht einer Volumenreduktion auf $60,5 \%$ des Ausgangswertes. Unter der Therapie mit rt-PA und PAI-1 konnte bei den von uns untersuchten Schweinen demnach eine Reduktion des Blutungsvolumens um 39,5 \% erzielt werden.

\section{8 Ödemverlauf der rt-PA-PAI-Gruppe}

Das initiale Ödem der rt-PA-PAI-Gruppe variierte zwischen noch nicht nachweisbar bis zu $9.69 \mathrm{~cm}^{3}$. Das mittlere Ödemvolumen betrug 2,46 $\mathrm{cm}^{3}\left(+/-3,72 \mathrm{~cm}^{3}\right)$.

Alle 6 Tiere boten bei der zweiten MRT-Messung vergrößerte Ödemvolumina dar. Die Extremwerte variierten zwischen $9,45 \mathrm{~cm}^{3}$ und 43,44 $\mathrm{cm}^{3}$. Die Durchschnittsgröße betrug $24,62 \mathrm{~cm}^{3}\left(+/-11,21 \mathrm{~cm}^{3}\right)$. Das Volumen vergrößerte sich also um 22,16 cm³ oder um $1000 \%$. Die Messung der Volumina am Sektionstag ergab Extremwerte zwischen 4,5 $\mathrm{cm}^{3}$ und 35,72 $\mathrm{cm}^{3}$. Entsprechend einem Mittel von 11,94 $\mathrm{cm}^{3}\left(+/-11,93 \mathrm{~cm}^{3}\right)$. Über den gesamten Beobachtungszeitraum ergibt sich so eine Zunahme des Ödemvolumens von $9,48 \mathrm{~cm}^{3}$. Prozentual ausgedrückt zeigt sich eine Zunahme auf $485 \%$.

\subsection{T2-Relaxationszeit (T2rt) und ADC der rt-PA-PAI-Gruppe}

Für die T2rt wurde postoperativ ein Mittelwert von 144,8 ms festgestellt, die Werte variierten hier zwischen 134 und 164 ms. Für den ADC ergab sich ein postoperatives Mittel von 74,5 x $10^{-6} \mathrm{~mm}^{2} / \mathrm{s}$, wobei hier die Werte zwischen 72 und $77 \times 10^{-6} \mathrm{~mm}^{2} / \mathrm{s}$ schwankten. Auch in der rt-PA-PAI Gruppe zeigte sich in der zweiten Messung eine deutliche Zunahme sowohl der T2rt als auch des ADC. Mittelwerte von 283,4 ms (T2rt) und 144, $08 \times 10^{-6} \mathrm{~mm}^{2} / \mathrm{s}$ (ADC) stellen dies eindrucksvoll dar. Am Sektionstag zeigte sich eine drastische Abnahme der Werte. Die mittlere T2rt lag bei $168,1 \mathrm{~ms}$ und der mittlere ADC bei $109 \times 10^{-6} \mathrm{~mm}^{2} / \mathrm{s}$. 


\subsection{Vergleich Kontrollgruppe vs. rt-PA-Gruppe vs. rt-PA-PAI-Gruppe}

Die Daten der drei Gruppen wurden mittels eines zweiseitigen, ungepaartem Student's-T Test analysiert. Unterschiede der Gruppen wurden bei Werten von $\mathrm{P}<0,05$ als signifikant angenommen.

\subsubsection{Hämatomvolumen}

Vergleicht man die drei Gruppen im Hinblick auf das Hämatomvolumen direkt miteinander, so ist besonders der Zeitraum zwischen Operation und zweiter postoperativer Messung von Bedeutung. Die rt-PA-Gruppe zeigt hier einen deutlichen Abfall des Blutungsvolumens. Von den direkt postoperativ gemessenen Blutvolumina (durchschnittliches Volumen $3,7 \mathrm{~cm}^{3}$ ) verkleinerte sich das Volumen im Mittel um 1,28 $\mathrm{cm}^{3}$ auf 2,42 $\mathrm{cm}^{3}$. Dies entspricht einer Volumenreduktion um 34,6\% innerhalb der ersten vier postoperativen Tage. Die Kontrollgruppe konnte in diesem Zeitraum nur eine Volumenreduktion um 21,7 \% verzeichnen, von $3,84 \mathrm{~cm}^{3}$ auf $3.0 \mathrm{~cm}^{3}$. Die rt-PA-PAI-Gruppe zeigte eine Reduktion des Initialhämatoms um 29,7 \% innerhalb der ersten 3 / 4 Tage postoperativ, entsprechend einer Abnahme der Volumina von $3,5 \mathrm{~cm}^{3}$ auf $2,96 \mathrm{~cm}^{3}$. Im weiteren Verlauf setzt sich diese Tendenz in der Abnahme des Hämatoms in allen drei Gruppen fort. Die größte Volumenreduktion im Zeitraum von Tag 3 / 4 postoperativ bis zum Sektionstag findet sich erneut in der rt-PA-Gruppe mit 1,06 $\mathrm{cm}^{3}$, in der Kontrollgruppe beträgt die Abnahme 0,38 $\mathrm{cm}^{3}$, in der rt-PA-PAI-Gruppe $0,84 \mathrm{~cm}^{3}$. Betrachtet man den ganzen Beobachtungszeitraum so nahm das Hämatomvolumen in der rt-PA-Gruppe um 63,3 \% ab, in der Kontrollgruppe um 31,8 \% und in der rt-PA-PAI-Gruppe um 39,5 \%. Die Reduktion des Hämatoms in der rt-PAGruppe unterscheidet sich dabei signifikant $(\mathrm{P}=0,034)$ von der Kontrollgruppe. Im Vergleich der Hämatomreduktion in der Kontroll- und rt-PA-PAI-Gruppe wurde kein signifikanter Unterschied $(\mathrm{P}=0,56)$ festgestellt. 


\subsubsection{Grafik Hämatomvolumen}

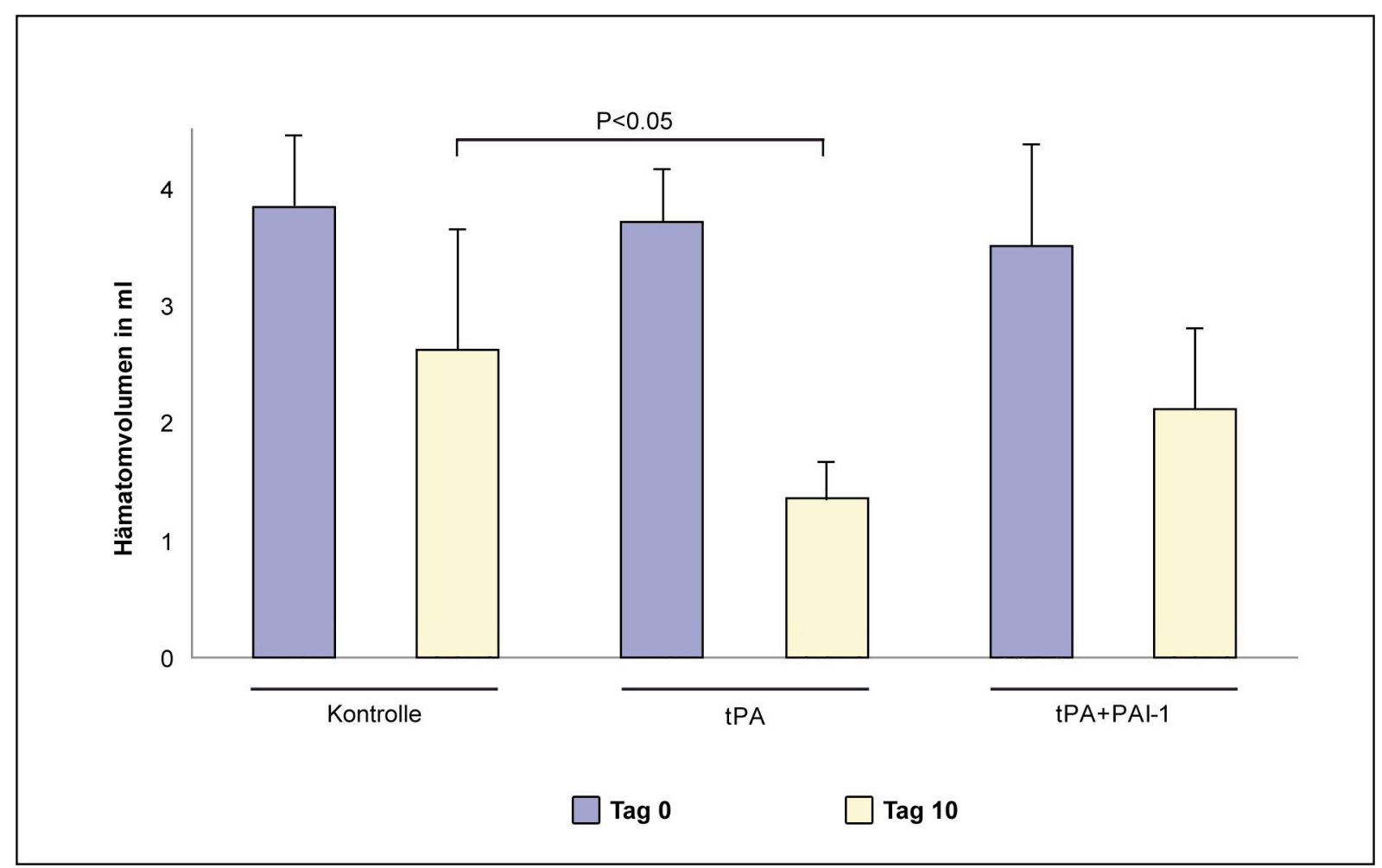

Abb.4: Die Grafik zeigt die Durchschnittsvolumina des Hämatoms der unterschiedlichen Versuchsgruppen an Tag 0 und Tag 10. Gemessen wurde direkt postoperativ (Tag 0), an Tag 4 und am Sektionstag (Tag 10). 


\subsection{3 Ödemvolumen}

Sowohl in der Kontroll- als auch in der rt-PA-PAI-Gruppe ließ sich ein Trend in der Ödementwicklung erkennen. Das Ödemvolumen vergrößerte sich im Zeitraum zwischen Messung 1 und 2 stark, bei Messung 3 (am Sektionstag) hatte das Ödem in beiden Gruppen wieder an Volumen verloren. In Zahlen ausgedrückt vergrößerte sich das Ödemvolumen innerhalb der ersten vier postoperativen Tage von anfänglich $0,91 \mathrm{~cm}^{3}$ in der Kontrollgruppe und 2,46 $\mathrm{cm}^{3}$ in der rt-PA-PAI-Gruppe auf $14,82 \mathrm{~cm}^{3}$ in der Kontrollgruppe beziehungsweise $24,62 \mathrm{~cm}^{3}$ in der rt-PA-PAI-Gruppe. Am Sektionstag fielen die Volumina auf Werte von 12,9 $\mathrm{cm}^{3}$ in der Kontrollgruppe und $11,94 \mathrm{~cm}^{3}$ in der rt-PA-PAI-Gruppe ab. Die mit rt-PA behandelten Tiere zeigten einen anderen Verlauf der Ödementwicklung. Auch hier zeigte sich eine stark ausgeprägte, Zunahme des Ödemvolumens bis zur zweiten postoperativen Messung. Von initial $0,53 \mathrm{~cm}^{3}$ vergrößerte sich das Ödemvolumen auf $17,37 \mathrm{~cm}^{3}$. Eine Volumenreduktion im weiteren Verlauf wie in den zwei anderen Versuchsgruppen blieb jedoch aus. Stattdessen nahm das Ödem weiter an Volumen zu, 14,1 $\mathrm{cm}^{3}$ zwischen zweiter und dritter Messung und 30,94 $\mathrm{cm}^{3}$ bezogen auf den gesamten Beobachtungszeitraum. Die Ödemzunahme ist im Vergleich zwischen Kontrollgruppe und rt-PA-Gruppe signifikant (P = 0,05) größer in der rt-PA-Gruppe. Im Vergleich zwischen rt-PA- und rt-PA-PAI-Gruppe konnte ein signifikant $(\mathrm{P}=0,03)$ kleineres Ödem in der rt-PA-PAI-Gruppe festgestellt werden. 


\subsubsection{Grafik Ödemvolumen}

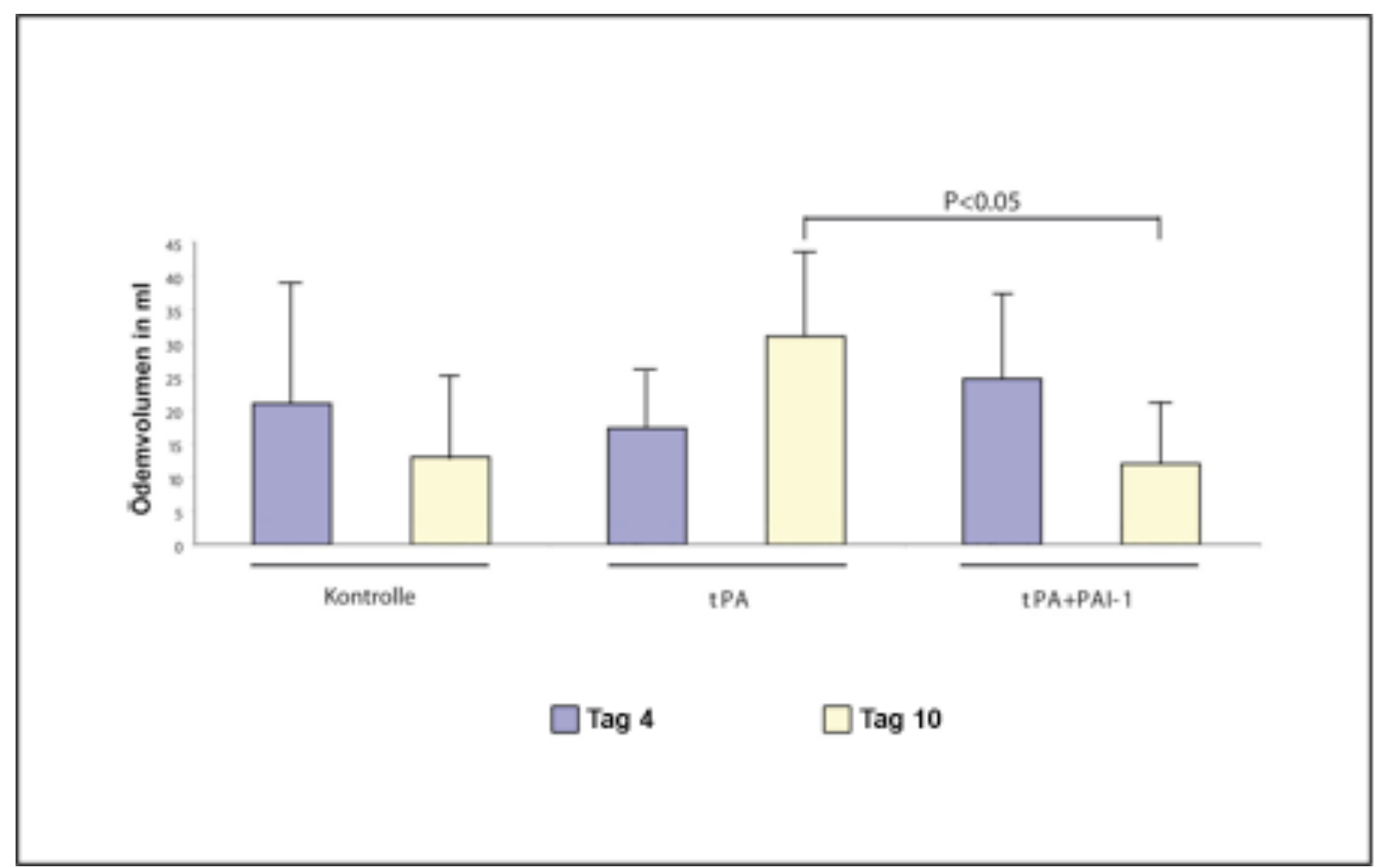

Abb.5: Dargestellt ist das durchschnittliche Ödemvolumen der 3 Versuchsgruppen. Messzeitpunkte waren wiederum Tag 0, Tag 4 und Tag 10 postoperativ, wobei sich in dieser Grafik die Darstellung auf Tag 4 und Tag 10 begrenzt. 


\subsubsection{T2-Relaxationszeit und ADC}

Bei Betrachtung der T2rt-Entwicklung innerhalb der verschiedenen Versuchsgruppen fällt auf, dass sowohl in der rt-PA-Gruppe als auch in der rt-PA-PAI-Gruppe eine massive Zunahme der T2rt innerhalb der ersten vier postoperativen Tage zu verzeichnen ist. So vergrößert sich der Mittelwert der rt-PA-Gruppe von initial 123,5 ms auf 258,1 ms, d.h. also um $210 \%$. Auch in der rt-PA-PAI-Gruppe ist eine drastische Zunahme von $195 \%$ bemerkbar. Die Mittelwerte steigen hier von 145,6 ms auf 283,4 ms. Auch in der Kontrollgruppe ist eine Zunahme der T2rt bis zum zweiten Messtermin sichtbar. Diese ist jedoch weit weniger ausgeprägt. Die Zunahme beträgt hier knapp $21 \%$, von 121,7 ms auf 146,98 ms. Im weiteren Verlauf nimmt in allen 3 Gruppen die T2rt wieder ab, sie erreicht jedoch lediglich in der Kontrollgruppe annähernd ihren Ausgangswert wieder. Auffallend ist dass die Abnahme der T2rt in der rt-PA-PAI-Gruppe größer ist als in den anderen beiden Gruppen, die relativ parallele Verläufe vorweisen. Die rt-PA-PAI-Gruppe weist eine Abnahme der T2rt von 283,4 ms auf 168,1 ms, sprich $41 \%$ auf. Innerhalb der rt-PA-Gruppe beträgt die Abnahme lediglich $21 \%$, in der Kontrollgruppe $17 \%$.

Der Verlauf des ADC folgt einem ähnlichen Muster. Auch hier zeigen die rt-PA-PAI-Tiere und rt-PA-Tiere eine drastische Zunahme des ADC im Zeitraum zwischen erster und zweiter postoperativer Untersuchung. Ausgehend von einem Mittelwert von $73 \times 10^{-6} \mathrm{~mm}^{2} / \mathrm{s}$ steigt der Wert in der rt-PA-Gruppe auf $142 \times 10^{-6} \mathrm{~mm}^{2} / \mathrm{s}(+95,5 \%)$ an. In der rt-PA-PAI-Gruppe ist ein Anstieg von $74,5 \times 10^{-6} \mathrm{~mm}^{2} / \mathrm{s}$ auf $144,08 \times 10^{-6} \mathrm{~mm}^{2} / \mathrm{s}$ bemerkbar. Dies entspricht einem Zuwachs von 93,3 \%. Der Zuwachs der Kontrollgruppe verläuft verhältnismäßig moderat, von $73,3 \times 10^{-6} \mathrm{~mm}^{2} / \mathrm{s}$ auf $86,7 \times 10^{-6} \mathrm{~mm}^{2} / \mathrm{s}(+18,2 \%)$. Bis zum Sektionstag zeigt nun auch der ADC einen abnehmenden Verlauf, wobei analog zur T2rt-Entwicklung die rt-PA-PAIGruppe die steilste Abnahme verzeichnet. Sie beträgt $25 \%$, von $144,08 \times 10^{-6} \mathrm{~mm}^{2} / \mathrm{s}$ auf 109 x $10^{-6} \mathrm{~mm}^{2} / \mathrm{s}$. In der rt-PA-Gruppe beträgt die Reduktion $12 \%$, von $142 \times 10^{-6} \mathrm{~mm}^{2} / \mathrm{s}$ auf 126 x $10^{-6} \mathrm{~mm}^{2} / \mathrm{s}$. Die geringste Abnahme verzeichnet die Kontrollgruppe mit 5,7 \%, von 86,7 x $10^{-6} \mathrm{~mm}^{2} / \mathrm{s}$ auf $81,8 \times 10^{-6} \mathrm{~mm}^{2} / \mathrm{s}$. 


\subsubsection{Grafik T2rt}

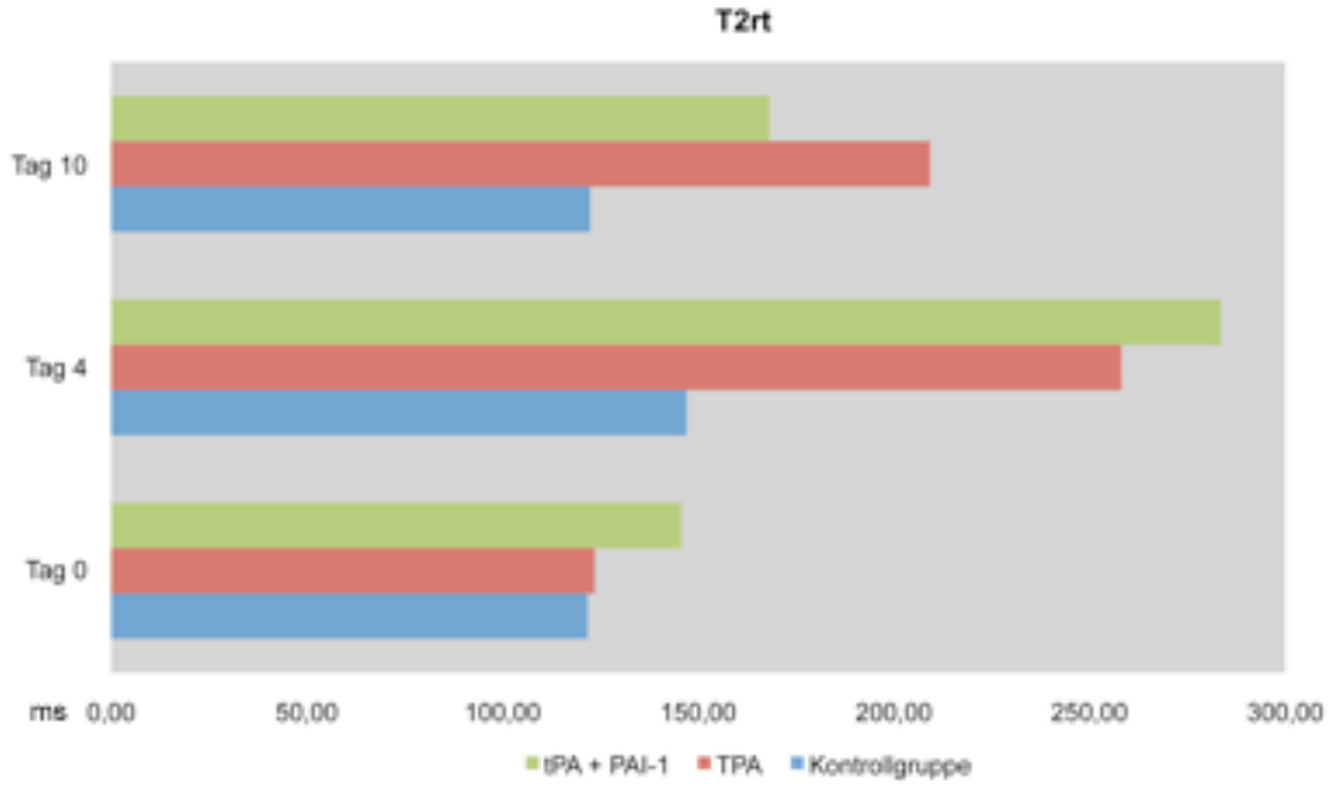

Abb.6: Die Grafik zeigt die Werte der T2-Relaxationszeit (in ms) innerhalb der 3 Versuchsgruppen über den Beobachtungszeitraum. 


\subsubsection{Grafik ADC}

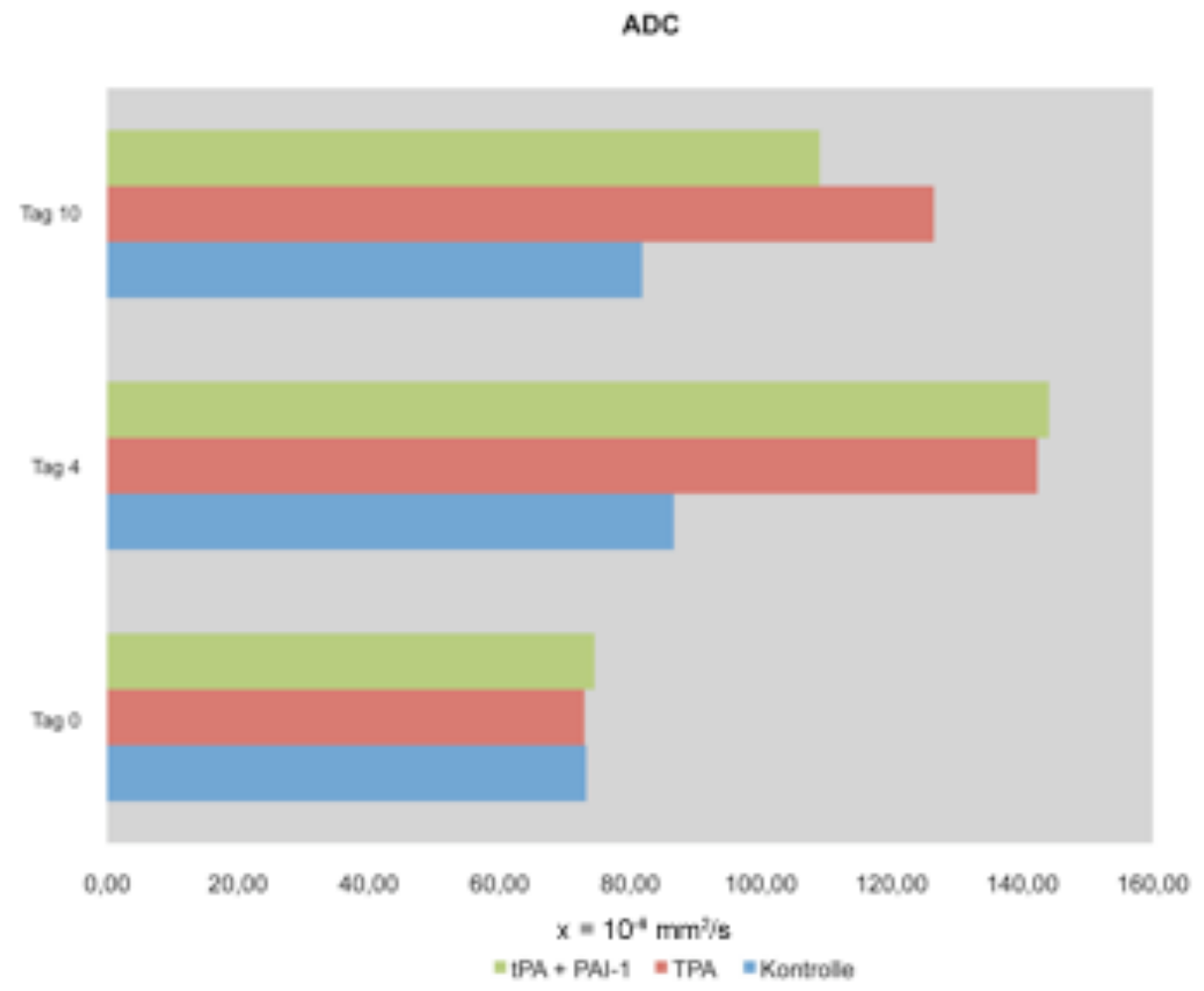

Abb. 7: Dargestellt sind die Werte des ADC (Masseinheit $\times 10^{-6} \mathrm{~mm}^{2} / \mathrm{s}$ ) im Beobachtungszeitraum. 


\subsection{Datentabelle der Kontrollgruppe}

\begin{tabular}{|c|c|c|c|c|}
\hline \multicolumn{2}{|c|}{$\begin{array}{c}\text { Tiernummer und Menge } \\
\text { der intrazerebralen } \\
\text { Blutinjektion }\end{array}$} & $\begin{array}{c}\text { 1. Kontrolle } \\
\text { (post-OP) }\end{array}$ & $\begin{array}{c}\text { 2. Kontrolle } \\
\text { (4. post-OP } \\
\text { Tag) }\end{array}$ & $\begin{array}{c}\text { 3.Kontrolle } \\
\text { (10.post-Op } \\
\text { Tag) }\end{array}$ \\
\hline \multirow{2}{*}{$\begin{array}{c}\text { Tier 2 } \\
7 \mathrm{ml}\end{array}$} & Hämatom & $1,83 \mathrm{~cm}^{3}$ & $1,686 \mathrm{~cm}^{3}$ & $1,632 \mathrm{~cm}^{3}$ \\
\cline { 2 - 5 } & Ödem & $1,31 \mathrm{~cm}^{3}$ & $7,776 \mathrm{~cm}^{3}$ & $2,508 \mathrm{~cm}^{3}$ \\
\hline \multirow{2}{*}{ Tier 3 } & Hämatom & $2,192 \mathrm{~cm}^{3}$ & $1,904 \mathrm{~cm}^{3}$ & $1,684 \mathrm{~cm}^{3}$ \\
\cline { 2 - 5 } $7 \mathrm{ml}$ & Ödem & $1,56 \mathrm{~cm}^{3}$ & $9,78 \mathrm{~cm}^{3}$ & $4,32 \mathrm{~cm}^{3}$ \\
\hline \multirow{2}{*}{$\begin{array}{c}\text { Tier 6 } \\
8 \mathrm{ml}\end{array}$} & Hämatom & $2,52 \mathrm{~cm}^{3}$ & $1,44 \mathrm{~cm}^{3}$ & $\mathrm{n} \cdot \mathrm{V}$. \\
\cline { 2 - 5 } Tier 10 & Ödem & $6,24 \mathrm{~cm}^{3}$ & $32,4 \mathrm{~cm}^{3}$ & $\mathrm{n} \cdot \mathrm{V}$. \\
\cline { 2 - 5 } $6 \mathrm{ml}$ & Hämatom & $1,644 \mathrm{~cm}^{3}$ & $1,42 \mathrm{~cm}^{3}$ & $1,44 \mathrm{~cm}^{3}$ \\
\hline \multirow{2}{*}{ Tier 11 } & Ödem & $0 \mathrm{~cm}^{3}$ & $7,968 \mathrm{~cm}^{3}$ & $12,384 \mathrm{~cm}^{3}$ \\
\cline { 2 - 5 } $7 \mathrm{ml}$ & Hämatom & $6,416 \mathrm{~cm}^{3}$ & $5,328 \mathrm{~cm}^{3}$ & $4,24 \mathrm{~cm}^{3}$ \\
\hline \multirow{2}{*}{ Tier 20 } & Ödem & $0,83 \mathrm{~cm}^{3}$ & $29,584 \mathrm{~cm}^{3}$ & $30,576 \mathrm{~cm}^{3}$ \\
\hline $7 \mathrm{ml}$ & Hämatom & $7,14 \mathrm{~cm}^{3}$ & $4,736 \mathrm{~cm}^{3}$ & $4,148 \mathrm{~cm}^{3}$ \\
\cline { 2 - 5 } & Ödem & $0,87 \mathrm{~cm}^{3}$ & $19,128 \mathrm{~cm}^{3}$ & $14,74 \mathrm{~cm}^{3}$ \\
\hline
\end{tabular}

Tabelle 2: Hämatom- und Ödemvolumina der Kontrollgruppe an den jeweiligen Kontrolltagen 


\subsection{Datentabelle der rt-PA-Gruppe}

\begin{tabular}{|c|c|c|c|c|}
\hline \multicolumn{2}{|c|}{$\begin{array}{c}\text { Tiernummer und Menge } \\
\text { der intrazerebralen } \\
\text { Blutinjektion }\end{array}$} & \multirow{2}{*}{$\begin{array}{c}\begin{array}{c}\text { 1. Kontrolle } \\
\text { (post-OP) }\end{array} \\
6,72 \mathrm{~cm}^{3} \\
\end{array}$} & \multirow{2}{*}{$\begin{array}{c}\text { 2. Kontrolle } \\
\begin{array}{c}\text { (4. post-OP } \\
\text { Tag) }\end{array} \\
3,776 \mathrm{~cm}^{3} \\
\end{array}$} & \multirow{2}{*}{$\begin{array}{c}\begin{array}{c}\text { 3.Kontrolle } \\
\text { (10.post-Op } \\
\text { Tag) }\end{array} \\
2,16 \mathrm{~cm}^{3}\end{array}$} \\
\hline Tier 4 & Hämatom & & & \\
\hline $7 \mathrm{ml}$ & Ödem & $0 \mathrm{~cm}^{3}$ & $24,36 \mathrm{~cm}^{3}$ & $48,692 \mathrm{~cm}^{3}$ \\
\hline \multirow{2}{*}{$\begin{array}{c}\text { Tier } 5 \\
7 \mathrm{ml}\end{array}$} & Hämatom & $5,344 \mathrm{~cm}^{3}$ & $4,416 \mathrm{~cm}^{3}$ & $2,150 \mathrm{~cm}^{3}$ \\
\hline & Ödem & $0 \mathrm{~cm}^{3}$ & $21,92 \mathrm{~cm}^{3}$ & $48,03 \mathrm{~cm}^{3}$ \\
\hline \multirow{2}{*}{$\begin{array}{c}\text { Tier } 7 \\
5 \mathrm{ml}\end{array}$} & Hämatom & $0,812 \mathrm{~cm}^{3}$ & $0,416 \mathrm{~cm}^{3}$ & $0,408 \mathrm{~cm}^{3}$ \\
\hline & Ödem & $0,52 \mathrm{~cm}^{3}$ & $23,536 \mathrm{~cm}^{3}$ & $42 \mathrm{~cm}^{3}$ \\
\hline \multirow{2}{*}{$\begin{array}{c}\text { Tier } 12 \\
7 \mathrm{ml}\end{array}$} & Hämatom & $1,08 \mathrm{~cm}^{3}$ & $0,424 \mathrm{~cm}^{3}$ & $0,416 \mathrm{~cm}^{3}$ \\
\hline & Ödem & $0 \mathrm{~cm}^{3}$ & $23,192 \mathrm{~cm}^{3}$ & $36,192 \mathrm{~cm}^{3}$ \\
\hline \multirow{2}{*}{$\begin{array}{c}\text { Tier } 13 \\
7 \mathrm{ml}\end{array}$} & Hämatom & $2,448 \mathrm{~cm}^{3}$ & $1,908 \mathrm{~cm}^{3}$ & $0,76 \mathrm{~cm}^{3}$ \\
\hline & Ödem & $0,792 \mathrm{~cm}^{3}$ & $2,868 \mathrm{~cm}^{3}$ & $10,384 \mathrm{~cm}^{3}$ \\
\hline \multirow{2}{*}{$\begin{array}{c}\text { Tier } 14 \\
8 \mathrm{ml}\end{array}$} & Hämatom & $6,96 \mathrm{~cm}^{3}$ & $5,323 \mathrm{~cm}^{3}$ & $3,048 \mathrm{~cm}^{3}$ \\
\hline & Ödem & $0,688 \mathrm{~cm}^{3}$ & $10,528 \mathrm{~cm}^{3}$ & $16,78 \mathrm{~cm}^{3}$ \\
\hline \multirow{2}{*}{$\begin{array}{c}\text { Tier } 18 \\
7 \mathrm{ml}\end{array}$} & Hämatom & $5,84 \mathrm{~cm}^{3}$ & $0,78 \mathrm{~cm}^{3}$ & $0,576 \mathrm{~cm}^{3}$ \\
\hline & Ödem & $1,736 \mathrm{~cm}^{3}$ & $15,216 \mathrm{~cm}^{3}$ & $18,216 \mathrm{~cm}^{3}$ \\
\hline
\end{tabular}

Tabelle 3: Hämatom- und Ödemvolumina der rt-PA-Gruppe zu den jeweiligen Kontrolltagen 


\subsection{Datentabelle der rt-PA-PAI-Gruppe}

\begin{tabular}{|c|c|c|c|c|}
\hline \multicolumn{2}{|c|}{$\begin{array}{c}\text { Tiernummer und Menge } \\
\text { der intrazerebralen } \\
\text { Blutinjektion }\end{array}$} & $\begin{array}{c}\text { 1. Kontrolle } \\
\text { (post-OP) }\end{array}$ & $\begin{array}{c}\text { 2. Kontrolle } \\
\text { (4. post-OP } \\
\text { Tag) }\end{array}$ & $\begin{array}{c}\text { 3.Kontrolle } \\
(\mathbf{1 0 . p o s t - O p} \\
\text { Tag) }\end{array}$ \\
\hline \multirow{2}{*}{$\begin{array}{c}\text { Tier 9 } \\
7 \mathrm{ml}\end{array}$} & Hämatom & $2,512 \mathrm{~cm}^{3}$ & $1,392 \mathrm{~cm}^{3}$ & $1,248 \mathrm{~cm}^{3}$ \\
\cline { 2 - 5 } & Ödem & $0 \mathrm{~cm}^{3}$ & $43,44 \mathrm{~cm}^{3}$ & $35,728 \mathrm{~cm}^{3}$ \\
\hline \multirow{2}{*}{$\begin{array}{c}\text { Tier 11a } \\
7 \mathrm{ml}\end{array}$} & Hämatom & $2,096 \mathrm{~cm}^{3}$ & $1,192 \mathrm{~cm}^{3}$ & $1.084 \mathrm{~cm}^{3}$ \\
\cline { 2 - 5 } & Ödem & $0 \mathrm{~cm}^{3}$ & $23,016 \mathrm{~cm}^{3}$ & $4,932 \mathrm{~cm}^{3}$ \\
\hline \multirow{2}{*}{$\begin{array}{c}\text { Tier 15 } \\
8 \mathrm{ml}\end{array}$} & Hämatom & $0,74 \mathrm{~cm}^{3}$ & $0,584 \mathrm{~cm}^{3}$ & $0,484 \mathrm{~cm}^{3}$ \\
\cline { 2 - 5 } & Ödem & $0,268 \mathrm{~cm}^{3}$ & $21,5 \mathrm{~cm}^{3}$ & $6,944 \mathrm{~cm}^{3}$ \\
\hline \multirow{2}{*}{ Tier 16 } & Hämatom & $3,264 \mathrm{~cm}^{3}$ & $2,448 \mathrm{~cm}^{3}$ & $1,72 \mathrm{~cm}^{3}$ \\
\cline { 2 - 5 } $6 \mathrm{ml}$ & Ödem & $2,216 \mathrm{~cm}^{3}$ & $9,456 \mathrm{~cm}^{3}$ & $7,888 \mathrm{~cm}^{3}$ \\
\hline \multirow{2}{*}{$\begin{array}{c}\text { Tier 17 } \\
7 \mathrm{ml}\end{array}$} & Hämatom & $7,472 \mathrm{~cm}^{3}$ & $5,248 \mathrm{~cm}^{3}$ & $4,944 \mathrm{~cm}^{3}$ \\
\cline { 2 - 5 } & Ödem & $9,696 \mathrm{~cm}^{3}$ & $21,164 \mathrm{~cm}^{3}$ & $4,5 \mathrm{~cm}^{3}$ \\
\hline \multirow{2}{*}{ Tier 21 } & Hämatom & $4,944 \mathrm{~cm}^{3}$ & $3,872 \mathrm{~cm}^{3}$ & $3,192 \mathrm{~cm}^{3}$ \\
\cline { 2 - 5 } $7 \mathrm{ml}$ & Ödem & $2,58 \mathrm{~cm}^{3}$ & $29,184 \mathrm{~cm}^{3}$ & $11,64 \mathrm{~cm}^{3}$ \\
\hline
\end{tabular}

Tabelle 4: Hämatom- und Ödemvolumina der rt-PA-PAI-Gruppe an den jeweiligen Kontrolltagen 
3.14 Datentabelle zur T2rt- und ADC-Messung der Kontrollgruppe

\begin{tabular}{|c|c|c|c|c|}
\hline \multicolumn{2}{|c|}{$\begin{array}{c}\text { Tiernummer und Menge } \\
\text { der intrazerebralen } \\
\text { Blutinjektion }\end{array}$} & \multirow{2}{*}{$\begin{array}{c}\begin{array}{c}\text { 1. Kontrolle } \\
\text { (post-OP) }\end{array} \\
137 \\
\end{array}$} & \multirow{2}{*}{$\begin{array}{c}\begin{array}{c}\text { 2. Kontrolle } \\
\text { (4. post-OP } \\
\text { Tag) }\end{array} \\
145 \\
\end{array}$} & \multirow{2}{*}{$\begin{array}{c}\begin{array}{c}\text { 3.Kontrolle } \\
\text { (10.post-Op } \\
\text { Tag) }\end{array} \\
120 \\
\end{array}$} \\
\hline Tier 2 & $\mathrm{~T} 2 \mathrm{rt}$ & & & \\
\hline $7 \mathrm{ml}$ & $\mathrm{ADC}$ & 74 & 86 & 81,2 \\
\hline \multirow{2}{*}{$\begin{array}{c}\text { Tier } 3 \\
7 \mathrm{ml}\end{array}$} & $\mathrm{T} 2 \mathrm{rt}$ & 112 & 133,2 & 142 \\
\hline & $\mathrm{ADC}$ & 73 & 86 & 89,6 \\
\hline \multirow{2}{*}{$\begin{array}{c}\text { Tier } 6 \\
8 \mathrm{ml}\end{array}$} & $\mathrm{T} 2 \mathrm{rt}$ & 119 & 153 & n.V \\
\hline & $\mathrm{ADC}$ & 72 & 92 & n.V. \\
\hline \multirow{2}{*}{$\begin{array}{c}\text { Tier } 10 \\
6 \mathrm{ml}\end{array}$} & $\mathrm{T} 2 \mathrm{rt}$ & 120 & 152 & 123 \\
\hline & $\mathrm{ADC}$ & 73 & 85,9 & 79,8 \\
\hline \multirow{2}{*}{$\begin{array}{c}\text { Tier } 11 \\
7 \mathrm{ml}\end{array}$} & $\mathrm{T} 2 \mathrm{rt}$ & 121,5 & 143,7 & 110,9 \\
\hline & $\mathrm{ADC}$ & 76 & 86,5 & 79,8 \\
\hline \multirow{2}{*}{$\begin{array}{c}\text { Tier } 20 \\
7 \mathrm{ml}\end{array}$} & $\mathrm{T} 2 \mathrm{rt}$ & 117 & 155 & 111 \\
\hline & $\mathrm{ADC}$ & 72 & 84,3 & 78,9 \\
\hline
\end{tabular}

Tabelle 5: T2rt und ADC der Kontrolgruppe an den jeweiligen Kontrolltagen 


\subsection{Datentabelle zur T2rt- und ADC-Messung der rt-PA-Gruppe}

\begin{tabular}{|c|c|c|c|c|}
\hline \multicolumn{2}{|c|}{$\begin{array}{c}\text { Tiernummer und Menge } \\
\text { der intrazerebralen } \\
\text { Blutinjektion }\end{array}$} & \multirow{2}{*}{$\begin{array}{c}\text { 1. Kontrolle } \\
\text { (post-OP) } \\
\text { n.V. } \\
\end{array}$} & \multirow{2}{*}{$\begin{array}{c}\begin{array}{c}\text { 2. Kontrolle } \\
\text { (4. post-OP } \\
\text { Tag) }\end{array} \\
161\end{array}$} & \multirow{2}{*}{$\begin{array}{c}\begin{array}{c}\text { 3.Kontrolle } \\
\text { (10.post-Op } \\
\text { Tag) }\end{array} \\
192,5\end{array}$} \\
\hline Tier 4 & $\mathrm{~T} 2 \mathrm{rt}$ & & & \\
\hline $7 \mathrm{ml}$ & $\mathrm{ADC}$ & n.V. & 98 & 146 \\
\hline \multirow{2}{*}{$\begin{array}{c}\text { Tier } 5 \\
7 \mathrm{ml}\end{array}$} & $\mathrm{T} 2 \mathrm{rt}$ & 115 & 295,9 & 248,4 \\
\hline & $\mathrm{ADC}$ & 72 & 165 & 138 \\
\hline \multirow{2}{*}{$\begin{array}{c}\text { Tier } 7 \\
5 \mathrm{ml}\end{array}$} & $\mathrm{T} 2 \mathrm{rt}$ & 136,2 & 275,8 & 232,1 \\
\hline & $\mathrm{ADC}$ & 72 & 144 & 108 \\
\hline \multirow{2}{*}{$\begin{array}{c}\text { Tier } 12 \\
7 \mathrm{ml}\end{array}$} & $\mathrm{T} 2 \mathrm{rt}$ & 119 & 247 & 206 \\
\hline & $\mathrm{ADC}$ & 73,2 & 147 & 142 \\
\hline \multirow{2}{*}{$\begin{array}{c}\text { Tier } 13 \\
7 \mathrm{ml}\end{array}$} & $\mathrm{T} 2 \mathrm{rt}$ & 132 & 335 & 200 \\
\hline & $\mathrm{ADC}$ & 74 & 152 & 115 \\
\hline \multirow{2}{*}{$\begin{array}{c}\text { Tier } 14 \\
8 \mathrm{ml}\end{array}$} & $\mathrm{T} 2 \mathrm{rt}$ & 118 & 246 & 186 \\
\hline & $\mathrm{ADC}$ & 76 & 155 & 110 \\
\hline \multirow{2}{*}{$\begin{array}{c}\text { Tier } 18 \\
7 \mathrm{ml}\end{array}$} & $\mathrm{T} 2 \mathrm{rt}$ & 121 & 246 & 199,4 \\
\hline & $\mathrm{ADC}$ & 73 & 133 & 125 \\
\hline
\end{tabular}

Tabelle 6: T2rt und ADC der rt-P-Gruppe an den jeweiligen Kontrolltagen 
3.16 Datentabelle zur T2rt- und ADC-Messung der rt-PA-PAI-Gruppe

\begin{tabular}{|c|c|c|c|c|}
\hline \multicolumn{2}{|c|}{$\begin{array}{c}\text { Tiernummer und Menge } \\
\text { der intrazerebralen } \\
\text { Blutinjektion }\end{array}$} & $\begin{array}{c}\text { 1. Kontrolle } \\
\text { (post-OP) }\end{array}$ & $\begin{array}{c}\text { 2. Kontrolle } \\
\text { (4. post-OP } \\
\text { Tag) }\end{array}$ & $\begin{array}{c}\text { 3.Kontrolle } \\
\text { (10.post-Op } \\
\text { Tag) }\end{array}$ \\
\hline \multirow{2}{*}{ Tier 9 } & T2rt & 136,6 & 243 & 206 \\
\cline { 2 - 5 } $7 \mathrm{ml}$ & ADC & 75 & 144 & 109 \\
\hline \multirow{2}{*}{$\begin{array}{c}\text { Tier 11 } \\
7 \mathrm{ml}\end{array}$} & T2rt & 138 & 323 & 180 \\
\cline { 2 - 5 } Tier 15 & ADC & 72,8 & 138,7 & 116 \\
\cline { 2 - 5 } $8 \mathrm{ml}$ & T2rt & 134 & 277 & 142 \\
\hline \multirow{2}{*}{ Tier 16 } & ADC & 72 & 169 & 109 \\
\cline { 2 - 5 } $6 \mathrm{ml}$ & ADC & 73 & 253 & 169 \\
\hline \multirow{2}{*}{$\begin{array}{c}\text { Tier 17 } \\
7 \mathrm{ml}\end{array}$} & T2rt & 160 & 259 & 186 \\
\cline { 2 - 5 } & ADC & 76 & 135 & 108 \\
\hline \multirow{2}{*}{ Tier 21 } & T2rt & 169 & 346 & 124 \\
\cline { 2 - 5 } $7 \mathrm{ml}$ & ADC & 77 & 156 & 106 \\
\hline
\end{tabular}

Tabelle 7: T2rt und ADC der rt-PA-PA-Gruppe an den jeweiligen Kontrolltagen 


\subsection{Beispiel MRT-Aufnahmen der Ödemverläufe :}

Tier 12 (rt-PA-Gruppe)
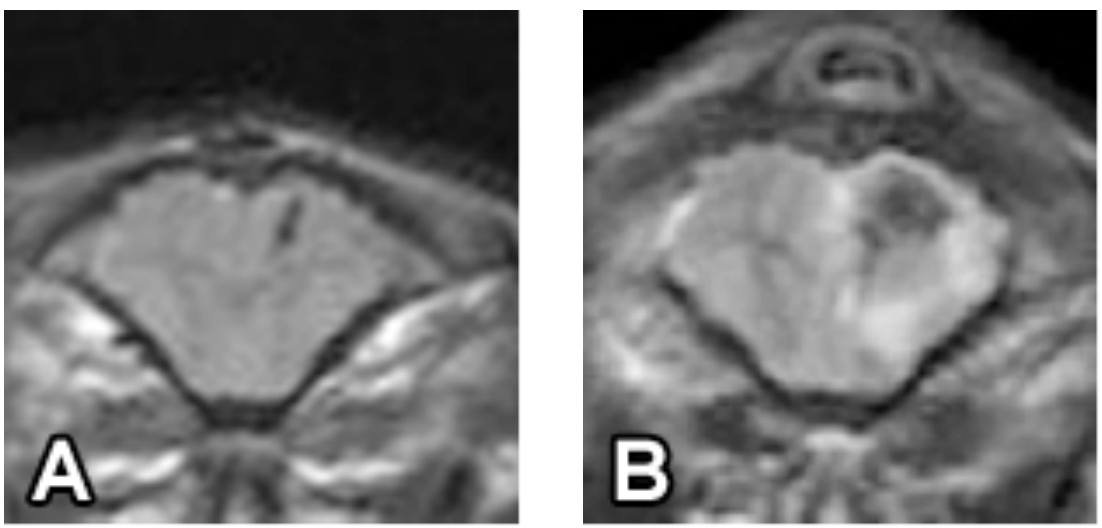

Abb. 8: FLAIR-gewichtete MRT-Aufnahme zur Ödemdarstellung an Tag 0 (A, links) und an Tag 10 (B, rechts). Es zeigt sich eine deutliche Zunahme des Ödems von $0 \mathrm{~cm}^{3}$ an Tag 0 auf $36 \mathrm{~cm}^{3}$ an Tag 10.

Tier 9 (rt-PA-PAI-Gruppe)
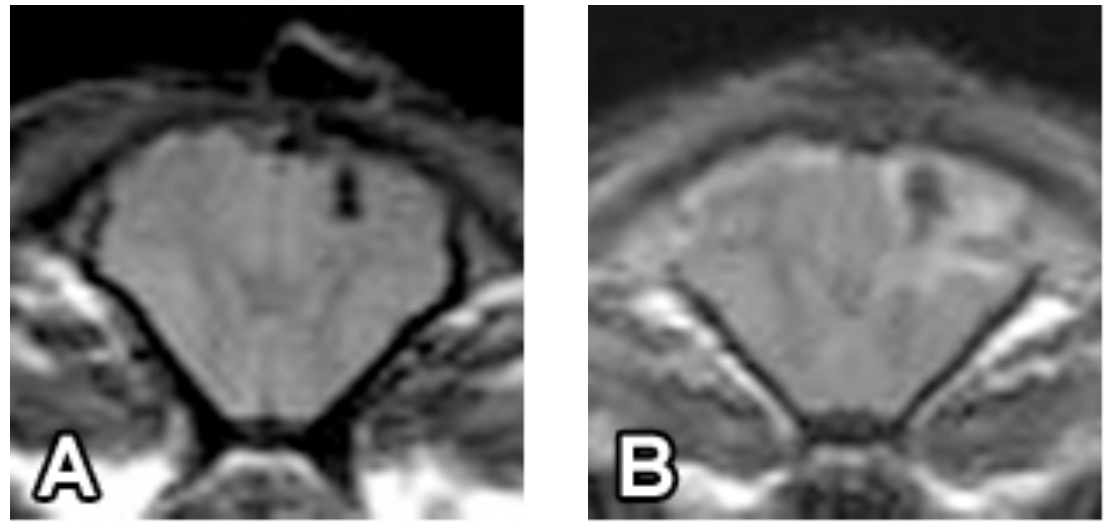

Abb. 9: FLAIR-gewichtete MRT-Aufnahme zur Ödemdarstellung an Tag 0 (A, links) und Tag 10 (B, rechts). Es zeigt sich eine Zunahme des Ödems von $0 \mathrm{~cm}^{3}$ an Tag 0 auf $35 \mathrm{~cm}^{3}$ an Tag 10. 
Tier 11 (Kontrollgruppe)
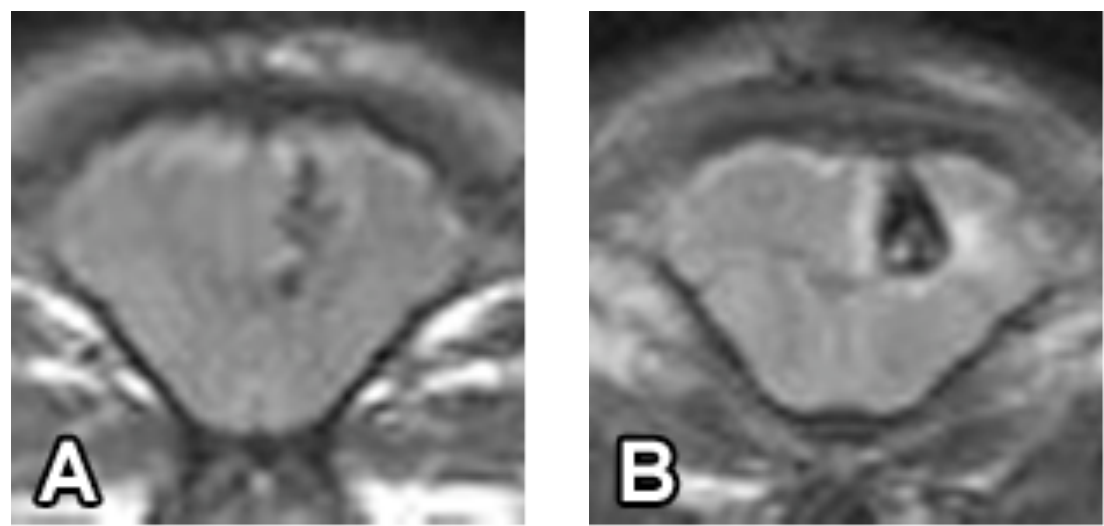

Abb. 10: FLAIR-gewichtete MRT-Aufnahme zur Ödemdarstellung an Tag 0 (A, links) und an Tag 10 (B, rechts). Es zeigt sich eine Zunahme des Ödems von $0,83 \mathrm{~cm}^{3}$ an Tag 0 auf $30 \mathrm{~cm}^{3}$ an Tag 10. 


\subsection{Beispiel MRT-Aufnahmen der Hämatomverläufe:}

Tier 12 (rt-PA-Gruppe)
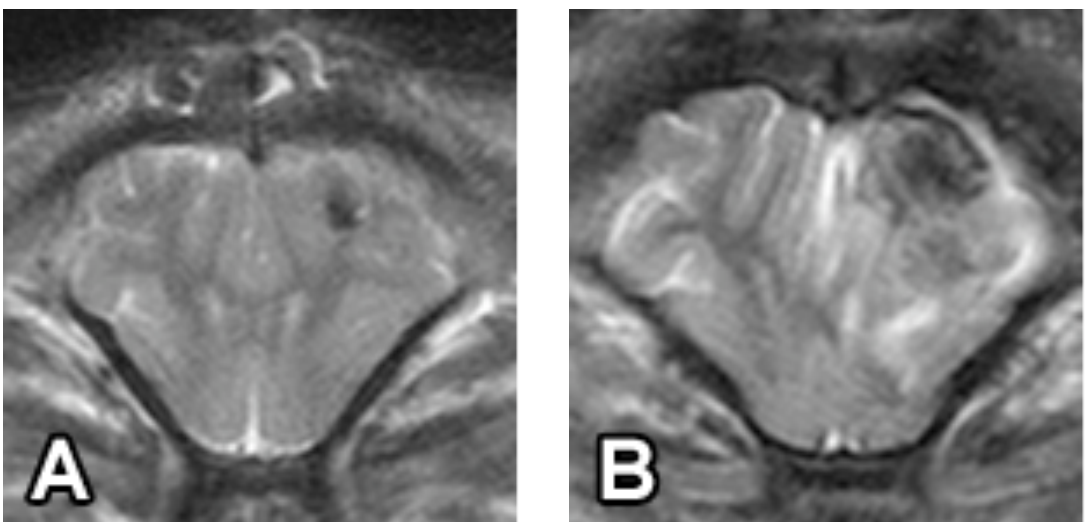

Abb.11: T2-gewichtete MRT-Aufnahme zur Hämatomdarstellung an Tag 0 (A, links) und an Tag 10 (B, rechts). Es zeigt sich eine Abnahme des Hämatoms von $1,08 \mathrm{~cm}^{3}$ an Tag 0 auf $0,416 \mathrm{~cm}^{3}$ an Tag 10.

Tier 17 (rt-PA-PAI-Gruppe)
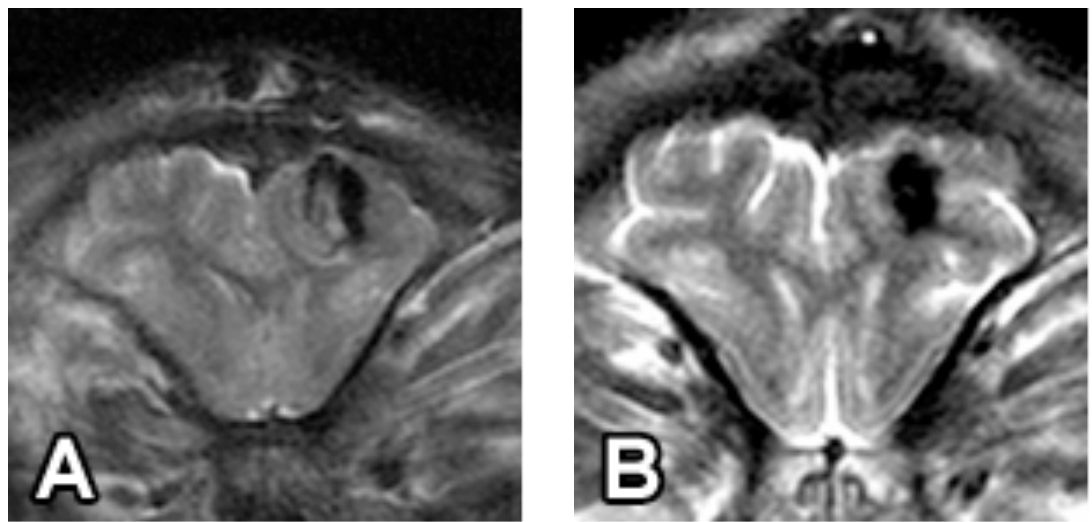

Abb.12: T2-gewichtete MRT-Aufnahme zur Hämatomdarstellung an Tag 0 (A, links) und an Tag 10 (B, rechts). Es zeigt sich eine Abnahme des Hämatoms von 7,472 $\mathrm{cm}^{3}$ an Tag 0 auf 4,944 $\mathrm{cm}^{3}$ an Tag 10. 
Tier 10 (Kontrollgruppe)
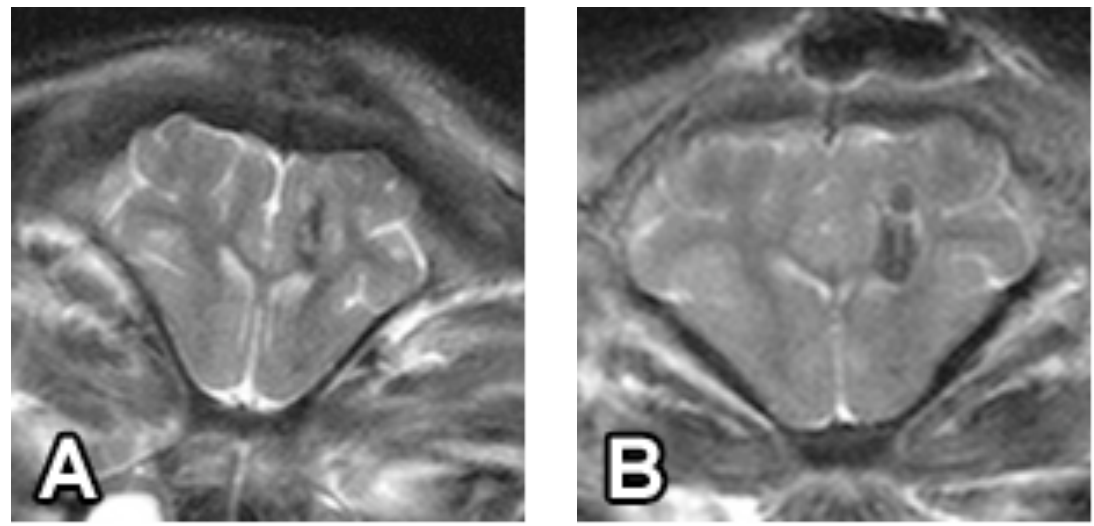

Abb.13: T2-gewichtete MRT-Aufnahme zur Hämatomdarstellung an Tag 0 (A, links) und an Tag 10 (B, rechts). Es zeigt sich eine Abnahme des Hämatoms von 1,644 $\mathrm{cm}^{3}$ an Tag 0 auf 1,44 cm an Tag 10. 


\section{Diskussion}

\subsection{Das Hämatom}

In unserem Versuch zeigte sich bei der Gegenüberstellung der magnetresonanztomografisch gemessenen Hämatomgrößen der verschiedenen Versuchsgruppen:

1. In der rt-PA-Gruppe konnte eine Reduktion des Hämatoms um 63,3\% in Vergleich zum Ausgangswert erzielt werden.

2. In der rt-PA-PAI-Gruppe wurde das Hämatomvolumen um 39,5\% verringert, wobei hier der Hauptteil der Reduktion in den ersten 3 Tagen stattfand.

3. Die Kontrollgruppe konnte eine Reduktion um 31,8 \% vorweisen.

Wie bereits in anderen Studien festgestellt (Rohde et al. 2002), so zeigen auch unsere Daten eine signifikant größere Abnahme des Hämatomvolumens in der rt-PA-Gruppe im Vergleich zur Kontroll- und, als neuer Aspekt, auch zur rt-PA-PAI-Gruppe. Die schnelle Reduktion des Hämatoms gilt als eines der Hauptziele in der Behandlung von intrazerebralen Blutungen, da von verschiedenen Autoren die beim Hämatomabbau entstehenden ödeminduzierenden Substanzen als Ursache der oft zu beobachtenden sekundären Hirnschädigung und damit der progredienten Verschlechterung des neurologischen Status des Patienten mit einer ICB angesehen werden (Wagner et al. 1999). Die Arbeitsgruppe um Nehls zeigte, dass nach frühzeitiger und möglichst vollständiger Entfernung intrazerebraler Raumforderungen (simuliert durch Balloninjektion) der zerebrale Blutfluss signifikant besser und die periläsionale Ischämie signifikant geringer ist als bei Persistenz der Raumforderung (Nehls et al. 1990).

Weitere histologische Studien belegten die Alteration des perihämatomalen Hirngewebes. In Tiermodellen wurden u.a. Ödembildung, Gliose, Nekrose und sekundäre Blutungen 6 h bis 3 Tage nach Blutung und ohne Hämatomentfernung beobachtet (Del Bigio et al. 1996; Enzmann et al. 1981; Etou et al. 1990). In den Versuchen von Kobari et al. (1988) zeigte sich nach Injektion von arteriellem Blut in die Basalganglien verschiedener Versuchskatzen ein intrakranieller Druckanstieg, vermutlich induziert durch das Volumen des Hämatoms. Dementsprechend verringerten sich zerebrales Blutvolumen und zerebraler Blutfluss signifikant (Kobari et al. 1988). Die Erkenntnis, dass die Größe der ischämischen Areale mit der Größe des Hämatomvolumens korreliert, basiert auf den tierexperimentellen Versuchen 
von Nath et al. Je größer in ihren Versuchen das Hämatomvolumen war, desto größer erschienen die ischämischen Areale (Nath et al. 1986). Lee EJ et al. kamen 1999 zu denselben Resultaten, auch in ihrem Versuch konnte eine Korrelation zwischen zerebraler Hämodynamik und Blutungsvolumen nachgewiesen werden. Es zeigte sich eine Korrelation zwischen Reduktion des Blutflusses und Einschränkung der intrazerebralen Mikrozirkulation. Eine globale Änderung des zerebralen Blutdruckes schien weniger Effekt zu haben (Lee et al. 1999).

In einer tierexperimentellen Studie an Affen zeigten Bullock et al. (1988) eine ausgeprägte Reduktion des zerebralen Blutflusses perihämatomal, sowie einen Anstieg des intrakraniellen Druckes bis zu einer Stunde nach Injektion des Blutes (Bullock et al. 1988). Die Annahme, dass diese lokale Ischämie bei der Entstehung eines Ödems, sei es vasogener oder zytotoxischer Natur, eine Rolle spielen könnte, teilt Bullock mit Yang. Dieser wies in seiner Studie ebenfalls eine Ischämie als Folge einer Raumforderung nach, wenn auch im Rattenhirn (Yang et al. 1994). Ein von verschiedenen Autoren eingesetztes Modell zur Simulation einer ICB ist die Ballondilatation. Sinar et al. verwendeten dieses Modell in ihren Studien an Ratten. Die von ihnen beobachtete bis zu 4 Stunden anhaltende Reduktion des zerebralen Blutflusses ipsilateral der Blutung sowie der intrakranielle Druckanstieg ließen sie schlussfolgern, dass eine mechanische Schädigung der Mikrogefäße für die Ischämie verantwortlich sein könnte (Sinar et al. 1987). Kingman et al. zeigten, dass eine Prolongation der Ballonexpansion mit einer Erhöhung der Blutflussreduktion einhergeht (Kingman et al. 1988).

Der Ballon ist mit Sicherheit ein brauchbares Modell zur Simulation bzw. Replikation der raumfordernden Effekte einer ICB, die biologischen und chemischen Effekte der Blutung bzw. der Blutgerinnung bleiben jedoch unberücksichtigt (Nehls et al. 1990). Yang et al. (1994) schlussfolgerten, dass das Mikroballonmodell letztendlich als Modell einer ICB nicht ausreicht, da die negativen Effekte des Hämatoms und der Blutabbauprodukte fehlen (Yang et al. 1994). Diese sind allerdings neben der Verdrängung von Hirngewebe durch die Raumforderung mitverantwortlich für sekundäre neuronale Schädigung und die persistierende Reduktion des zerebralen Blutflusses (Qureshi et al. 1999).

Auch die Ödementwicklung scheint mit der Blutungsgröße, bzw. den verschiedenen Blutbestandteilen verknüpft zu sein. 


\subsection{Das Ödem}

Das Hirnödem ist eine wichtige Folge bzw. Begleiterscheinung der intrazerebralen Blutung. Das Ödem kann für den sekundären Anstieg des intrakraniellen Druckes und somit auch im negativsten Fall für Gehirnherniationen mit Hirnstammkompression und Tod verantwortlich sein (Anderson et al. 1985). Klinische Studien zeigten, dass ein Höhepunkt der durch intrakranielle Blutungen verursachten Todesfälle in den ersten zwei Tagen nach Blutung auftritt (Jungbluth P 2004). Eine mögliche Ursache wurde in der schnellen progressiven Ödementwicklung gesehen (Bradley 1993; Brott et al. 1992). Der zeitliche Beginn der Ödementwicklung ist umstritten. Bubis et al. konnten im Kortex von Nagetieren schon 5 Minuten nach Eintritt einer Ischämie ein beginnendes Ödem nachweisen (Bubis et al. 1976), der Gruppe um O’Brien et al. (1974) gelang dies an Katzen erst nach 4 Stunden (O'Brien et al. 1974; Jungbluth P 2004). Schuier et al. (1980) berichteten hingegen schon von einer Ödemformation im Katzenhirn nach einer Stunde (Schuier und Hossmann 1980). Crockard et al. (1980) verzeichneten eine Latenzzeit von 60 Minuten, bis in Nagetierhirnen ein Ödem nachweisbar war (Crockard et al. 1980).

Suzuki und Ebina veranschaulichten das Konzept des „toxischen intrazerebralen Blutes“. In ihrem Vergleich zwischen intrazerebralen Blutinjektionen und Infusionen eines Ö1/Wachsgemisches zeigte sich eine durch Blutinjektionen deutlich vermehrte Alteration, vor allem bezüglich des Ödems. Der Masseneffekt allein, durch einen Mikroballon simuliert, erzeugte überhaupt kein Ödem (Suzuki et al. 1976). Weitere Argumente für die toxischen Eigenschaften des Blutes selbst lieferten Wagner et al. (1996). Sie zeigten an Schweinen, denen autologes Blut injiziert wurde, eine bereits eine Stunde später einsetzende Ödementwicklung in der zur Blutung ipsilateralen Hemisphäre als auch eine in dieser Hirnregion verstärkte Immunreaktivität für Serumproteine. Diese Akkumulation von Serumproteinen konnte nicht durch eine erhöhte Permeabilität der Blut-Hirn-Schranke erklärt werden, sondern stammte aus dem Hämatom selbst. Folglich ist das Hämatom selbst die Ursache des durch die Akkumulation hervorgerufenen massiven prolongierten Ödems (Wagner et al. 1996). Eine schnelle Reduktion des Hämatoms, wie in unserem Versuch durch rt-PA, entspricht auf diesen Grundlagen einer geringeren Einwirkzeit, sprich Wirkung, der Serumproteine als auch der anderen bei Hämatomabbau entstehenden Stoffe.

Yang et al. (1994) beobachteten eine zeitgleich stattfindende Ödementwicklung bei Ratten nach intrazerebralen Blutungen sowie eine Konglomeration osmotisch aktiver Substanzen 
(Yang et al. 1994). Im Laufe der Hämatomformation gerinnt das Blut im Hirnparenchym, koaguliert, und unterzieht sich damit einer Formationsänderung. Das Hämatom zieht sich zusammen und bildet im Innern einen Kern aus kompakten Erythrozyten. Am Rand dieses Kernes lagern sich Plasmaproteine ab. Diese Proteine lassen den onkotischen Druck im extrazellulären Raum ansteigen, was wiederum über einen Wassereinstrom ins Interstitium zu einem vasogenen Ödem führt (Wagner et al. 1996). Bei einem Vergleich von spontanen ICBs mit sekundären ICBs nach systemischer Lysetherapie entdeckten Gebel et al. (2000), dass eine Ödementwicklung nach spontaner ICB weitaus häufiger auftrat. Dies führte zu der Schlussfolgerung, dass das Klotting des Blutes ein wichtiger pathogenetischer Faktor in der hyperakuten Ödementwicklung sein muss (Gebel et al. 2000; Yang et al. 1994).

\subsection{Gerinnung und Ödem}

Der Effekt der Koagulation einer ICB auf das umliegende Hirnparenchym wurde von der Arbeitsgruppe um Xi untersucht. In ihrer Studie aus dem Jahr 1998 verglichen sie die Ödementwicklung in Schweinehirnen nach intrazerebraler Hämatombildung durch Injektion von autologem sowie heparinisiertem Blut. In der histologischen Aufbereitung nach $24 \mathrm{~h}$ zeigte sich in der heparinisierten Gruppe kein Ödem, ganz im Gegensatz zur Vergleichsgruppe, die ausgedehnte Ödeme aufzuweisen hatte. Die Inaktivierung von Thrombin durch einen Komplex von Heparin und AT III sowie anderen Faktoren, wurde als ausschlaggebender Faktor identifiziert (Xi et al. 1998b).

Die Studien der Arbeitsgruppe um Lee bekräftigten diese These (Lee et al. 1999; Lee et al. 1995; Lee et al. 1996b; Lee et al. 1997). Sie zogen das Fazit, dass die Gerinnungskaskade an der Ödembildung nach einer ICB maßgeblich beteiligt ist, somit also der Hauptgrund für das Ödem im chemisch-toxischen Bereich zu suchen ist (Lee et al. 1995).

\subsection{Zytotoxizität der Blut- und Plasmabestandteilen}

Blut- und Plasmaproteine werden als entscheidende Effektoren in Hinblick auf die Ödembildung diskutiert. Intakte Erythrozyten sind nicht in der Lage ein Ödem zu verursachen. Lysierte Erythrozyten, deren Inhaltsstoffe auf Hirnparenchym treffen, können ein ausgedehntes Ödem verursachen (Gröschel 2002). Der Gruppe um Xi et al. (1998) gelang es, dies anhand tierexperimenteller Studien an Ratten zu belegen. Sie sahen vor allem das Hämoglobin als toxischen und damit ödeminduzierenden Faktor an. (Xi et al. 1998a). Thrombin, welches aus dem Hämatom freigesetzt wird, bzw. sein chemischer Effekt auf 
Hirnparenchym, stellt für Lee et al. (1996) den Hauptgrund der perihämorraghischen Ödementwicklung dar. In ihrer Studie zum direkten Einfluss von Thrombin auf das Hirnparenchym von Ratten konnte nach intrazerebraler Thrombininjektion eine Ödementwicklung nachgewiesen werden. Bei der gemeinsamen Applikation von Hirudin oder anderen synthetischen Thrombininhibitoren mit Thrombin wurde keine Ödembildung beobachtet (Lee et al. 1996a). Die Cofaktoren und Substrate der Prothrombinase, einem Enzymkomplex, der die Thrombinproduktion fördert, sind im Plasma und in den Erythrozyten vorhanden. Neben den Gerinnungsfaktoren V, X und $\mathrm{Ca}^{2+}$ werden noch Phospholipide benötigt, die unter anderem auf Zellmembranen lokalisiert sind. Diese Faktoren findet man auch in den Bestandteilen eines Hämatoms, wo sie die Umwandlung von Prothrombin zu Thrombin akzelerieren. Neben seiner Hauptfunktion in der Gerinnungskaskade, der Umwandlung von Fibrinogen $\mathrm{zu}$ Fibrin, ist Thrombin noch an anderen Stoffwechselprozessen, wie z.B. Entzündungsreaktionen, Wundheilungen, Chemotaxis, Plättchenaggregation und Zytokin-Freisetzung beteiligt (Lee et al. 1997). Die Arbeitsgruppe um Wagner et al. (1999) verwendete für ihre Studie ebenfalls ein Schweinemodell zur Behandlung mit rt-PA. Hierbei wurde den Schweinen autologes Blut zur Induktion einer ICB injiziert, diese Blutung wurde in der rt-PA-Gruppe mit $0.3 \mathrm{mg}$ rt-PA infundiert, und nach 20 Minuten Einwirkzeit wurde das lysierte Hämatom aspiriert. Nach 24 Stunden wurden die Tiere eingeschläfert, das Hirn histologisch aufgearbeitet. Im Vergleich zur Kontrollgruppe (unbehandelte Schweine) zeigte sich eine Hämatomreduktion um $72 \%$, sowie eine Ödemdezimierung auf $33 \%$ des Ausgangswertes in der rt-PA-Gruppe. Die histologischen Präparate der Hirne zeigten in der unbehandelten Gruppe eine Störung der Blut-HirnSchranke, wohingegen die mit rt-PA behandelten Schweine die Störung nicht aufwiesen. Dies wurde als Effekt der frühen Evakuierung der Blutung in der rt-PA-Gruppe angesehen. Es wurde außerdem die Hypothese aufgestellt, dass rt-PA die interstitielle Fibrinolyse beschleunigt, was zu einer schnelleren Resorption von Fibrinbruchstücken führt. Durch das Fehlen der wasser- und proteinbindenden Fibrinreste soll die Ödembildung verhindert werden (Wagner et al. 1999). Vergleiche hierzu die Arbeit von Gröschel aus dem Jahre 2002 (Gröschel 2002).

Auch Rohde et al. (2002) nutzten ein Schweinemodell zur Lyse intrazerebraler Hämatome. Der entscheidende Unterschied war jedoch der Tag der Datenerhebung. Während Wagner et al. (1999) die Daten bereits 24 Stunden postoperativ erhob und somit keine Daten über die fortlaufende Hämatom- und Ödementwicklung sammelte, wurde bei Rohde et al. (2002) der Tag der Datenerhebung auf den 10. postoperativen Tag gelegt. Dies ermöglichte die 
Beurteilung einer sekundären Ödembildung. In der rt-PA-Gruppe zeigte sich ein Maximum der periläsionalen Ödembildung bzw. des Ödemvolumens nach dem vierten bis zum zehnten Tag, dieses war signifikant größer im Vergleich zum Ödemvolumen der Kontrollgruppe. Diese wies einen Rückgang des Ödemvolumens ab Tag 4 auf. Ein protektiver Effekt von rtPA oder der frühen Hämatomausräumung auf die Ödementwicklung konnte folglich nicht festgestellt werden (Rohde et al. 2002).

$\mathrm{Xi}$ et al. (1998) konnten in ihren tierexperimentellen Studien nach Infusion von Vollblut zwar eine Ödementwicklung am ersten Tag nachweisen, das Maximum des Ödemvolumens zeigte sich jedoch erst am dritten Tag nach Infusion, in der kontralateralen Hemisphäre zeigte sich das Maximum am 7. Tag (Xi et al. 1998b).

Auch andere Autoren berichten von maximalen Ödemausprägungen zwischen Tag 3 und Tag 7 (Enzmann et al. 1981; Mun-Bryce et al. 1993; Tomita et al. 1994).

In der Studie von Thiex et al. (2004) wurde untersucht, welche Rolle endogenes und exogenes t-PA bei der Entwicklung des perifokalen Ödems nach experimenteller intrazerebraler Blutung spielt. Wildtyp-Mäusen und t-PA-Gen-defizienten Mäusen wurde nach Induktion einer ICB rt-PA injiziert. 24 Stunden später wies die t-PA-Gen-defiziente Gruppe ein signifikant kleineres Ödemvolumen auf. In den Messungen an Tag 3 bzw. 7 konnte jedoch kein signifikanter Unterschied des Ödemvolumens zwischen den beiden Versuchsgruppen mehr festgestellt werden. Folglich kann man davon ausgehen, dass endogenes t-PA in der Frühphase der Ödementwicklung eine Rolle spielt, wohingegen exogenes t-PA die Ödementwicklung ab Tag 3 fördert (Thiex et al. 2004a).

Der hier vorliegende Versuch lief über einen Beobachtungszeitraum von 10 Tagen. Das von uns verwendete Schweinemodell entspricht dem Modell der Vorversuche von Rohde et al. Wir beobachteten das Maximum des Ödemvolumens in der rt-PA-Gruppe nach dem 4. bis zum 10. Tag. In der Kontroll- sowie der rt-PA-PAI-Gruppe zeigte sich das größte Ödemvolumen am 4. Tag mit Reduktion bis zum 10. Tag. Unser Versuch bestätigte folglich die Ergebnisse der Vorversuche bezüglich des verspätet auftretenden Ödems. Gleichzeitig demonstrierten wir, dass eindeutig das rt-PA mit dem Ödem in Verbindung steht. Außerdem zeigten wir, dass durch die Gabe des Inhibitors PAI-1 die Ödembildung verhindert werden konnte, leider auf Kosten der fibrinolytischen Fähigkeiten.

Die Vielzahl und Komplexität der beschriebenen Pathomechanismen verdeutlichen, dass die genaue Genese der Ödementwicklung noch immer unklar ist. Man kann jedoch davon ausgehen, dass wohl alle genannten Pathomechanismen eine mehr oder weniger große Rolle 
in der perihämatomalen Ödemevolution spielen. Auf der Basis unserer Versuchsergebnisse stellt sich die Frage nach einer potentiellen Toxizität des rt-PA auf das Hirnparenchym.

\subsection{Gewebeständiger Plasminogenaktivator und rekombinanter t-PA}

Zum ersten Mal beschrieben wurde das Vorkommen eines gewebeständigen Plasminogenaktivators von Astrup et al. (1948). Ihre Versuche zeigten, dass Gewebescheiben verschiedener Säugetierorgane die Proteolyse von Fibrin in Anwesenheit von Plasminogen steigern (Astrup und Permin 1948). Todd et al. (1959) nutzten histochemische Verfahren zur sicheren Lokalisation der Aktivität des t-PA in vaskulären Endothelzellen (Todd 1959). Das Gen, welches humanes t-PA kodiert, befindet sich auf Chromosom 8 (Rajput et al. 1985). TPA wird in vivo als ein 72.000 Dalton schweres und einkettiges Polypeptid synthetisiert. Endogene Proteasen wie Plasmin und Kallikrein spalten das Polypeptid in seine doppelkettige Form (Ichinose et al. 1984). T-PA zeigt eine erhöhte fibrinolytische Aktivität, welche durch Fibrin noch weiter gesteigert werden kann (Hoylaerts et al. 1982). Das natürlich vorkommende Protein t-PA katalysiert die Konversion des inaktiven Proenzyms Plasminogen in die aktive Serinprotease Plasmin (Loscalzo und Braunwald 1988). Eine Hemmung der tPA-Wirkung auf Plasminogen ist durch mehrere Plasmafaktoren möglich. Alpha-2Antiplasmin, ein direkter Plasmininhibitor, bindet auch an t-PA und hemmt seine enzymatische Aktivität (Korninger und Collen 1981). In Thrombozyten, Endothelzellen und Plasma wurde Plasminogenaktivatorinhibitor (PAI) -1, sowie PAI-2, welcher vor allem die doppelkettige Form hemmt, nachgewiesen (Erickson et al. 1984; Kruithof et al. 1984; Loskutoff et al. 1983). Durch Klonierung und Charakterisierung der cDNA des t-PA ist heute eine Produktion durch rekombinante Techniken möglich (Pennica et al. 1983). In dieser Studie wurde der rekombinante gewebeständiger Plasminogenaktivator (rt-PA) Alteplase genutzt. Dieser wird gentechnologisch unter Verwendung von Zellkulturen des chinesischen Hamsters hergestellt. Durch die Bildung von Plasmin überdauert die fibrinolytische Aktivität des t-PA seine eigentliche Halbwertszeit (Röttger 2002).

\subsection{Fibrinolytische Effektivität von rt-PA}

Wir verwendeten zur Lyse experimentell erzeugter intrazerebraler Hämatome rt-PA. Dieser wurde einmalig nach Induktion der Blutung appliziert, nach einer Einwirkzeit von 15 Minuten folgte die vorsichtige Aspiration des verflüssigten Blutklots. Die Dosis rt-PA in mg entsprach dabei dem mittels magnetresonanztomographischer Aufnahmen bestimmten Durchmesser des 
Hämatoms in cm. Bis zum durchschnittlich zehnten Tage ließ sich so eine Reduktion des Blutungsvolumens um 63,3\% in der rt-PA Gruppe erzielen. Ohne Therapie reduzierte sich das Hämatomvolumen um 31,8 \%. Bei Injektion von rt-PA plus PAI-1 betrug die Volumenreduktion $39,5 \%$.

Ebina et al. (1990) untersuchten im Rahmen ihrer Studie den Wirkungsgrad ausgewählter hämolytischer Substanzen. Es wurden sowohl rt-PA, als auch Urokinase zum einen miteinander, zum anderen mit Heparin sowie Elastase, einem Gemisch aus Fibrinolysin und Desoxyribonuclease kombiniert. 6 Stunden nach Applikation zeigten sich Hämolyseraten von bis zu 88,9 \% bei Kombinationen mit rt-PA, die Kombinationen mit Urokinase erreichten eine maximale Auflösung von 27,5 \% (Ebina et al. 1990).

Thomas et al. (1993) wiesen einen dosisabhängigen Effekt des rt-PA nach. Bei experimentellem Verschluss der Arteria cerebri media betrug die optimale Dosierung 6,3 $\mathrm{mg} / \mathrm{kg}$ Körpergewicht, gegeben über einen Zeitraum von 2 Stunden. Dosierungen ober- und unterhalb dieses Optimums führten zu einer Verminderung sowohl der Häufigkeit als auch des Ausmaßes der Thrombolyse (Thomas et al. 1993).

Wagner et al. (1996) injizierten rt-PA in 3 Stunden zuvor induzierte Hämatome im Schwein. Liquifizierte Gerinnselanteile wurden 20 Minuten später aspiriert, es wurde eine Reduktion des Hämatomvolumens um mehr als 70 \% erreicht (Wagner et al. 1996).

Eine mögliche Erklärung für die Reduktion des thrombolytischen Effektes bei sehr hohen Dosen ist das sogenannte „Plasminogen-Steal-Phänomen“. Bei diesem wird durch extreme systemische Konversion von Plasminogen zu Plasmin vermehrt Plasminogen aus dem Hämatom freigesetzt. Dies bedeutet, dass fibrinogengebundenes Plasminogen verloren geht und dass als Folge sich die Wirkkraft des Plasminogenaktivators reduziert (Torr et al. 1992). Bei einer lokalen Applikation von rt-PA dürfte dieses Phänomen folglich kaum eine Rolle spielen (Röttger 2002).

Ein Vergleich des fibrinolytischen Effektes im Tierversuch mit klinischen Studien ist schwierig, da im klinischen Einsatz meist mehrmals rt-PA appliziert und das Hämatom mehrmals drainiert wird. Verschiedene Studien zeigten jedoch gute Lyseraten (zwischen 64,8 $\%$ und 75,8 \%) bei Behandlung intrazerebraler Blutungen (Thiex et al. 2004b). 


\subsection{Toxizität des rt-PA}

Den unwiderlegbar guten fibrinolytischen Eigenschaften des rt-PA werden immer wieder potentielle Nebenwirkungen entgegengesetzt. Wang et al. (1999) zeigten, dass durch t-PA eine Hämoglobin-induzierte Neurotoxizität noch verstärkt wird. Insbesondere hohe lokale Konzentrationen von t-PA, wie sie bei der lokalen Fibrinolyse von intrazerebralen Blutungen anfallen, verstärken den Hämoglobin induzierten Zelltod (Wang et al. 1999).

In experimentellen Studien konnte gezeigt werden, dass t-PA in Kombination mit Thrombin eine verstärkte Neurotoxizität aufweist. Die Arbeitsgruppe um Figueroa et al. (1998) wies in ihrer tierexperimentellen Studie an Ratten nach, dass eine Injektion von t-PA oder Urokinase in Kombination mit Thrombin zu einem verstärkten Ödem, sowie bei Injektion von t-PA plus Thrombin auch zu einer erhöhten Mortalität führt. Als Maßeinheit wurde der Natrium-, Wasser- und Kaliumgehalt der Rattenhirne 24 Stunden nach Injektion histologisch bestimmt. Die Autoren glauben, dass die Serinproteasen eine entscheidende Rolle spielen, hier vor allem Nexin-1 und Plasminogenaktivatorinhibitor-1 (PAI-1). Beide Proteasen finden sich im Hirnparenchym und inhibieren sowohl Thrombin als auch t-PA. Folglich würde eine Injektion von t-PA mehr Proteasen in Anspruch nehmen, wodurch weniger Thrombin, welches als potenter Ödemauslöser bekannt ist, inhibiert wird. Eine erhöhte neurotoxische Wirkung des Thrombins mit Entstehung eines vergleichsweise ausgeprägten Ödems wäre die Folge (Figueroa et al. 1998).

Kontrovers wird diskutiert, ob Plasminogenaktivatoren alleine neurotoxische Effekte besitzen bzw. als Effektor die Neurotoxizität anderer Stoffe verstärken. Figueroa et al. konnte bei direkter t-PA-Injektion keine neurotoxische Wirkung nachweisen (Figueroa et al. 1998). Die Rolle von rt-PA als Exzitotoxin untersuchten Tsirka et al. (1997), indem die Empfindlichkeit gentechnisch veränderter Mäuse gegenüber neurotoxischen Substanzen getestet wurde. T-PAknock-out-Mäuse waren neurotoxischen Substanzen gegenüber weniger sensitiv. Auf die Injektion eines Glutamatanalogons in die Hippokampusregion reagierten die t-PA-defizienten Mäuse nicht signifikant mit einem neuronalen Zelluntergang. Bei zusätzlicher Gabe von t-PA stellte sich jedoch ein massiver Zellverlust ein, eine alleinige Applikation von t-PA zeigte keinen Zelluntergang (Tsirka 1997).

T-PA-defiziente Mäuse wurden auch in den Versuchen von Nagai et al. (2001) genutzt. Durch Sauerstoff- und Glukoseentzug wurde ein ischämischer Insult hervorgerufen. Kulturen der kortikalen Neurone der Wildtyp- und knock-out-Mäuse wurden angelegt, um die potentiellen systemischen Effekte von t-PA zu unterdrücken. In der Gruppe der knock-out-Mäuse kam es seltener zu neuronalem Zelltod, was sich allerdings durch die nachträgliche Gabe von t-PA 
antagonisieren ließ. Ein direkter Einfluss von t-PA auf neuronalen Zelltod, zumindest im ischämischem Milieu, ohne systemische Einflüsse, scheint somit bewiesen (Nagai et al. 2001).

Goto et al. (2007) bezeichneten die Therapie mit rt-PA in seinem Fazit zu seiner Studie zur direkten Neurotoxizität von rt-PA in vivo in Abhängigkeit von der applizierten Menge als „doppelschneidiges Schwert“. 18 Ratten wurden in 3 Gruppen eingeteilt, denen in steigender Dosierung rt-PA injiziert wurde. Mit steigender Konzentration von rt-PA konnte eine signifikant größer werdende kortikale Läsion mit degenerierten Neuronen und geschwollenen perineuronalen Astrozyten beobachtet werden. Bei höchster rt-PA-Dosierung wiesen die im ipsilateralen Hippokampus gelegenen CA1 Neurone nekrotische Veränderungen auf (Goto et al. 2007).

T-PA kann zu rezeptor-vermittelter Apoptose und somit auch zu exzitotoxischem Zelltod führen, wie sich in einer Studie in Lurcher-Mäusen zeigen ließ. Die Lurcher-Maus ist eine spontane Mausmutation, bei der prämature Apoptosen von zerebellären Neuronen auftreten. Die Mutation ist in einer Glutatmatrezeptoruntereinheit lokalisiert, wodurch es zu einem starken Kalziumeinstrom kommt. Untersucht wurden Wildtyp- und t-PA-knock-out Mäuse. Es zeigte sich eine verzögerte Apoptose der Zerebellumzellen bei den t-PA-knock-out Mäusen (Lu und Tsirka 2002).

Nicole et al. (2001) untersuchten die Beziehung zwischen t-PA- und NMDA-Rezeptoren. So scheint t-PA den durch glutaminerge Rezeptoren vermittelten neuronalen Zelltod zu erhöhen. T-PA spaltet ein 15 bis $20 \mathrm{kDa}$ großes Fragment von der NR1-Untereinheit des NMDARezeptors ab, was einen Anstieg der NMDA-gekoppelten intrazellulären Calciumkonzentration zur Folge hat. Dies kann den Zelltod auslösen. Injektionen von NMDA führten im Striatum zu Zelluntergang, die alleinige t-PA-Injektion in das Striatum zeigte keinen schädigenden Auswirkungen. Eine kombinierte Injektion von t-PA und NMDA hingegen vergrößerte das Volumen der durch NMDA-Injektion entstandenen Läsionen um $50 \%$. Die Autoren schlossen daraus, dass t-PA die NMDA-Aktivierung potenziert (Nicole et al. 2001).

Thiex et al. (2007) untersuchten, ob durch die Kombination von rt-PA und dem nicht kompetitiven NMDA-Rezeptor-Antagonisten MK801 der ödem- und entzündungsauslösende Effekt des rt-PA gemildert werden kann. 20 Schweinen wurde nach der Induktion einer Blutung MK801 i.v. appliziert. 10 Schweine erhielten zusätzlich rt-PA. Im Beobachtungszeitraum von 10 Tagen zeigte sich keine signifikante Ödemvergrößerung in der MK801-rt-PA-Gruppe. In der rt-PA-Gruppe zeigte sich hingegen eine signifikante Zunahme 
des Ödemvolumens am 4. postoperativen Tag, nicht jedoch an Tag 10. Thiex et al. (2007) schlossen daraus, dass die Kombination von rt-PA und neuroprotektiven Agenzien, wie NMDA-Rezeptor-Antagonisten, die Möglichkeit bietet, die neurotoxischen Eigenschaften des rt-PA unter Beibehaltung der fibrinolytischen Fähigkeiten zu inhibieren (Thiex et al. 2007). In der hier vorliegenden Studie wurde versucht, durch die Kombination von rt-PA mit PAI-1 die rt-PA-vermittelte Neurotoxizität und Ödembildung durch t-PA zu reduzieren.

\subsection{Plasminogenaktivatorinhibitor 1 (PAI-1)}

PAI-1 ist ein Serinproteaseninhibitor (Serpin) und der primäre, physiologische Inhibitor der Plasminogenaktivatoren (Urokinase, t-PA). In seiner Form als einkettiges Glykoprotein beinhaltet es ein reaktives Zentrum, dass nur im aktiven Zustand des Proteins für Plasminogenaktivatoren erreichbar ist. Im inaktiven Zustand ist das reaktive Zentrum nicht erreichbar. PAI-1 wird von verschiedenen Geweben, wie Herz, Lunge, Muskel, Aorta und Fett produziert (Schneider et al. 2008).

Es gelang uns zu zeigen, dass die zusätzliche Gabe von PAI-1 bei rt-PA-Injektion zur Hämatomlyse eine signifikante Verringerung des Ödemvolumens im Vergleich zur alleinigen Lyse mit rt-PA bewirkte. Die Ödemvolumina der rt-PA-PAI-Gruppe gleichen annähernd der Kontrollgruppe. Daraus lässt sich die in anderen Studien beschriebene neuroprotektive Rolle des PAI-1 bestätigen.

\subsection{PAI-1 als Neuroprotektor}

Die Arbeitsgruppe um Armstead et al. (2006) untersuchte die Möglichkeit einer Unterdrückung der neurotoxischen Eigenschaften unter Beibehaltung der fibrinolytischen Qualitäten des rt-PA. Hierzu wurde die rt-PA-Applikation mit dem von PAI-1 abgeleiteten Peptid EEIIMD gekoppelt. EEIIMD ist ein Hexapeptid und entspricht den Aminosäuresequenzen 350-355 des PAI-1. In Versuchen mit exogenem t-PA an Rattenhirnen und mit endogenem t-PA an Schweinehirnen zeigte sich, dass EEIIMD die Toxizität sowohl des endo- als auch exogenen t-PA reduziert. Die fibrinolytische Qualität des t-PA wurde durch EEIIMD nicht vermindert. Die Wirkmechanismen des EEIIMD sind nicht geklärt, als mögliche Erklärung wird die Unterdrückung der t-PA-induzierten und ödeminduzierenden Vasodilatation angeführt (Armstead et al. 2006)

Hua et al. (2002) untersuchten die Konzentration von PAI-1 im Rattenhirn 24 Stunden nach Induktion einer intrazerebralen Blutung oder nach Injektion von Thrombin. Es zeigte sich ein 
Anstieg der PAI-1-Konzentration im perihämatomalen Hirnparenchym. Nach Thrombininjektion konnte ein Anstieg des PAI-1-Spiegels perihämatomal, jedoch nicht kontralateral, festgestellt werden. Die t-PA-Konzentration blieb auf einem konstanten Niveau. Die Autoren postulierten, dass die erhöhte PAI-1-Konzentration zu einer sekundären Neuroprotektivität führt. Begründet wurde dies durch die Limitierung der durch Thrombin oder eine andere Serinprotease induzierten Toxizität (Hua et al. 2002).

Soeda et al. (2008) zeigten einen neuroprotektiven Effekt von PAI-1 in vitro. In neuronal differenzierten Phäochromocytomzellen (PC-12-Zellen) der Ratte führte ein PAI-1-Mangel zu einer signifikanten Reduktion von Bcl-2 und Bcl- $\mathrm{X}_{\mathrm{L}}$ mRNA und einem Anstieg von Bcl- $\mathrm{X}_{\mathrm{s}}$ und Bax mRNA. Diese Verschiebung im Gleichgewicht der anti- und proapoptotischen Bcl2-Gruppe führte zu vermehrter Apoptose über eine Caspase-3-Aktivierung, Cytochrom C Ausstrom aus den Mitochondrien und DNA-Fragmentation. PAI-1 hat also eine antiapoptotische Wirkung in Neuronen, welche unabhängig von der Wirkung als Proteaseinhibitor ist (Soeda et al. 2008).

\subsection{Die Ursache des perihämatomalen Ödems}

Die Frage nach der Ursache des eine intrazerebrale Blutung begleitenden Ödems ist noch ungeklärt. Generell unterscheidet man ein vasogenes, zytotoxisches/zelluläres und interstitielles Ödem.

Ebisu et al. (1993) untersuchten die Möglichkeit einer Klassifikation des Ödems mit Hilfe des MRTs. Hierzu verursachten sie bei Wistar-Ratten die 3 verschiedenen Ödemarten, durch die Intoxikation mit Triethyl-Tin (TET) (zytotoxisches Ödem), durch Kaolin induzierten Hydrocephalus (interstitielles Ödem) und durch Zufügen von $-80^{\circ} \mathrm{C}$ kaltem Trockeneis auf die Dura mater (vasogenes Ödem). Die konventionelle T2-gewichtete Bildgebung ermöglichte keine Differenzierung der verschiedenen Ödemarten, erst die Diffusionsgewichteten Bilder machten eine Unterscheidung der Ödemtypen möglich. Der apparent diffusion coefficient (ADC) zeigte deutliche Unterschiede im Wassergehalt der Ödemtypen. So hatte das zytotoxische Ödem einen verringerten und weniger anisotropen ADC, das vasogene Ödem einen erhöhten und mehr anisotropen ADC als die gesunde weiße Hirnsubstanz. Interstitielle Ödeme zeigten einen noch höheren und anisotroperen ADC. Die Autoren folgerten, dass eine Unterscheidung des Ödems durch Messung des ADC möglich ist (Ebisu et al. 1993). 
Fu et al. (1990) untersuchten die Möglichkeit der Wasserdarstellung im Hirngewebe mit Hilfe der T1- und T2-Relaxationszeit. Anhand von Katzenmodellen wurden Hirnödemtypen simuliert und der Wassergehalt der weißen Substanz der verschiedenen Versuchsgruppen miteinander verglichen. Sowohl T1- als auch T2-Relaxationszeit zeigte eine gute Korrelation zum Wassergehalt des Gewebes, jedoch war die T2-Relaxationszeit (T2-rt) sensitiver, Veränderungen im parenchymalen Wassergehalt festzustellen (Fu et al. 1990).

In der hier vorliegenden Studie wurde sowohl die T2rt als auch der ADC perihämatomal bestimmt. Es zeigte sich ein deutlicher Anstieg an Tag 4 sowohl in der rt-PA- als auch in der rt-PA-PAI-Gruppe. In der Kontrollgruppe war der Anstieg weniger stark ausgeprägt. An Tag 10, dem Sektionstag, zeigte sich dann eine Verkürzung der T2rt in allen 3 Gruppen, am stärksten in der rt-PA-PAI-Gruppe.

Einen ähnlichen Verlauf zeigt der ADC. Sowohl in der rt-PA- als auch rt-PA-PAI-Gruppe zeigt sich eine starke Zunahme am 4. Tag postoperativ. In der Kontrollgruppe war kaum eine Zunahme nachweisbar. Am Tag 10 war der ADC in alle Gruppen reduziert, am stärksten in der rt-PA-PAI Gruppe.

Basierend auf diesen Messungen schließen wir auf einen vasogenen, extrazellulären Ursprung des Ödems. Desweiteren zeigt sich ein durch PAI-1 vermitteltes schnelleres Abklingen des Ödems, bzw. eine deutliche Abnahme der extrazellulär eingelagerten Flüssigkeit.

\subsection{1 Übertragbarkeit des Modells auf den Menschen}

Durch die Ähnlichkeit des Gerinnungssystems wählten wir das Schwein als Versuchstier für dieses Experiment. Dies sollte eine Übertragbarkeit der komplexen pathophysiologischen Vorgänge, wie die Schädigung im perihämatomalen Hirnparenchym mit konsekutiver Ödementwicklung, auf den Menschen gewährleisten. Auch das gut gyrierte Hirn mit ausreichend weißer Substanz zeichnet das Schwein als Versuchstier erster Wahl aus (Wagner et al. 1996).

Die Simulation einer intrazerebralen Blutung durch Injektion von autologem Blut kommt der humanen Situation nahe, da nicht nur ein Masseneffekt resultiert, sondern auch die toxischen Wirkungen der Blutbestandteile auf das Hirnparenchym induziert werden. Kritisch zu beurteilen ist die Schaffung einer Hämatomhöhle durch Aufblasen eines Mikroballons, wobei allerdings Vorversuche gezeigt hatten, dass dies nur einen äußerst geringen Effekt auf die perihämatomale Ödemformation hat (Lee et al. 1996a; Rohde et al. 2002). 
Potentielle Effekte der Narkose durch Barbiturate müssen berücksichtigt werden, schließlich sind die Versuchstiere während der Operation und MRT-Kontrollen über mehrere Stunden narkotisiert. Verschiedene Autoren schließen eine Beeinflussung der Reaktion des Hirnparenchyms auf eine regionale zerebrale Ischämie durch die Barbituratnarkose nicht aus (Branston et al. 1979; Michenfelder und Milde 1975).

Durch das Alter der Versuchsschweine fehlten die typischen histologisch erfassbaren degenerativen Veränderungen eines alten chronisch hypertensiven Patienten mit intrazerebraler Blutung, wie z.B. perivaskuläre Mikroinfarkte, Lakunenbildung, perivaskuläre Mikrohämatome oder fibrinoide Gefäßnekrosen (Chester et al. 1978).

\subsection{Die fibrinolytische Therapie einer ICB}

$\mathrm{Zu}$ den ersten Studien der fibrinolytischen Qualitäten von Urokinase gehören die Arbeiten von Narayan et al. (1985). In den tierexperimetellen Studien von Narayan et al. (1985) war 24 Stunden nach Injektion von 0,2 ml Blut und 10.000 U Urokinasen bei $83 \%$ der behandelten Tiere kein Klot mehr nachweisbar. In der Kontrollgruppe konnte eine Auflösung nur bei 33 \% der Tiere beobachtet werden (Narayan et al. 1985). Altumbabic et al. (1989) untersuchten in der Ratte die Lyse von durch Kollagenase induzierten Hämatomen durch $3000 \mathrm{U}$ Streptokinase. Nach einer Stunde konnten 20 bis $100 \mu \mathrm{L}$ liquifizierten Klots aspiriert werden. In den folgenden 7 Wochen erfolgte eine funktionelle Testung der Tiere. Nur am 1. und 2. Tag konnte ein signifikanter Unterschied zwischen Streptokinase- und Kontrollgruppe festgestellt werden. Die histologische Untersuchung zeigte einen deutlicheren Neuronenverlust sowie ausgedehntere Gebiete mit reaktiver Gliose in der Kontrollgruppe (Altumbabic et al. 1998). Aydin et al. (1994) beobachteten bei höherem Blutvolumen (0,5 ml) und niedrigerer Urokinasemenge (2200 U Urokinase) nach 24 Stunden eine Lyse bei $90 \%$ der mit Urokinase behandelten Tiere. Bei den Kontrolltieren betrug die Lysequote $20 \%$. Histologisch wurde keine Schädigung des perihämatomalen Gewebes nachgewiesen (Aydin et al. 1994).

Auch in den ersten klinischen Studien wurden Fibrinolytika der ersten Generation, vor allem Urokinase, eingesetzt.

Matsumoto et al. (1984) konnten bei allen 51 im Rahmen ihrer Studie untersuchten Patienten nach Lyse mit Urokinase das Hämatom vollständig aspirieren (Matsumoto und Hondo 1984).

In einer Studie von Mohadjer et al. (1992) wurden den untersuchten Patienten nach partieller Evakuation der Hämatomhöhle 2 bis 3 mal je 5.000 bis 10.000 U Urokinase appliziert. 
Durchschnittlich waren nach 20,2 Monaten von 85 Patienten 29,4\% verstorben. Die Überlebenden wiesen jedoch zu 2/3 eine gute bis sehr gute Lebensqualität auf. Die gegenüber anderen Arbeiten stark erhöhte Mortalität führten sie auf die Tatsache zurück, dass nur Patienten mit großen raumfordernden Blutungen und sich verschlechternden klinischen Symptomen operiert wurden. Kleine Hämatome wurden konservativ therapiert (Mohadjer et al. 1992).

Die Verwendung von rt-PA zur Lyse intrazerebraler Blutungen wurde von Lippitz et al. (1994) erstmals publiziert. Bei 10 Patienten erfolgte eine stereotaktische Hämatomaspiration 5 bis 24 Stunden nach Blutung. Zur Entfernung des restlichen Hämatoms wurden nach 24 Stunden 3 mg rt-PA über einen Katheter appliziert. Je nach Residualvolumen des Hämatoms wurde die rt-PA-Applikation alle 24 Stunden für ein bis drei Tage wiederholt. Am Ende der rt-PA-Behandlung konnten im Mittel Residualvolumina von $16 \%$ des Ausgangswertes gemessen werden. Diese Volumenminderungen der Hämatome gingen nicht immer mit einer Verbesserung des klinischen Status einher. Hinweise für eine mögliche Toxizität des rt-PA gab es nicht (Lippitz et al. 1994).

Schaller et al. (1995) veröffentlichten eine Serie von 14 Patienten. Nach stereotaktischer Insertion eines Katheters, spätestens 72 Stunden nach der Blutung, folgte eine vorsichtige manuelle Aspiration und die Injektion von rt-PA. Die initiale Dosierung entsprach hierbei dem maximalen Hämatomurchmesser in cm. Bei Resthämatomen wurde die Lyse wiederholt, durchschnittlich wurden 9,9 mg rt-PA injiziert. 13 Patienten zeigten nach 5 Tagen eine vollständige Auflösung der ICB. Nach einer mittleren Beobachtungszeit von 6,6 Monaten waren 14,3\% der Patienten verstorben, während 7,1 \% sich sehr gut erholten. Auch in dieser Studie gab es keinen Hinweis auf eine mögliche Toxizität des rt-PA (Schaller et al. 1995).

1997 veröffentlichten Slansky et al. eine Studie zur Lyse mit rt-PA. 56 Patienten wurden einer stereotaktischen Aspiration der Basalganglienblutungen unter Kombination mit einer lokalen Fibrinolyse mittels rt-PA unterzogen. Das präoperative Hämatomvolumen betrug durchschnittlich $51 \mathrm{ml}$. Insgesamt brachte die Kombinationstherapie aus primärer Aspiration und anschließender Lysetherapie eine Volumenreduktion um 78 \% innerhalb von 8 Tagen. Eine deutliche klinische Besserung wurde beobachtet. In $9 \%$ der Fälle kam es zu aspirationsassozierten Nachblutungen. Die Mortalität betrug 26 \% (Slansky et al. 1997).

Rohde et al. (2000) publizierten eine Serie von 27 Patienten, deren intrazerebrale Hämatome mit rt-PA lysiert wurden. Im Vordergrund der Studie stand die Evaluierung der rahmenlosen anstelle der rahmengestützten Stereotaxie zur Aspiration und Katheteranlage entlang der Hämatomachse. Bei 25 Patienten konnte durch Hämatomaspiration und wiederholter rt-PA- 
Lyse das Blutungsvolumen innerhalb von zwei Tagen von durchschnittlich $52 \mathrm{ml}$ auf $17 \mathrm{ml}$ reduziert werden. Bei zwei Patienten wurde eine Vergrößerung der Blutung beobachtet. In einem Beobachtungszeitraum von 30 Tagen verstarben 5 Patienten an den Folgen der initialen Blutung, ein Patient starb an einer Nachblutung. 16 Patienten konnten nach Hause entlassen werden, behielten aber Hemiparesen zurück, vier Patienten hatten bei Entlassung lediglich ein leichtes neurologisches Defizit (Rohde et al. 2000).

Teernstra et al. (2003) veröffentlichten die erste randomisierte Studie, die die stereotaktische Aspiration und Hämatomlyse mit konservativer Behandlung verglich. In diese Multicenterstudie wurden 71 Patienten einbezogen, 36 wurden innerhalb von 72 Stunden nach Blutung chirurgisch behandelt. Die restlichen 35 Patienten wurden konservativ therapiert. Trotz eines signifikant kleineren Hämatomvolumens nach Behandlung in der chirurgisch therapierten Gruppe konnte kein Unterschied in der 6-Monatsmortalität festgestellt werden (56\% nach chirurgischer Therapie, $59 \%$ nach konventioneller Therapie). Auch die hohe Nachblutungsrate in der chirurgisch therapierten Gruppe von $22 \%$ wird für die schlechten Ergebnisse dieser Gruppe verantwortlich gemacht (Teernstra et al. 2003).

Die Gruppe um Thiex et al. (2004) untersuchte den Unterschied zwischen rahmenloser und rahmengebundener stereotaktischer Hämatompunktion. Es wurden Daten von 126 Patienten retrospektiv ausgewertet. 53 Patienten wurden rahmengebunden, 75 ohne Rahmen operiert. Beide Gruppen erhielten eine anschließende Lysetherapie mit rt-PA. Es zeigte sich eine sehr gute Effizienz beider Gruppen in Bezug auf die Reduktion des Hämatoms (im Mittel 75,8 \% in der rahmengebundenen, 64,8 \% in der rahmenlosen Gruppe). Die Nachblutungsrate gab mit 13,3 \% keinen Hinweis auf eine erhöhte Gefährdung durch rt-PA-Gabe. Trotz dieser guten Lyseergebnisse war die Anzahl der Patienten mit guten klinischen Ergebnissen, vor allem bei älteren Patienten > 65 Jahre, ernüchternd (Thiex et al. 2004b).

Carhuapoma et al. (2008) überprüften an einer Kohorte von 15 Patienten retrospektiv, ob es bei der Lyse mit rt-PA zu einer Vergrößerung des perihämatomalen Ödems kommt. Es zeigte sich eine deutliche Relation zwischen Größe des Hämatoms und Ödemausmaß. Eine Verstärkung des Ödems durch die rt-PA-Gabe konnte nicht gesehen werden (Carhuapoma et al. 2008).

Das retrospektive Design der meisten Studien sowie die fehlende Balance der einzigen prospektiven randomisierten Studie erlauben keine abschließende Bewertung der Sicherheit und insbesondere der Effizienz der minimal invasiven Lysetherapie. 


\section{$5 \quad$ Zusammenfassung}

Der Schlaganfall ist die häufigste neurologische Erkrankung und mit $12 \%$ aller Todesfälle die dritthäufigste Todesursache in Deutschland. 10 bis $15 \%$ aller Schlaganfälle werden durch intrazerebrale Blutungen verursacht. Bisher existiert keine allseits akzeptierte Behandlungsmethode für spontane intrazerebrale Blutungen von mittlerer Größe. Einigkeit besteht einzig darin, dass eine möglichst schnelle und vollständige Entfernung des Hämatoms angestrebt werden sollte. Eine mögliche Therapieoption ist die Lyse des Blutklots mit Plasminogenaktivator und anschließender Aspiration, respektive Drainage, der liquifizierten Blutung. Man kann sich vorstellen, dasss diese minimalinvasive Hämatomentfernung den Krankheitsverlauf positiv beeinflussen könnte.

Experimentelle Ergebnisse zeigten jedoch, dass durch rt-PA-Injektion zwar eine sehr gute Hämatomvolumenreduktion erreicht, gleichzeitig aber durch das rt-PA das perihämatomale Ödem verstärkt wird. Dies könnte auf eine neurotoxische Wirkung des Plasminogenaktivators zurückzuführen sein.

In unserer tierexperimentellen Studie versuchten wir die rt-PA-assozierte Ödementwicklung durch die Kombination der Lysetherapie mit PAI-1 zu reduzieren. Wir zeigten, dass durch eine sich an die rt-PA-Lyse anschließende Applikation von PAI-1 die perihämatomale Ödembildung in der Tat signifikant vermindert werden kann. Dies geht allerdings mit einer Reduktion der Effektivität der rt-PA-Lyse einher, die Hämatomvolumenreduktion nach rt-PAund PAI-1-Gabe gleicht fast der Volumenreduktion durch Resorptionsvorgänge. Ein klinischer Nutzen der Kombination von rt-PA und PAI-1 in der Therapie der ICB ist somit in Frage zu stellen. Gleichzeitig bestätigten unsere Ergebnisse frühere Studien bezüglich einer verspäteten perihämatomalen Ödembildung ab dem 3. postoperativen Tag in der rt-PAGruppe. Ein klarer Zusammenhang zwischen Plasminogenaktivator und Ödembildung wurde festgestellt. Darüber hinaus zeigten unsere Ergebnisse einen extrazellulären, vasogenen Ursprung des Ödems an.

Weitere Studien sind notwendig, um zu untersuchen, ob der klinische Effekt der minimalinvasiven Lysetherapie in der Tat der chirurgischen und der konservativen Therapie überlegen ist. Die Pathogenese des Ödems bei Lysetherapie muss genauer definiert werden, bzw. sollten weitere Strategien zur Ödemprävention untersucht werden. Die Ödemprävention ist, wie von uns gezeigt, möglich.

Auch hinsichtlich der Kombination von rt-PA mit PAI-1 sollten weitere Untersuchungen durchgeführt werden. Bei diesen sollte durch Wahl unterschiedlicher Injektionszeitpunkte von 
rt-PA und PAI-1 versucht werden, den positiven Effekt des rt-PA auf die

Hämatomvolumenreduktion als auch den positiven Effekt des PAI-1 auf die Ödemunterdrückung zu erzielen. 


\section{Literaturverzeichnis}

Akkawi S, Nassar T, Tarshis M, Cines DB Higazi AA (2006): "LRP and alphavbeta3 mediate tPA activation of smooth muscle cells." Am J Physiol Heart Circ Physiol 291(3): H1351-1359.

Altumbabic M, Peeling J Del Bigio MR (1998): "Intracerebral hemorrhage in the rat: effects of hematoma aspiration." Stroke 29(9): 1917-1922; discussion 1922-1913.

Anderson DK, Saunders RD, Demediuk P, Dugan LL, Braughler JM, Hall ED, Means ED Horrocks LA (1985): "Lipid hydrolysis and peroxidation in injured spinal cord: partial protection with methylprednisolone or vitamin E and selenium." Cent Nerv Syst Trauma 2(4): 257-267.

Armstead WM, Cines DB Higazi AA (2005): "Plasminogen activators contribute to impairment of hypercapnic and hypotensive cerebrovasodilation after cerebral hypoxia/ischemia in the newborn pig." Stroke 36(10): 2265-2269.

Armstead WM, Nassar T, Akkawi S, Smith DH, Chen XH, Cines DB Higazi AA (2006): "Neutralizing the neurotoxic effects of exogenous and endogenous tPA." Nat Neurosci 9(9): 1150-1155.

Astrup T Permin PM (1948): "Fibrinokinase and fibrinolytic enzymes." Nature 161(4096): 689.

Auer LM, Deinsberger W, Niederkorn K, Gell G, Kleinert R, Schneider G, Holzer P, Bone G, Mokry M, Korner E, et al. (1989): "Endoscopic surgery versus medical treatment for spontaneous intracerebral hematoma: a randomized study." J Neurosurg 70(4): 530535.

Aydin IH, Takci E, Kadioglu HH, Kayaoglu CR Tuzun Y (1994): "The effect of urokinase on experimental intracerebral haematomas." Zentralbl Neurochir 55(1): 29-34.

Batjer HH, Reisch JS, Allen BC, Plaizier LJ Su CJ (1990): "Failure of surgery to improve outcome in hypertensive putaminal hemorrhage. A prospective randomized trial." Arch Neurol 47(10): 1103-1106.

Bergmann SR, Fox KA, Ter-Pogossian MM, Sobel BE Collen D (1983): "Clot-selective coronary thrombolysis with tissue-type plasminogen activator." Science 220(4602): 1181-1183.

Bladin CF, Alexandrov AV, Bellavance A, Bornstein N, Chambers B, Cote R, Lebrun L, Pirisi A Norris JW (2000): "Seizures after stroke: a prospective multicenter study." Arch Neurol 57(11): 1617-1622.

Braaten JV, Handt S, Jerome WG, Kirkpatrick J, Lewis JC Hantgan RR (1993): "Regulation of fibrinolysis by platelet-released plasminogen activator inhibitor 1: light scattering and ultrastructural examination of lysis of a model platelet-fibrin thrombus." Blood 81(5): 1290-1299.

Bradley WG, Jr. (1993): "MR appearance of hemorrhage in the brain." Radiology 189(1): 1526.

Branston NM, Hope DT Symon L (1979): "Barbiturates in focal ischemia of primate cortex: effects on blood flow distribution, evoked potential and extracellular potassium." Stroke 10(6): 647-653.

Broderick J, Connolly S, Feldmann E, Hanley D, Kase C, Krieger D, Mayberg M, Morgenstern L, Ogilvy CS, Vespa P, et al. (2007): "Guidelines for the management of spontaneous intracerebral hemorrhage in adults: 2007 update: a guideline from the American Heart Association/American Stroke Association Stroke Council, High 
Blood Pressure Research Council, and the Quality of Care and Outcomes in Research Interdisciplinary Working Group." Stroke 38(6): 2001-2023.

Broderick JP, Brott T, Tomsick T, Huster G Miller R (1992): "The risk of subarachnoid and intracerebral hemorrhages in blacks as compared with whites." N Engl J Med 326(11): 733-736.

Broderick JP, Brott T, Tomsick T, Miller R Huster G (1993a): "Intracerebral hemorrhage more than twice as common as subarachnoid hemorrhage." J Neurosurg 78(2): 188191.

Broderick JP, Brott TG, Duldner JE, Tomsick T Huster G (1993b): "Volume of intracerebral hemorrhage. A powerful and easy-to-use predictor of 30-day mortality." Stroke 24(7): 987-993.

Brott T, Thalinger K Hertzberg V (1986): "Hypertension as a risk factor for spontaneous intracerebral hemorrhage." Stroke 17(6): 1078-1083.

Brott TG, Haley EC, Jr., Levy DE, Barsan W, Broderick J, Sheppard GL, Spilker J, Kongable GL, Massey S, Reed R, et al. (1992): "Urgent therapy for stroke. Part I. Pilot study of tissue plasminogen activator administered within 90 minutes." Stroke 23(5): 632-640.

Bubis JJ, Fujimoto T, Ito U, Mrsulja BJ, Spatz M Klatzo I (1976): "Experimental cerebral ischemia in Mongolian gerbils. v. Ultrastructural changes in H3 sector of the hippocampus." Acta Neuropathol 36 (3): 285-294.

Bullock R, Brock-Utne J, van Dellen J Blake G (1988): "Intracerebral hemorrhage in a primate model: effect on regional cerebral blood flow." Surg Neurol 29(2): 101-107.

Carhuapoma JR, Barrett RJ, Keyl PM, Hanley DF Johnson RR (2008): "Stereotactic aspiration-thrombolysis of intracerebral hemorrhage and its impact on perihematoma brain edema." Neurocrit Care $\underline{8}$ (3): 322-329.

Chen ZL Strickland S (1997): "Neuronal death in the hippocampus is promoted by plasmincatalyzed degradation of laminin." Cell 91(7): 917-925.

Chester EM, Agamanolis DP, Banker BQ Victor M (1978): "Hypertensive encephalopathy: a clinicopathologic study of 20 cases." Neurology 28 (9 Pt 1): 928-939.

Chiu D, Krieger D, Villar-Cordova C, Kasner SE, Morgenstern LB, Bratina PL, Yatsu FM Grotta JC (1998): "Intravenous tissue plasminogen activator for acute ischemic stroke: feasibility, safety, and efficacy in the first year of clinical practice." Stroke 29(1): 1822.

Crabbe SJ Cloninger CC (1987): "Tissue plasminogen activator: a new thrombolytic agent." Clin Pharm $\underline{6}(5): 373-386$.

Crockard A, Iannotti F, Hunstock AT, Smith RD, Harris RJ Symon L (1980): "Cerebral blood flow and edema following carotid occlusion in the gerbil." Stroke 11(5): 494-498.

Deinsberger W, Vogel J, Kuschinsky W, Auer LM Boker DK (1996): "Experimental intracerebral hemorrhage: description of a double injection model in rats." Neurol Res 18(5): 475-477.

Del Bigio MR, Yan HJ, Buist R Peeling J (1996): "Experimental intracerebral hemorrhage in rats. Magnetic resonance imaging and histopathological correlates." Stroke 27(12): 2312-2319; discussion 2319-2320.

Dennis MS, Burn JP, Sandercock PA, Bamford JM, Wade DT Warlow CP (1993): "Longterm survival after first-ever stroke: the Oxfordshire Community Stroke Project." Stroke 24(6): 796-800.

Ebina K, Okabe S, Manabe H Iwabuchi T (1990): "[Experimental study on liquefaction of intracranial hematoma: usefulness of tissue-plasminogen activator (t-PA), a hematolytic agent, and its combination]." No Shinkei Geka 18(10): 927-934. 
Ebisu T, Naruse S, Horikawa Y, Ueda S, Tanaka C, Uto M, Umeda M Higuchi T (1993): "Discrimination between different types of white matter edema with diffusionweighted MR imaging." J Magn Reson Imaging 3(6): 863-868.

Ehrlich HJ, Gebbink RK, Keijer J, Linders M, Preissner KT Pannekoek H (1990): "Alteration of serpin specificity by a protein cofactor. Vitronectin endows plasminogen activator inhibitor 1 with thrombin inhibitory properties." J Biol Chem 265(22): 13029-13035.

Ehrlich HJ, Keijer J, Preissner KT, Gebbink RK Pannekoek H (1991): "Functional interaction of plasminogen activator inhibitor type 1 (PAI-1) and heparin." Biochemistry $\underline{30}(4)$ : 1021-1028.

Enzmann DR, Britt RH, Lyons BE, Buxton JL Wilson DA (1981): "Natural history of experimental intracerebral hemorrhage: sonography, computed tomography and neuropathology." AJNR Am J Neuroradiol 2(6): 517-526.

Erickson LA, Ginsberg MH Loskutoff DJ (1984): "Detection and partial characterization of an inhibitor of plasminogen activator in human platelets." J Clin Invest 74(4): 14651472.

Etou A, Mohadjer M, Braus D Mundinger F (1990): "Stereotactic evacuation and fibrinolysis of cerebellar hematomas." Stereotact Funct Neurosurg 54-55: 445-450.

Fewel ME, Thompson BG, Jr. Hoff JT (2003): "Spontaneous intracerebral hemorrhage: a review." Neurosurg Focus 15(4): E1.

Figueroa BE, Keep RF, Betz AL Hoff JT (1998): "Plasminogen activators potentiate thrombin-induced brain injury." Stroke 29(6): 1202-1207; discussion 1208.

$\mathrm{Fu}$ Y, Tanaka K Nishimura S (1990): "Evaluation of brain edema using magnetic resonance proton relaxation times." Adv Neurol 52: 165-176.

Gebel JM, Brott TG, Sila CA, Tomsick TA, Jauch E, Salisbury S, Khoury J, Miller R, Pancioli A, Duldner JE, et al. (2000): "Decreased perihematomal edema in thrombolysis-related intracerebral hemorrhage compared with spontaneous intracerebral hemorrhage." Stroke 31(3): 596-600.

Goßrau P : "Wertigkeit des Apparent Diffusion Coefficient (ADC) in der Funktionsdiagnostik der großen Speicheldrüsen und der Beurteilung der pathologischen Veränderung mittels Magnetresonanztomografie bei 1,5 T und 3 T." Med. Diss. Hamburg 2005.

Goto H, Fujisawa H, Oka F, Nomura S, Kajiwara K, Kato S, Fujii M, Maekawa T Suzuki M (2007): "Neurotoxic effects of exogenous recombinant tissue-type plasminogen activator on the normal rat brain." J Neurotrauma 24(4): 745-752.

Gröschel $\mathrm{K}$ : "Effekt der minimalinvasenfibrinolytischen Therapie und Aspiration intrazerebraler Blutungen auf das perifokale Ödem: Eine tierexperimentelle Langzeitstudie." Med.Diss. Aachen 2002.

Hacke W, Brott T, Caplan L, Meier D, Fieschi C, von Kummer R, Donnan G, Heiss WD, Wahlgren NG, Spranger M, et al. (1999): "Thrombolysis in acute ischemic stroke: controlled trials and clinical experience." Neurology 53(7 Suppl 4): S3-14.

Hart RG, Boop BS Anderson DC (1995): "Oral anticoagulants and intracranial hemorrhage. Facts and hypotheses." Stroke 26(8): 1471-1477.

Hindersin P, Heidrich R Endler S (1984): "Haemostasis in cerebrospinal fluid. Basic concept of antifibrinolytic therapy of subarachnoid haemorrhage." Acta Neurochir Suppl (Wien) 34: 1-77.

Hoylaerts M, Rijken DC, Lijnen HR Collen D (1982): "Kinetics of the activation of plasminogen by human tissue plasminogen activator. Role of fibrin." J Biol Chem 257(6): 2912-2919. 
Hua Y, Xi G, Keep RF, Wu J, Jiang Y Hoff JT (2002): "Plasminogen activator inhibitor-1 induction after experimental intracerebral hemorrhage." J Cereb Blood Flow Metab 22(1): 55-61.

Ichinose A, Kisiel W Fujikawa K (1984): "Proteolytic activation of tissue plasminogen activator by plasma and tissue enzymes." FEBS Lett 175(2): 412-418.

Jungbluth P :"Histopathologische Veränderungen einer intrazerebralen Blutung nach operativer Ausräumung im Vergleich zur fibrinolytischen und konservativen Therapie derselben." Med. Diss. Aachen 2004.

Juvela S, Heiskanen O, Poranen A, Valtonen S, Kuurne T, Kaste M Troupp H (1989): "The treatment of spontaneous intracerebral hemorrhage. A prospective randomized trial of surgical and conservative treatment." J Neurosurg 70(5): 755-758.

Juvela S, Hillbom M Palomaki H (1995): "Risk factors for spontaneous intracerebral hemorrhage." Stroke 26(9): 1558-1564.

Kamman RL, Go KG, Brouwer W Berendsen HJ (1988): "Nuclear magnetic resonance relaxation in experimental brain edema: effects of water concentration, protein concentration, and temperature." Magn Reson Med 6(3): 265-274.

Kingman TA, Mendelow AD, Graham DI Teasdale GM (1988): "Experimental intracerebral mass: description of model, intracranial pressure changes and neuropathology." $\mathrm{J}$ Neuropathol Exp Neurol 47(2): 128-137.

Kobari M, Gotoh F, Tomita M, Tanahashi N, Shinohara T, Terayama Y Mihara B (1988): "Bilateral hemispheric reduction of cerebral blood volume and blood flow immediately after experimental cerebral hemorrhage in cats." Stroke 19(8): 991-996.

Kolominsky-Rabas PL Heuschmann PU (2002): "[Incidence, etiology and long-term prognosis of stroke]." Fortschr Neurol Psychiatr 70(12): 657-662.

Kolominsky-Rabas PL, Weber M, Gefeller O, Neundoerfer B Heuschmann PU (2001): "Epidemiology of ischemic stroke subtypes according to TOAST criteria: incidence, recurrence, and long-term survival in ischemic stroke subtypes: a population-based study." Stroke 32(12): 2735-2740.

Korninger C Collen D (1981): "Neutralization of human extrinsic (tissue-type) plasminogen activator in human plasma: no evidence for a specific inhibitor." Thromb Haemost 46(3): 662-665.

Kothari R, Pancioli A, Brott T Broderick J (1996): "Thrombolytic therapy for cerebral infarction." Acad Emerg Med $\underline{3}(9)$ : 881-892.

Kruithof EK, Tran-Thang C, Ransijn A Bachmann F (1984): "Demonstration of a fast-acting inhibitor of plasminogen activators in human plasma." Blood 64(4): 907-913.

Lee EJ, Hung YC Lee MY (1999): "Early alterations in cerebral hemodynamics, brain metabolism, and blood-brain barrier permeability in experimental intracerebral hemorrhage." J Neurosurg 91(6): 1013-1019.

Lee KR, Betz AL, Keep RF, Chenevert TL, Kim S Hoff JT (1995): "Intracerebral infusion of thrombin as a cause of brain edema." J Neurosurg 83(6): 1045-1050.

Lee KR, Betz AL, Kim S, Keep RF Hoff JT (1996a): "The role of the coagulation cascade in brain edema formation after intracerebral hemorrhage." Acta Neurochir (Wien) 138(4): 396-400; discussion 400-391.

Lee KR, Colon GP, Betz AL, Keep RF, Kim S Hoff JT (1996b): "Edema from intracerebral hemorrhage: the role of thrombin." J Neurosurg $\underline{84}(1)$ : 91-96.

Lee KR, Kawai N, Kim S, Sagher O Hoff JT (1997): "Mechanisms of edema formation after intracerebral hemorrhage: effects of thrombin on cerebral blood flow, blood-brain

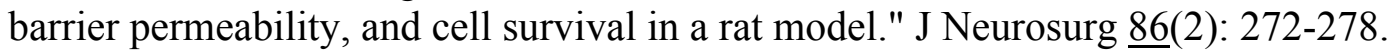


Levi M, Biemond BJ, van Zonneveld AJ, ten Cate JW Pannekoek H (1992): "Inhibition of plasminogen activator inhibitor-1 activity results in promotion of endogenous thrombolysis and inhibition of thrombus extension in models of experimental thrombosis." Circulation 85(1): 305-312.

Lippitz BE, Mayfrank L, Spetzger U, Warnke JP, Bertalanffy H Gilsbach JM (1994): "Lysis of basal ganglia haematoma with recombinant tissue plasminogen activator (rtPA) after stereotactic aspiration: initial results." Acta Neurochir (Wien) 127(3-4): 157-160.

Loscalzo J Braunwald E (1988): "Tissue plasminogen activator." N Engl J Med 319(14): $925-$ 931.

Loskutoff DJ, van Mourik JA, Erickson LA Lawrence D (1983): "Detection of an unusually stable fibrinolytic inhibitor produced by bovine endothelial cells." Proc Natl Acad Sci

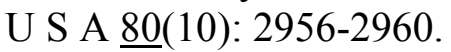

Lu W Tsirka SE (2002): "Partial rescue of neural apoptosis in the Lurcher mutant mouse through elimination of tissue plasminogen activator." Development 129(8): 20432050 .

Matsumoto K Hondo H (1984): "CT-guided stereotaxic evacuation of hypertensive intracerebral hematomas." J Neurosurg 61(3): 440-448.

Mayfrank L, Lippitz B, Groth M, Bertalanffy H Gilsbach JM (1993): "Effect of recombinant tissue plasminogen activator on clot lysis and ventricular dilatation in the treatment of severe intraventricular haemorrhage." Acta Neurochir (Wien) 122(1-2): 32-38.

McKissock W (1961): "Primary Intracerebral Haemorrhage." Lancet 278(7196): 221-226.

Mendelow AD, Gregson BA, Fernandes HM, Murray GD, Teasdale GM, Hope DT, Karimi A, Shaw MD Barer DH (2005): "Early surgery versus initial conservative treatment in patients with spontaneous supratentorial intracerebral haematomas in the International Surgical Trial in Intracerebral Haemorrhage (STICH): a randomised trial." Lancet 365(9457): 387-397.

Michenfelder JD Milde JH (1975): "Influence of anesthetics on metabolic, functional and pathological responses to regional cerebral ischemia." Stroke $\underline{6}(4)$ : 405-410.

Mohadjer M, Braus DF, Myers A, Scheremet R Krauss JK (1992): "CT-stereotactic fibrinolysis of spontaneous intracerebral hematomas." Neurosurg Rev 15(2): 105-110.

Mun-Bryce S, Kroh FO, White J Rosenberg GA (1993): "Brain lactate and pH dissociation in edema: 1H- and 31P-NMR in collagenase-induced hemorrhage in rats." Am J Physiol 265(3 Pt 2): R697-702.

Nagai N, Yamamoto S, Tsuboi T, Ihara H, Urano T, Takada Y, Terakawa S Takada A (2001): "Tissue-type plasminogen activator is involved in the process of neuronal death induced by oxygen-glucose deprivation in culture." J Cereb Blood Flow Metab 21(6): 631-634.

Narayan RK, Narayan TM, Katz DA, Kornblith PL Murano G (1985): "Lysis of intracranial hematomas with urokinase in a rabbit model." J Neurosurg 62(4): 580-586.

Nassar T, Akkawi S, Shina A, Haj-Yehia A, Bdeir K, Tarshis M, Heyman SN Higazi AA (2004): "In vitro and in vivo effects of tPA and PAI-1 on blood vessel tone." Blood 103(3): 897-902.

Nath FP, Jenkins A, Mendelow AD, Graham DI Teasdale GM (1986): "Early hemodynamic changes in experimental intracerebral hemorrhage." J Neurosurg 65(5): 697-703.

Nehls DG, Mendelow DA, Graham DI Teasdale GM (1990): "Experimental intracerebral hemorrhage: early removal of a spontaneous mass lesion improves late outcome." Neurosurgery 27(5): 674-682; discussion 682. 
Nicole O, Docagne F, Ali C, Margaill I, Carmeliet P, MacKenzie ET, Vivien D Buisson A (2001): "The proteolytic activity of tissue-plasminogen activator enhances NMDA receptor-mediated signaling." Nat Med 7(1): 59-64.

Nilsson T, Wallen P Mellbring G (1984): "In vivo metabolism of human tissue-type plasminogen activator." Scand J Haematol 33(1): 49-53.

O'Brien MD, Jordan MM Waltz AG (1974): "Ischemic cerebral edema and the blood-brain barrier. Distributions of pertechnetate, albumin, sodium, and antipyrine in brains of cats after occlusion of the middle cerebral artery." Arch Neurol 30(6): 461-465.

Pennica D, Holmes WE, Kohr WJ, Harkins RN, Vehar GA, Ward CA, Bennett WF, Yelverton E, Seeburg PH, Heyneker HL, et al. (1983): "Cloning and expression of human tissue-type plasminogen activator cDNA in E. coli." Nature 301(5897): 214221.

Potter van Loon BJ, Rijken DC, Brommer EJ van der Maas AP (1992): "The amount of plasminogen, tissue-type plasminogen activator and plasminogen activator inhibitor type 1 in human thrombi and the relation to ex-vivo lysibility." Thromb Haemost 67(1): 101-105.

Pouratian N, Kassell NF Dumont AS (2003): "Update on management of intracerebral hemorrhage." Neurosurg Focus 15(4): E2.

Quinones-Hinojosa A, Gulati M, Singh V Lawton MT (2003): "Spontaneous intracerebral hemorrhage due to coagulation disorders." Neurosurg Focus 15(4): E3.

Qureshi AI, Wilson DA, Hanley DF Traystman RJ (1999): "No evidence for an ischemic penumbra in massive experimental intracerebral hemorrhage." Neurology 52 (2): 266272.

Rajput B, Degen SF, Reich E, Waller EK, Axelrod J, Eddy RL Shows TB (1985): "Chromosomal locations of human tissue plasminogen activator and urokinase genes." Science 230(4726): 672-674.

Rogove AD Tsirka SE (1998): "Neurotoxic responses by microglia elicited by excitotoxic injury in the mouse hippocampus." Curr Biol $\underline{8}(1): 19-25$.

Rohde V, Schaller C Hassler WE (1995): "Intraventricular recombinant tissue plasminogen activator for lysis of intraventricular haemorrhage." J Neurol Neurosurg Psychiatry 58(4): 447-451.

Rohde V, Rohde I, Reinges MH, Mayfrank L Gilsbach JM (2000): "Frameless stereotactically guided catheter placement and fibrinolytic therapy for spontaneous intracerebral hematomas: technical aspects and initial clinical results." Minim Invasive Neurosurg $\underline{43}(1): 9-17$.

Rohde V, Rohde I, Thiex R, Ince A, Jung A, Duckers G, Groschel K, Rottger C, Kuker W, Muller HD, et al. (2002): "Fibrinolysis therapy achieved with tissue plasminogen activator and aspiration of the liquefied clot after experimental intracerebral hemorrhage: rapid reduction in hematoma volume but intensification of delayed edema formation." J Neurosurg 97(4): 954-962.

Röttger C : "Die histopathologische Darstellung einer intrazerebralen Blutung unter fibrinolytischer Therapie: Eine tierexperimentelle Studie." Med.Diss. Aachen 2002.

Schaller C, Rohde V, Meyer B Hassler W (1995): "Stereotactic puncture and lysis of spontaneous intracerebral hemorrhage using recombinant tissue-plasminogen activator." Neurosurgery $\underline{36}$ (2): 328-333; discussion 333-325.

Schneider DJ, Chen Y Sobel BE (2008): "The effect of plasminogen activator inhibitor type 1 on apoptosis." Thromb Haemost 100(6): 1037-1040. 
Schuier FJ Hossmann KA (1980): "Experimental brain infarcts in cats. II. Ischemic brain edema." Stroke 11(6): 593-601.

Sinar EJ, Mendelow AD, Graham DI Teasdale GM (1987): "Experimental intracerebral hemorrhage: effects of a temporary mass lesion." J Neurosurg 66 (4): 568-576.

Slansky I LB, Spetzger U, Rohde V, Gilsbach JM (1997). Minimally Invasive Treatment of spontaneous intracerebral Hemorrhage: Stereotactic aspiration combined with clot lysis using recombinant tissue-plasminogen activator (rt-PA) in Therapeutic concepts in spontaneous intracerebral hemorrhage. Böker, Biermann Verlag: 37-41.

Soeda S, Koyanagi S, Kuramoto Y, Kimura M, Oda M, Kozako T, Hayashida S Shimeno H (2008): "Anti-apoptotic roles of plasminogen activator inhibitor-1 as a neurotrophic factor in the central nervous system." Thromb Haemost 100(6): 1014-1020.

Stoop AA, Lupu F Pannekoek H (2000): "Colocalization of thrombin, PAI-1, and vitronectin in the atherosclerotic vessel wall: A potential regulatory mechanism of thrombin activity by PAI-1/vitronectin complexes." Arterioscler Thromb Vasc Biol 20(4): 11431149.

Suzuki S, Ebina K, Ishii M Iwabuchi T (1976): "[Changes of subarachnoid space after the experimental subarachnoid hemorrhage in the dog. Scanning electron microscopical observation (author's transl)]." Neurol Med Chir (Tokyo) 16(4 pt 2): 323-330.

Tanswell P, Seifried E, Stang E Krause J (1991): "Pharmacokinetics and hepatic catabolism of tissue-type plasminogen activator." Arzneimittelforschung 41(12): 1310-1319.

Teernstra OP, Evers SM, Lodder J, Leffers P, Franke CL Blaauw G (2003): "Stereotactic treatment of intracerebral hematoma by means of a plasminogen activator: a multicenter randomized controlled trial (SICHPA)." Stroke 34(4): 968-974.

Thiex R, Kuker W, Muller HD, Rohde I, Schroder JM, Gilsbach JM Rohde V (2003): "The long-term effect of recombinant tissue-plasminogen-activator (rt-PA) on edema formation in a large-animal model of intracerebral hemorrhage." Neurol Res 25(3): 254-262.

Thiex R, Mayfrank L, Rohde V, Gilsbach JM Tsirka SA (2004a): "The role of endogenous versus exogenous tPA on edema formation in murine ICH." Exp Neurol 189(1): 2532.

Thiex R, Rohde V, Rohde I, Mayfrank L, Zeki Z, Thron A, Gilsbach JM Uhl E (2004b): "Frame-based and frameless stereotactic hematoma puncture and subsequent fibrinolytic therapy for the treatment of spontaneous intracerebral hemorrhage." $\mathrm{J}$ Neurol 251(12): 1443-1450.

Thiex R, Weis J, Krings T, Barreiro S, Yakisikli-Alemi F, Gilsbach JM Rohde V (2007): "Addition of intravenous N-methyl-D-aspartate receptor antagonists to local fibrinolytic therapy for the optimal treatment of experimental intracerebral hemorrhages." J Neurosurg 106(2): 314-320.

Thomas GR, Thibodeaux H, Bennett WF, Refino CJ, Badillo JM, Errett CJ Zivin JA (1993): "Optimized thrombolysis of cerebral clots with tissue-type plasminogen activator in a rabbit model of embolic stroke." J Pharmacol Exp Ther 264(1): 67-73.

Thrift AG, McNeil JJ, Forbes A Donnan GA (1996): "Risk factors for cerebral hemorrhage in the era of well-controlled hypertension. Melbourne Risk Factor Study (MERFS) Group." Stroke 27(11): 2020-2025.

Todd AS (1959): "The histological localisation of fibrinolysin activator." J Pathol Bacteriol 78: 281-283. 
Tomita H, Ito U, Ohno K Hirakawa K (1994): "Chronological changes in brain edema induced by experimental intracerebral hematoma in cats." Acta Neurochir Suppl (Wien) 60: 558-560.

Torr SR, Nachowiak DA, Fujii S Sobel BE (1992): "'Plasminogen steal" and clot lysis." J Am Coll Cardiol 19(5): 1085-1090.

Tsirka SE (1997): "Clinical implications of the involvement of tPA in neuronal cell death." J Mol Med 75(5): 341-347.

Tsirka SE, Rogove AD Strickland S (1996): "Neuronal cell death and tPA." Nature 384(6605): 123-124.

van Bruggen N, Roberts T. Chapter 3: MRI Measurement of Cerebral Water Diffusion and its Application to Experimental Research in: Biomedical Imaging in Experimental Neuroscience. CRC Press,Boca Raton, FL, USA: 2002:56-85.

Wagner KR, Xi G, Hua Y, Kleinholz M, de Courten-Myers GM, Myers RE, Broderick JP Brott TG (1996): "Lobar intracerebral hemorrhage model in pigs: rapid edema development in perihematomal white matter." Stroke 27(3): 490-497.

Wagner KR, Xi G, Hua Y, Zuccarello M, de Courten-Myers GM, Broderick JP Brott TG (1999): "Ultra-early clot aspiration after lysis with tissue plasminogen activator in a porcine model of intracerebral hemorrhage: edema reduction and blood-brain barrier protection." J Neurosurg 90(3): 491-498.

Wang X, Asahi M Lo EH (1999): "Tissue type plasminogen activator amplifies hemoglobininduced neurotoxicity in rat neuronal cultures." Neurosci Lett 274(2): 79-82.

Xi G, Keep RF Hoff JT (1998a): "Erythrocytes and delayed brain edema formation following intracerebral hemorrhage in rats." J Neurosurg 89(6): 991-996.

Xi G, Wagner KR, Keep RF, Hua Y, de Courten-Myers GM, Broderick JP, Brott TG Hoff JT (1998b): "Role of blood clot formation on early edema development after experimental intracerebral hemorrhage." Stroke 29(12): 2580-2586.

Yang GY, Betz AL, Chenevert TL, Brunberg JA Hoff JT (1994): "Experimental intracerebral hemorrhage: relationship between brain edema, blood flow, and blood-brain barrier

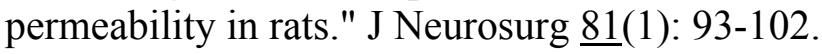

Zamarron C, Lijnen HR Collen D (1984): "Kinetics of the activation of plasminogen by natural and recombinant tissue-type plasminogen activator." J Biol Chem 259(4): 2080-2083. 


\section{Danksagung:}

Ich danke meinen Betreuern Herrn Professor Dr. med. Rohde, Frau Dr. med. Keric und Frau Professor Dr. med. Samadani für die gute Betreuung und tatkräftige Unterstützung im Rahmen dieser Arbeit.

Dank geht auch an das Team der Forschungsgruppe „MR-Forschung in Neurologie und Psychatrie“, allen voran an Herrn Dr. Kallenberg und Herrn Professor Dr. Dechent für das Erstellen der MRT-Aufnahmen sowie die Hilfe bei der Auswertung der Bilder.

Dem Team der Neuropathologie unter der Leitung von Herrn Professor Dr. med. Brück gebührt Dank für die Fixation der Schweinehirne sowie die Anfertigung der Schnitte.

Dank auch an Frau Dr. med. vet. Kimmina und Herrn Dr. med. vet. Schunk, sowie an das Team der ZTE für die gute Betreuung der Schweine und die Unterstützung im Rahmen der Operationen.

Außerdem danke ich Herrn Moreira für die Hilfestellungen im Rahmen der Datenformatierungen und der Bildbearbeitungen. 


\section{Lebenslauf:}

Ich wurde am 16.07.1982 in Lörrach geboren. Von 1989 bis 1993 besuchte ich die Dr-MaxMetzger-Grundschule in Schopfheim. 1993 wurde ich auf das Theodor-Heuss-Gymnasium Schopfheim versetzt. Dieses besuchte ich bis zum Bestehen meiner allgemeinen Hochschulreife im Jahre 2002. Im September desselben Jahres begann ich meinen Zivildienst im Seniorenpflegestift Haus Edelberg im Bifig in Schopfheim. Meine neunmonatige Tätigkeit dort war hauptsächlich in der Altenpflege angesiedelt. Im Oktober 2003 begann ich mein Studium der Humanmedizin an der Georg-August-Universität Göttingen, welches ich im Mai 2010 erfolgreich beendet habe. Seit Oktober 2010 bin ich als wissenschaftlicher Assistent in der orthopädischen Klinik (Chefarzt Prof. Dr. A. Kurth) der Universitätsmedizin Mainz beschäftigt. 